\title{
tila
}

Staidéar Fadaimseartha na

hÉireann um Dhul in Aois

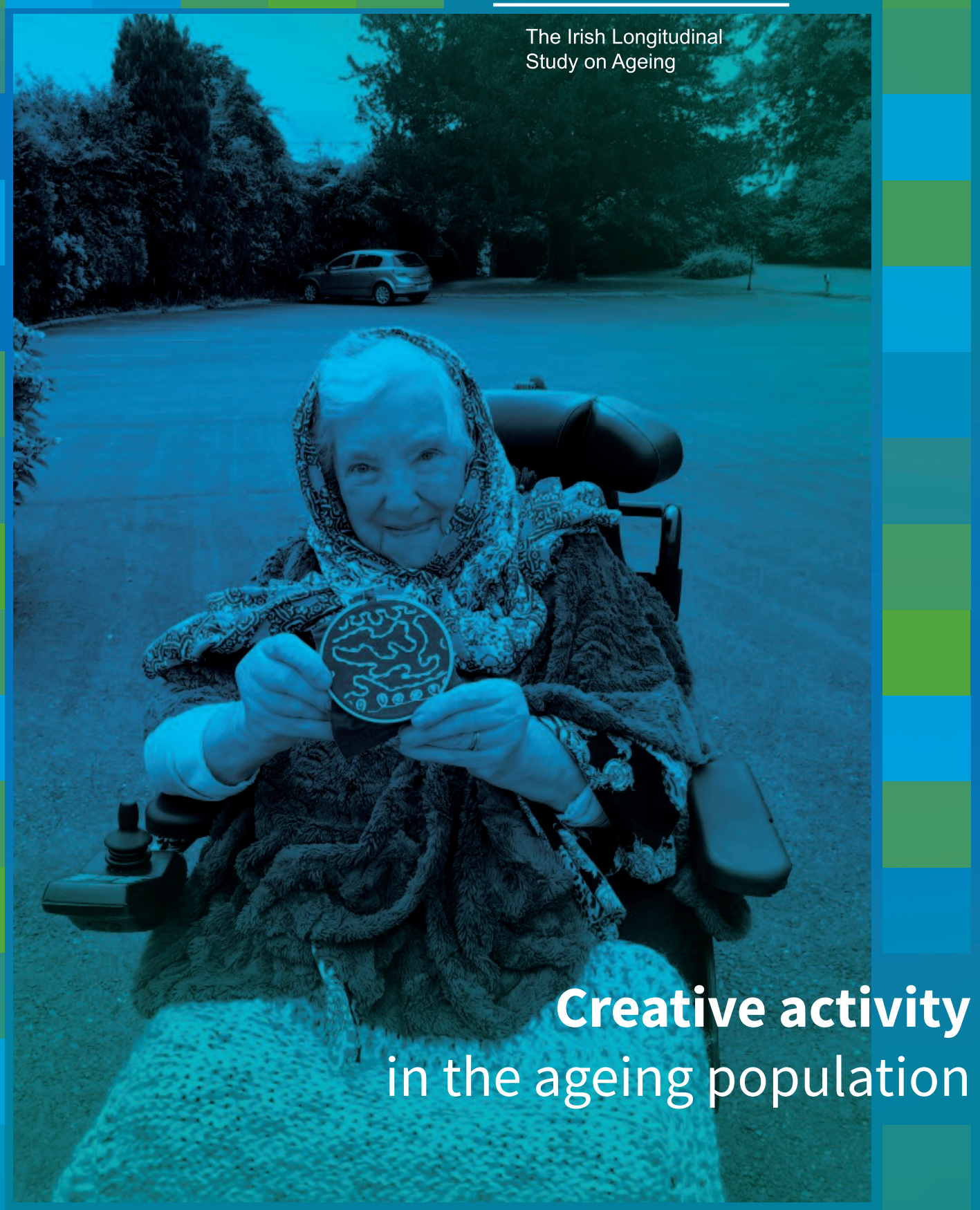

Josie McAteer, Creative Ireland Carlow, Borris Lace Project Photo credit Helen McAteer 


\section{Creative activity in the ageing population}

\section{Siobhan Scarlett, Ann Hever, Mark Ward, Rose Anne Kenny}

The Irish Longitudinal Study on Ageing

On behalf of the TILDA team

November 2021

Copyright @ The Irish Longitudinal Study on Ageing 2021

The Irish Longitudinal Study on Ageing

Trinity College Dublin

Dublin 2

Tel: +353 18962509

Email: tilda@tcd.ie

Website: www.tilda.ie

ISBN: 978-1-907894-37-4

https://www.doi.org/10.38018/TildaRe.2021-05

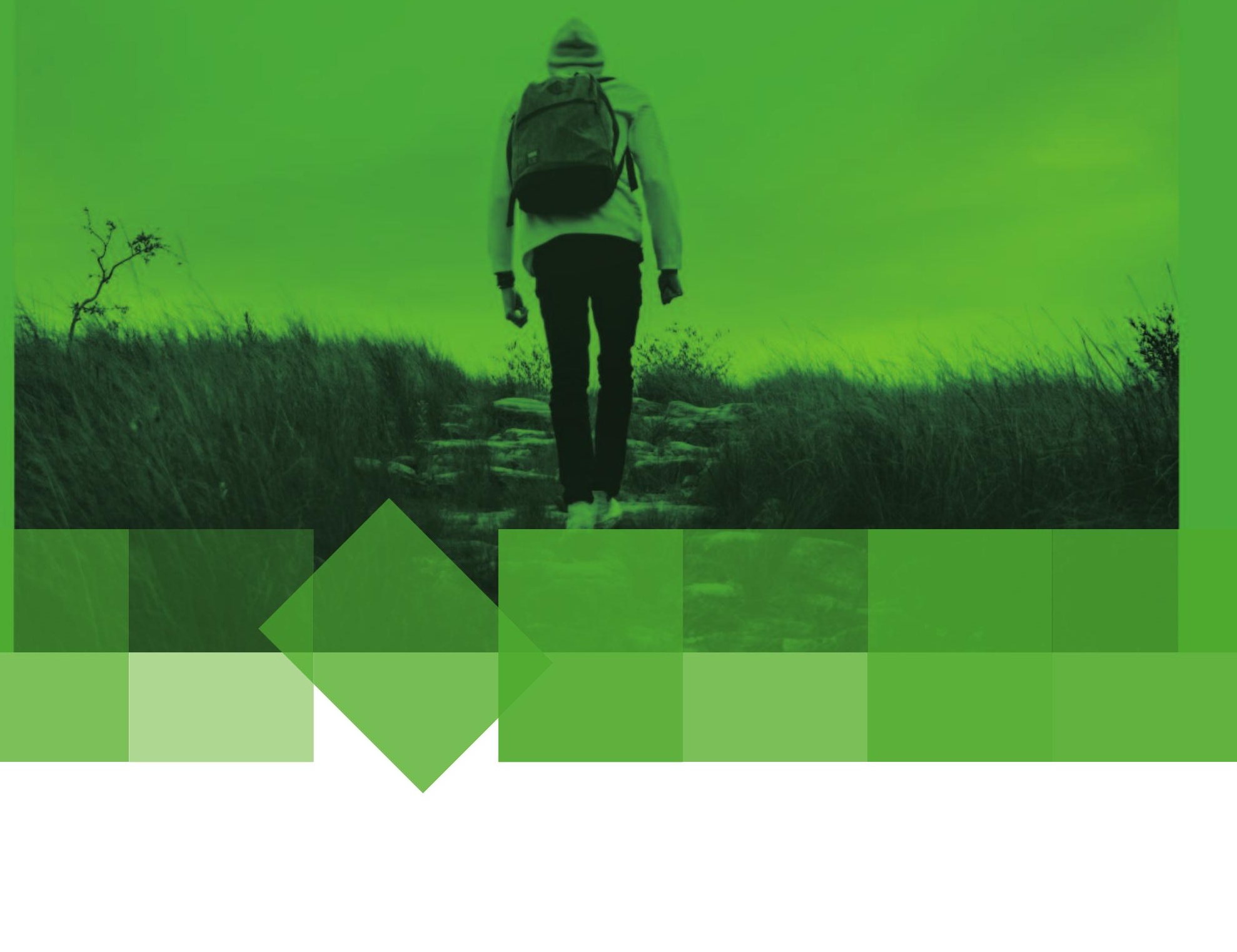




\section{Acknowledgements}

We would like to acknowledge the collaboration and vision of Creative Ireland who commissioned and supported this report together with the funders of the TILDA research studies, the Department of Health, the Health Research Board, Irish Life, The Atlantic Philantrophies, Science Foundation Ireland and the National Institutes of Health and National Institute on Aging.

We would also like to state that any views expressed in this report are not necessarily those of any of the funders. We would also like to thank the TILDA participants without whom this research would not be possible.

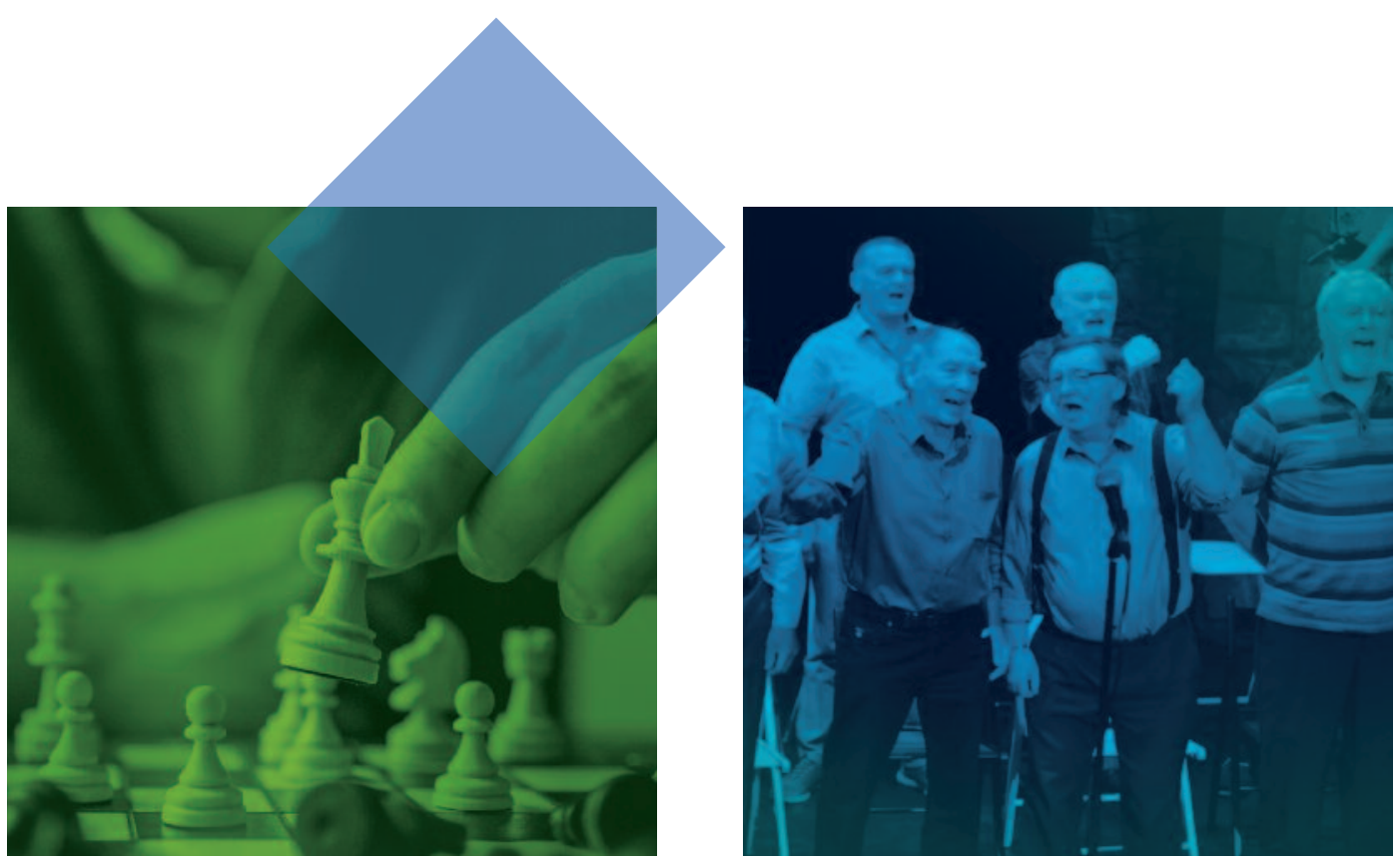




\section{Contents}

1. Introduction

2. Methodology 6

2.1. Data Collection $\quad 6$

2.2. Study Sample $\quad 6$

2.3. Measures 16

2.3.1. Demographic Characteristics $\quad 6$

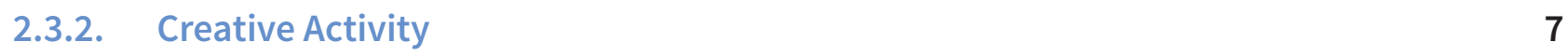

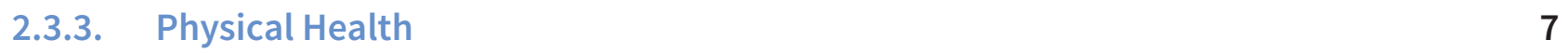

2.3.4. Quality of life $\quad 8$

$\begin{array}{ll}\text { 2.3.5. Loneliness } & \mathbf{8}\end{array}$

2.3.6. Mental Health $\quad 8$

2.3.7. Behavioural Health $\quad 8$

2.3.8. COVID-19 Questionnaire $\quad 9$

3. Creative Activity Participation in Older Adults 11

3.1. Frequency of involvement in creative activities in 2009-2011 11

3.2. Creative activity frequency by demographics 12

$\begin{array}{lll}\text { 3.3. } & \text { Creative activity score } & 17\end{array}$

4. Changes in participation from 2009-2018 20

4.1. Creative activity participation $\quad 20$

$\begin{array}{ll}\text { 4.2. } & \text { Creative activity score }\end{array}$

5. Creative activities and physical health 25

5.1. Creative activity by health, vision, hearing and disability 25

5.2. Differences in physical health between Wave 1 and Wave 5 


\section{Contents}

6. Creative activities, quality of life, loneliness and mental health 34

6.1. Creative activity and quality of life $\quad 34$

6.2. Creative activity and loneliness $\quad 34$

6.3. Creative activity and mental health 35

6.4. Differences in quality of life, loneliness and mental health between 37

Wave 1 and Wave 5

7. Creative activity and behavioural health 41

7.1. Creative activity and physical activity 41

7.2. Creative activity and smoking status 42

7.3. Differences in behavioural health between Wave 1 and Wave 5

8. Creative Activity during the COVID-19 restrictions 46

8.1. Involvement in creative activity during the COVID-19 restrictions 46

8.2. Reading books, magazines, or newspapers 47

8.3. Watching TV, Netflix, streaming movies, or shows 51

8.4. Doing hobbies, crafts or puzzles $\quad 55$

9. Discussion 59

9.1. Introduction 59

9.2. Creative activity during 2009-2018 59

9.3. Creative activity during the COVID-19 pandemic 60

9.4. Implications for policy and future directions $102 \quad 60$ 


\section{List of Tables}

Table 2.1.

Table 3.1.

Table 3.2.

Table 4.1

Table 4.2.

Table 5.2.

Table 6.1.

Table 7.1.

Table 7.2

Table 8.1.

Table 8.2.

Table 8.3.

Table 8.4.

Table 8.5.

Table 8.6.

Table 8.7.

Table 8.8.

Table 8.9

Table 8.10.
Sociodemographic characteristics of baseline sample $(n=6,914)$

Logistic regression model showing associations with weekly involvement in creative activities

Linear regression model showing associations with weekly involvement in creative activities

Proportion of older adults participating weekly in creative activities in Wave 5 of TILDA

Creative activity score by tertiles of low, moderate and high activity in Wave 1 and Wave 5

Linear regression model showing associations between creative activity score and self-rated health, vision, hearing and disability

Linear regression models predicting quality of life, loneliness and mental health outcomes by creative activity groups

Multinomial logistic regression model of associations between creative activity groups and physical activity group

Logistic regression model of associations between creative activity groups and smoker status

Sociodemographic characteristics of COVID-19 Questionnaire baseline sample $(n=3,596)$

Sociodemographic characteristics of time spent reading books, magazines, or newspapers

Multinomial logistic regression showing associations between sociodemographic characteristics and time spent reading books, magazines or newspapers

Linear regression models predicting quality of life, loneliness and depression and perceived stress by frequency of reading books, magazines or newspapers during COVID-19 restrictions

Sociodemographic characteristics of time spent watching TV, Netflix, streaming movies, or shows

Multinomial logistic regression showing associations between sociodemographic characteristics and time spent watching TV, Netflix, streaming movies, or shows during COVID19 restrictions

Linear regression models predicting quality of life, loneliness and depression and perceived stress by time spent watching TV, Netflix, streaming movies, or shows during COVID-19 restrictions

Sociodemographic characteristics of time spent doing hobbies, crafts or puzzles

Multinomial logistic regression showing associations between sociodemographic characteristics and time spent doing hobbies, crafts or puzzles

Linear regression models predicting quality of life, loneliness and depression and perceived 


\section{List of Figures}

Figure 3.1.

Figure 3.2.

Figure 3.3.

Figure 3.4.

Figure 3.5.

Figure 3.6.

Figure 3.7.

Figure 3.8.

Figure 3.9.

Figure 3.10.

Figure 3.11 .

Figure 3.12.

Figure 4.1

Figure 4.2.

Figure 4.3.

Figure 5.1.

Figure 5.2.

Figure 5.3.

Figure 5.4.

Figure 5.5.

Figure 5.6.

Figure 5.7.

Figure 5.8.

Figure 5.9.
Frequency of involvement in creative activities

Weekly involvement (\%) in active and passive participation

Listening to music or radio weekly by sex and age group

Listening to music or radio weekly by sex and educational attainment

Reading magazines or books weekly by sex and age group

Reading magazines or books weekly by sex and educational attainment

Spending time on creative hobbies or activities by sex and age group

Spending time on creative hobbies or activities by sex and educational attainment

Going to see films, concerts or plays weekly by sex and age group

Going to see films, concerts or plays weekly by sex and educational attainment

Creative activity score by five-year age bands

Creative activity score by sex, age group and educational attainment

Changes in weekly involvement in creative activity between 2009 - 2018

Changes in creative activity score tertiles from Wave 1 (2009-2011) to Wave 5 (2018) by Wave 5 age groups and sex

Changes in creative activity score tertiles from Wave 1 (2009-2011) to Wave 5 (2018) by educational attainment and sex

Self-rated hearing by creative activity score in Wave 1

Self-rated vision by creative activity score in Wave 1

Self-rated hearing by creative activity score in Wave 1

Disability by creative activity score in Wave 1

Chronic condition by creative activity score in Wave 1

Experience of pain by creative activity score in Wave 1

Proportion of older adults rating their physical health as fair/poor between Wave 1 to Wave 5 by sex and creative activity involvement groups

Proportion of older adults rating their vision as fair/poor between Wave 1 to Wave 5 by sex and creative activity involvement groups 


\section{List of Figures}

Figure 5.10. Proportion of older adults reporting a disability between Wave 1 to Wave 5 by sex and creative activity involvement groups

Figure 5.11. Proportion of older adults reporting a chronic condition between Wave 1 to Wave 5 by sex and creative activity involvement groups

Figure 5.12. Proportion of older adults reporting moderate/severe pain between Wave 1 to Wave 5 by sex and creative activity involvement groups

Figure 6.1. Quality of life scores by creative activity group

Figure 6.2.

Loneliness scores by creative activity group

Figure 6.3.

Depression scores by creative activity group

Figure 6.4.

Worry scores by creative activity group

Figure 6.5.

Perceived stress scores by creative activity group

Figure 6.6.

Wave 1 and Wave 5 mean quality of life scores by creative activity involvement groups

Figure 6.7.

Wave 1 and Wave 5 mean loneliness scores by creative activity involvement groups

Figure 6.8.

Wave 1 and Wave 5 mean depression scores by creative activity involvement groups

Figure 6.9.

Wave 1 and Wave 5 mean worry scores by creative activity involvement groups

Figure 6.10.

Wave 1 and Wave 5 mean stress scores by creative activity involvement groups

Figure 7.1.

Proportion of physical activity groups within creative activity groups by sex at Wave 1

Figure 7.2.

Creative activity groups by smoker status in Wave 1

Figure 7.3.

Proportion of older adults reporting high physical activity at Wave 1 and Wave 5 by creative activity involvement groups

Figure 7.4.

Proportion of current smokers at Wave 1 and Wave 5 by creative activity involvement groups

Figure 8.1.

Level of involvement in creative activities during the COVID-19 lockdown

Figure 8.2.

Quality of life, loneliness, depression and perceived stress mean scores by time spent reading books, magazines or newspapers during COVID-19 restrictions

Figure 8.3.

Quality of life, loneliness, depression and perceived stress mean scores by time spent watching TV, Netflix, streaming movies, or shows during COVID-19 restrictions

Figure 8.4. 


\section{Executive Summary}

The following report presents findings on creative activity participation among older adults in Ireland using data from The Irish Longitudinal Study on Ageing (TILDA). TILDA is a nationally representative study of community dwelling adults aged 50 years older $n$ Ireland. TILDA visits its participants every two years to interview them about their social, economic, health and financial situation. Information on involvement in creative activities is captured at each wave of data collection. In July 2020, TILDA additionally sent a questionnaire to each participant to capture the impact of the first COVID-19 lockdown period on their lives.

This research assesses involvement in a range of creative activities including going out to films, concerts or plays, reading books or magazines for pleasure, listening to music, radio, and doing creative activities or hobbies. Using the data available, we produced a 'creative activity score' for each individual, taking into account the number of creative activities they were involved in and the frequency they partook in each activity.

Using this data, we investigated how involvement in creative activities affects the health and wellbeing of older adults over a nine-year period (2009-2018) and the impact of changes in involvement during the COVID-19 pandemic. These findings detail the importance of access to creative activities in older ages, and provide the foundation for future, more in-depth analyses on involvement, motivations, and barriers to participation.

\section{Key findings}

Participation in creative activities was high among the older population, with over half of older adults reporting involvement in creative activities or hobbies at least weekly $(53.5 \%)$.

Older adults reporting the highest levels of involvement in creative activities reported the highest quality of life, and scored lowest on loneliness, depression, worry and stress measurements.

\section{The level of involvement in creative} activities was consistent between ages 50 74 years, before beginning to decline more rapidly from 75 years and older.

Higher educational attainment and higher income were strong driving factors for regular involvement in creative activities. Women were over three times more likely than men to read books, magazines or newspapers for pleasure weekly, while adults living in rural areas had lower involvement compared with those in urban areas. 
Declining vision and health, and an increase in disability impacted on participation in creative activities.

This association persisted after controlling for demographic factors.

Proportions of adults reporting high physical activity were highest among those also reporting moderate or high creative activity.

The lowest proportions of current smokers were among those reporting high creative activity.

Although overall levels of physical activity decreased over a nine-year period, the largest decrease was among men adults reporting a shift from high to low/moderate creative activity between time points. The proportion of those reporting high physical activity decreased from $43.8 \%$ to $23.1 \%$ in this group.
Time spent doing hobbies, crafts or puzzles increased among older adults during the first COVID-19 lockdown (March to November 2020). $26 \%$ of older adults reported doing hobbies, crafts or puzzles more often. Just $10 \%$ stated they did them less often.

Compared with before the pandemic, adults reporting they spent less time reading or doing hobbies, crafts or puzzles had higher loneliness, depression and perceived stress.

In conclusion, participation in creative activity is high among the older communitydwelling population and shows positive associations with health. Discrepancies in levels of participation were visible among those in lower educational and income groups and those with worse health, while participation appeared to decrease among adults living in rural areas during the COVID19 pandemic. Policies addressing lower participation levels in these at-risk groups and increasing access to creative activities in the community may act as a means of improving health and wellbeing. Future work will expand on the level of participation in arts, cultural and creative activities, barriers to access and motivations for involvement among the older population. 


\section{Introduction}

In March 2020, Ireland began implementing a range of restrictions to reduce the spread of COVID-19 in the population. Many of these restrictions focused on keeping the older population safe, but also resulted in isolation and lost social links. Research from The Irish Longitudinal Study on Ageing (TILDA) found that average loneliness in the adults aged 60 years and over during the first lockdown (March to November 2020) of the COVID-19 pandemic was more than double the average score in 2018/2019 and was associated with lower quality of life during this time (1). Depressive symptoms were now reported by almost $25 \%$ of this same group, compared with less than $10 \%$ in 2018 (2).

In July 2020, the Creativity in Older Age programme was launched with a view to introducing creative initiatives in a group hit hardest by the pandemic (3). These initiatives sought to offset some of the impact of the COVID-19 measures which, though necessary, impacted the lives of the older population. As part of the Creativity in Older Age programme, a research project with TILDA was undertaken to measure the effects of participation in creative activities on the health and wellbeing of the older population.

Creative activity can take many forms, encompassing both active participation involving making, doing, creating, playing, dancing and writing, and passive participation such as watching, looking at or listening. This report captures elements of both active and passive participation, focusing on participation in activities including going out to films, plays or concerts, reading books or magazines, listening to music and radio, and spending time on hobbies and/or creative activities (4). This range of activities includes the broad elements of creativity found in exhibitions, literature and digital culture, along with engagement through personal hobbies and creative activities.

Creative activity in older age has been shown to be beneficial for both physical and mental health (5-11). An intervention study on healthy, older adults in the US found that involvement in cultural programmes had positive impacts on general health, healthcare utilisation and loneliness over a period of just 12 months (10). Similarly, an evaluation of community-based arts programmes in England found participation lead to reductions in healthcare utilisation and feelings of isolation (11). An eightweek dance program for older adults resulted in increased life satisfaction among its participants (8), while a large review of creative art interventions targeting depression in older adults found the majority (51/75) had positive results (7).

Another intervention programme for older, isolated people which provided individuals with a range of activities and thus options suited to their own interests, had widespread benefits (6). Participants reported lower depression and loneliness and less healthcare utilisation in addition to increased physical activity, social interaction, self-worth and enjoyment of life (6). While the programme focused on creative activities, participants felt encouraged to take better care of their physical health and previously isolated individuals were becoming re-integrated with society through activity groups and shared social supports (6).

Benefits have been observed in passive participation also. For example, attendance at cultural events such as concerts, plays, museums, art exhibitions, cinemas and theatres is associated with reduced mortality in a large cohort study of the Swedish population aged $16-74$ years (12).

Using data from the Growing up in Ireland study, Smyth (2020) provided insights into arts and cultural participation among the younger population in Ireland (13). Sociodemographic gradients in participation were apparent, with higher involvement among young women and among those from professional/managerial or graduate socio-economic backgrounds in activities such as reading and cultural activities (13). Reading was associated with better academic performance, but in the young population, little relationship with outcomes such as emotional wellbeing was apparent (13). It is noted that those involved at a younger age were more likely to be those involved in their later adolescent years and that patterns established by then will likely contribute to involvement in adult life (13). It is expected these sociodemographic gradients will continue to play a role in participation later in the life course, but to date, little information is available on population levels of participation in creative activity among older, community-dwelling adults in Ireland.

This report will provide an overview of creative activity participation among the over-50s population in Ireland using information captured through TILDA. We will identify driving factors of engagement in activity and assess the impact of participation on the health and wellbeing of this population using data collected over nine years (2009 - 2018). Additionally, we will explore the impact on participation in creative activity during the first lockdown period of the COVID-19 era. 


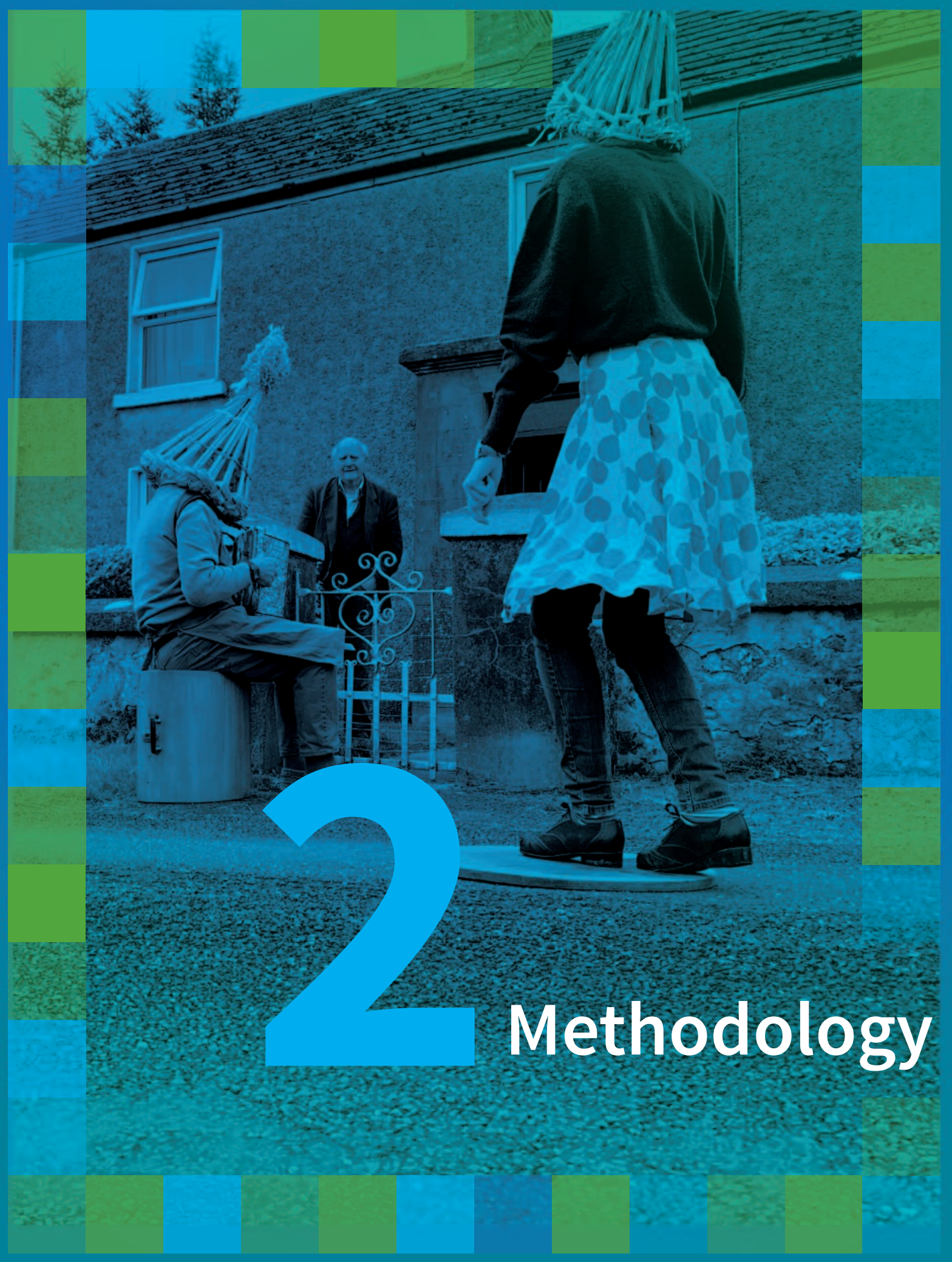




\section{Chapter 2 Methodology}

The Irish Longitudinal Study on Ageing (TILDA) is a nationally representative study of community-dwelling older adults aged 50 years and over in Ireland $(14,15)$. TILDA collects information on its participants every two years, referred to as a wave of data collection. The first wave of data collection taking place between October 2009 and February 2011. 8,175 adults aged 50 years and older took part in the first wave, representing 1 in 156 older adults in Ireland. To date, five waves of data have been collected, with the fifth wave taking place between January - December 2018.

\subsection{Data Collection}

At each wave of data collection, participants are invited to complete a computer-assisted personal interview (CAPI) administered by interviewers (4). Extensive information on the social, health and economic circumstances of the participants are captured. Following each interview, participants are given an optional self-completion questionnaire (SCQ) to complete, which contains more sensitive questions. In Wave 1 and 3 of TILDA, a health assessment was also offered to participants who had completed an interview. The health assessment was carried out in either a dedicated health assessment centre, or a modified health assessment was offered which could be completed in the participant's own home. Trained research nurses carried out a range of assessments covering the cardiovascular, vision, bone and cognitive health of the participant in addition to measuring walking speed and grip strength. Anthropometric measurements were captured and blood samples taken during the assessment. During the COVID-19 pandemic, TILDA also administered a standalone self-completion questionnaire capturing the experiences of participants during the first lockdown period $(1,16)$.

\subsection{Study Sample}

Analyses in chapters three to seven are based on participants who completed a self-completion questionnaire at Wave 1, and a sample of those who completed self-completion questionnaires at both Wave 1 and Wave 5 of TILDA. (Not all participants who completed a CAPI at Wave 1 also completed an SCQ; the baseline sample for the latter is therefore lower than the study population at baseline reported above.) Analysis in chapter eight focuses on participants who completed the COVID-19 selfcompletion questionnaire. Survey weights were applied to the Wave 1 and Wave 5 data for analyses to ensure these data are representative of the over 50s population in Ireland.

\subsection{Measures}

\subsubsection{Demographic Characteristics}

Detailed demographic characteristics were captured during the CAPI. This report uses information on participants' age, gender, educational attainment (primary level or none/secondary level/third level or higher), location of residence (urban/rural) and total household income quintiles (with quintile one representing the lowest income group, and quintile five the highest).

Table 2.1.

Sociodemographic

characteristics of baseline sample $(n=6,914)$

\begin{tabular}{ll}
\hline Age, mean (SD) & $64.2(9.6)$ \\
Age Group, \% (n) & \\
\hline $50-59$ years & $40.4(2,771)$ \\
60-69 years & $30.5(2,240)$ \\
70-79 years & $18.4(1,411)$ \\
80+ years & $10.8(491)$ \\
\hline Sex, \% (n) & \\
Male & \\
Female & $48.6(3,149)$ \\
\hline $\begin{array}{l}\text { Educational Attainment, \% (n) } \\
\text { Primary/None }\end{array}$ & $51.4(3,765)$ \\
Secondary & \\
Third Level/Higher & $32.4(1,943)$ \\
& $45.6(2,819)$ \\
\hline Location of residence, \% (n) & $22.0(2,150)$ \\
Urban & \\
Rural & $56.1(3,610)$ \\
\end{tabular}




\subsubsection{Creative Activity}

\subsubsection{Creative activity involvement}

During the self-completion questionnaire, participants are asked how often they participate in a range of social activities including a number of creative activities. These activities include:

Going out to films, plays and concerts

Reading books or magazines for pleasure

Listening to music, radio

- Spending time on hobbies or creative activities

Participants tick a box for each item to indicate if they participate in these activities 'daily/almost daily', 'once a week or more', 'twice a month or more', 'about once a month', 'every few months', 'about once or twice a year', 'less than once a year or never'.

\subsubsection{Creative Activity Score}

As a means of measuring different magnitudes of involvement, we calculated a composite measure of creative activity to account for the number of activities a participant states they are involved in, and the frequency they partake in this activity. For each activity, participants who respond they never take part received a score of 0 while those who take part 'daily/almost daily' received a score of 7 . The measure ranged from 0 to 28, with higher scores representing higher levels of involvement in creative activities.

\subsubsection{Physical Health}

\subsubsection{Self-rated health, vision and hearing}

Participants are asked to rate their health, vision and hearing as excellent, very good, good, fair or poor.

\subsubsection{Disability}

Participants are asked about difficulties with activities of daily living (ADLs) and instrumental activities of daily living (IADLs) which are a result of a health or memory problem, and which will last longer than three months. Examples of ADLs include dressing, walking across a room, or bathing/ showering. Examples of IADLs include preparing a hot meal, doing household chores or shopping for groceries. Participants who responded that they had at least one ADL or IADL are classified as having a disability for this report.

\subsubsection{Chronic conditions}

Participants are asked if they have ever been diagnosed by a doctor with any or some of a number of chronic conditions. We classified participants as having either no chronic conditions, or $\geq 1$ chronic condition from the following list:

Angina

Asthma

- Arthritis

Cancer

- Cataracts

Diabetes

Heart Attack

Heart Failure

High Blood Pressure
High Cholesterol
Hip Fracture
Lung Disease
Osteoporosis
Parkinson's Disease
Stroke
Ulcer




\subsubsection{Self-rated pain}

Participants are asked if they are troubled with pain, and if so whether the pain is mild, moderate or severe.

\subsubsection{Quality of life}

Quality of life was measured using the 12-item modified version of the CASP Scale (CASP-12) (17). Responses were captured on a four-point Likert scale and summed to create an overall quality of life score ranging from $0-36$, with higher scores indicating better quality of life.

\subsubsection{Loneliness}

Loneliness was captured using a five-item modified version of the University of California-Los Angeles (UCLA) Loneliness Scale (18). Responses were captured on a three-point Likert scale and summed to create an overall loneliness score ranging from 0 -10, with higher scores representing greater feelings of loneliness.

\subsubsection{Mental Health}

During the CAPI and SCQ, participants were asked to complete a number of scales which measure feelings of depression, loneliness, quality of life and stress.

\subsubsection{Depression}

Depressive symptoms were captured using an eight-item modified version of the Center for Epidemiological Depression Studies (CES-D8) Scale (19). Responses captured on a three-point Likert scale are summed to create an overall depression score ranging from 0-24, with higher scores representing greater symptoms of depression.

\subsubsection{Stress}

Stress was measured using the 4-item version of the Perceived Stress Scale (PSS-4)(20). Responses were captured on a fivepoint Likert scale and summed to create an overall stress score ranging from 0-16, with higher scores representing higher levels of perceived stress.

\subsubsection{Worry}

Worry was measured using the 8-item version of the Penn State Worry questionnaire (PSWQ-A) (21). Responses were captured on a five-point Likert scale and summed to create an overall stress score ranging from 0-40, with higher scores representing greater feelings of worry.

\subsubsection{Behavioural Health}

Information on behavioural health which might impact participation in creative activities, including smoking habits and physical activity, were captured during the CAPI. In this report, participants were classified as either current smokers or past/never smokers. Physical activity was measured using the Short Form International Physical Activity Questionnaire (22, 23). Participants were asked about the number of days and amount of time spent walking and/or in moderate and vigorous activity over the past seven days. Weighted by the intensity of the activity, the time spent is converted to MET-minutes (MET = Metabolic Equivalent of Task) and classified into low, moderate or high activity groups. 


\subsubsection{Physical Activity Groups}

High Activity:

$\geq 1500$ MET-minutes with 3 or more days of vigorous activity

or

$\geq 3000$ MET-minutes of combined activity for 7 days

Moderate Activity:

- $\geq 20$ minutes vigorous activity for more than 3 days

or

- 230 minutes combined walking and moderate activity for at least five days

or

- $\geq 600$ metabolic minutes of any combination of activity for at least five days

Low Activity:

- None of the criteria for either high or moderate activity

\subsubsection{COVID-19 Questionnaire}

\subsubsection{Creative Activities}

Participants were asked how often, since the outbreak of the COVID-19 pandemic, they engaged in a number of activities, including:

Reading books, magazines or newspapers (in print or online)

Watching TV, Netflix, streaming movies or shows

Doing hobbies, crafts, or puzzles

The response options included not at all, less often, about the same and more often.

\subsubsection{Financial Situation}

Changes in the financial situation of participants were also assessed. Participants were asked how they felt their current financial situation compared to before the beginning of the COVID-19 pandemic. Response options included / am much worse off, I am a little worse off, I am about the same, I am a little better off, I am much better off. 


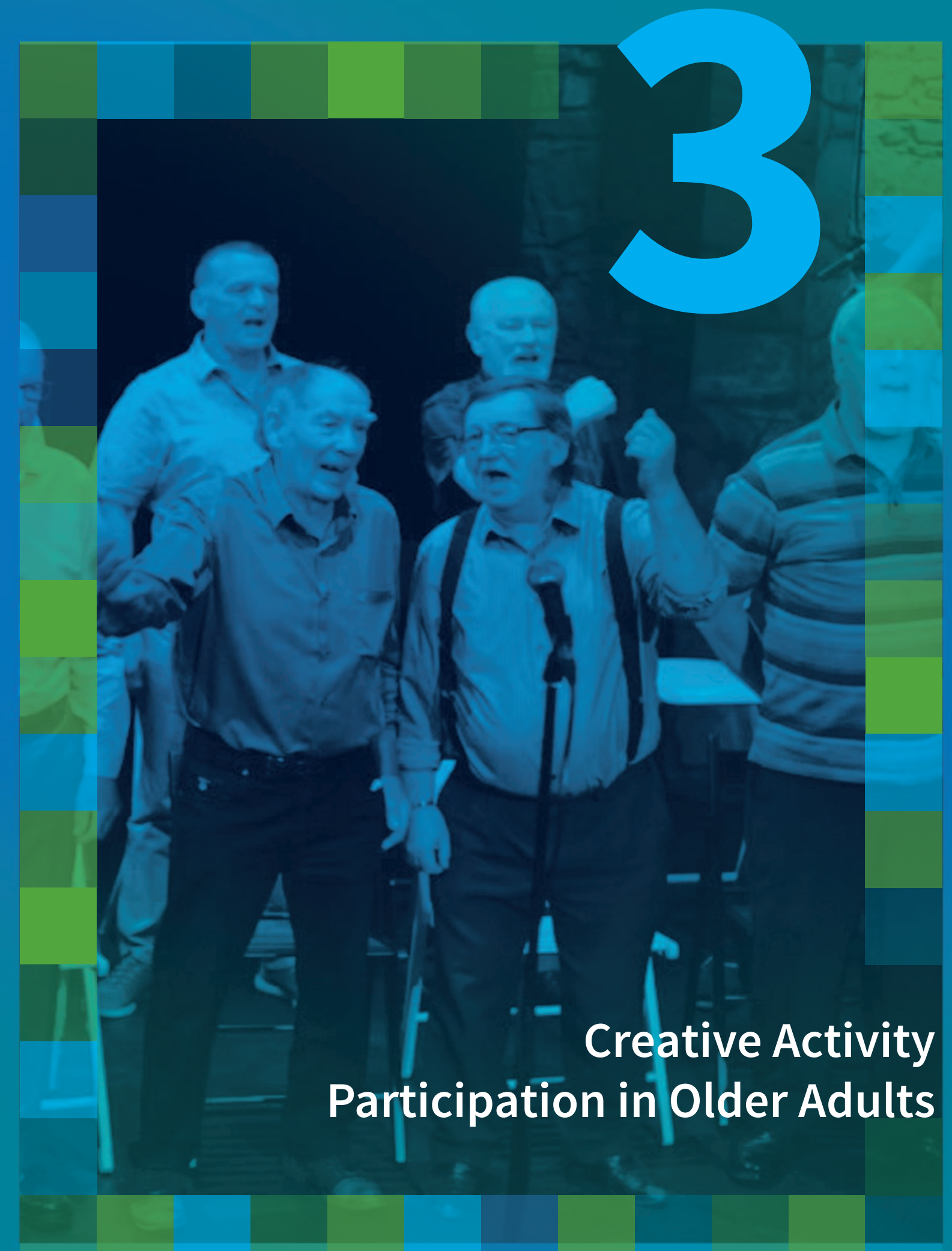

tilda.tcd.ie 


\section{Chapter 3 Creative Activity Participation in Older Adults}

\subsection{Frequency of involvement in creative activities in 2009-2011}

The activity most frequently undertaken was listening to music or the radio (Figure 3.1), with 84\% of older adults reporting that they listen to music or radio daily/almost daily, while just $1 \%$ report that they never listen.

Almost half of older adults (49.8\%) read books or magazines daily/almost daily, with a further $23.7 \%$ reading weekly and $6.8 \%$ reporting they never read books or magazines. $33.3 \%$ of older adults spend time on creative activities or hobbies weekly, with $20 \%$ engaging daily and $15 \%$ monthly, while $18.1 \%$ never spend time on creative activities or hobbies. The lowest frequency of involvement was going out to films, plays or concerts. Just $1 \%$ of older adults engage in these activities on a weekly basis, $10 \%$ on a monthly basis, and $61.7 \%$ less than monthly, while $25.6 \%$ never go to films, plays or concerts.

Figure 3.1. Frequency of involvement in creative activities
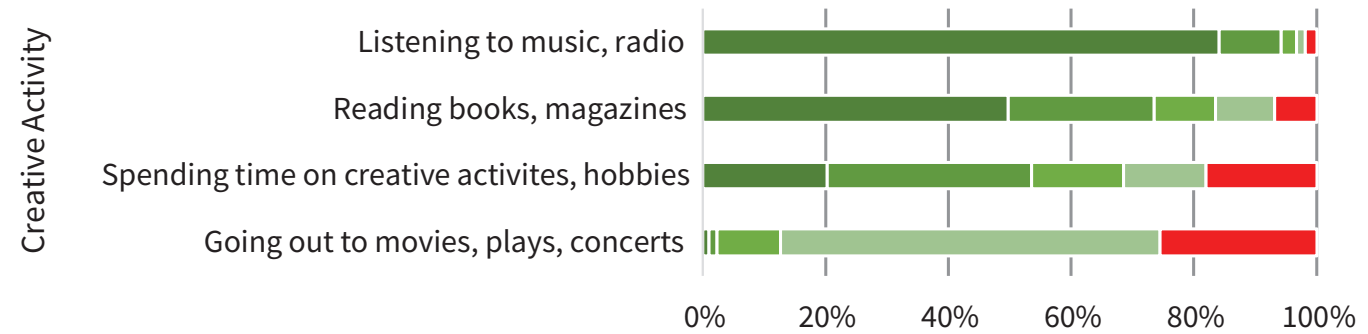

- Daily/Almost Daily $\quad$ Weekly $\quad$ Monthly $\quad$ Less than monthly $\quad$ Never

Overall, regular involvement on a weekly basis in creative activities was high (97.1\%). Involvement in each activity at least weekly was highest in passive participation such as listening to music or radio (94.1\%) and reading books or magazines (73.6\%) (Figure 3.2). In other activities, weekly involvement in going out to films, plays or concerts was just $2.3 \%$; however, $53.5 \%$ of older adults reported weekly involvement in creative activities or hobbies.

Figure 3.2. Weekly involvement (\%) in active and passive participation

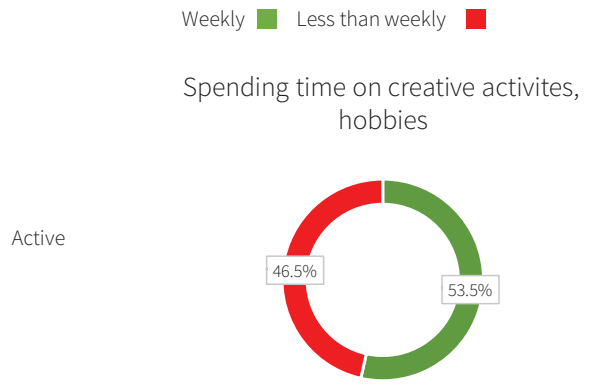

Listening to music, radio

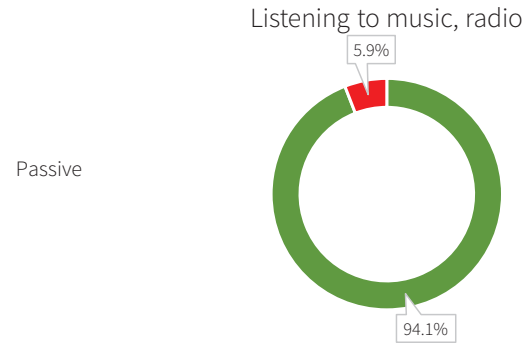

Going out to movies, plays, concerts

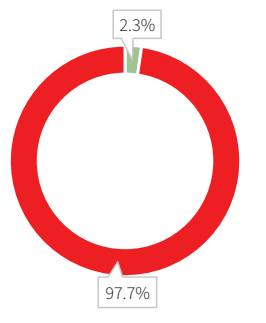

Reading books, magazines

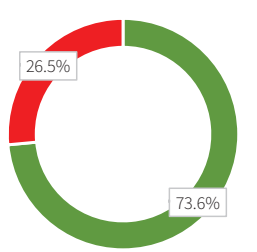




\subsection{Creative activity frequency by demographics}

Next, we looked at weekly involvement in activities by sex, age group and educational attainment during 2009-2011. Figure 3.3 shows the proportion of older adults listening to music or radio weekly by sex and age group, while Figure 3.4 breaks this down by sex and educational attainment. No sex, age or educational differences in listening to music or radio weekly were apparent, with a consistently high proportion (>90\%) listening weekly in each demographic group.

Figure 3.3. Listening to music or radio weekly by sex and age group

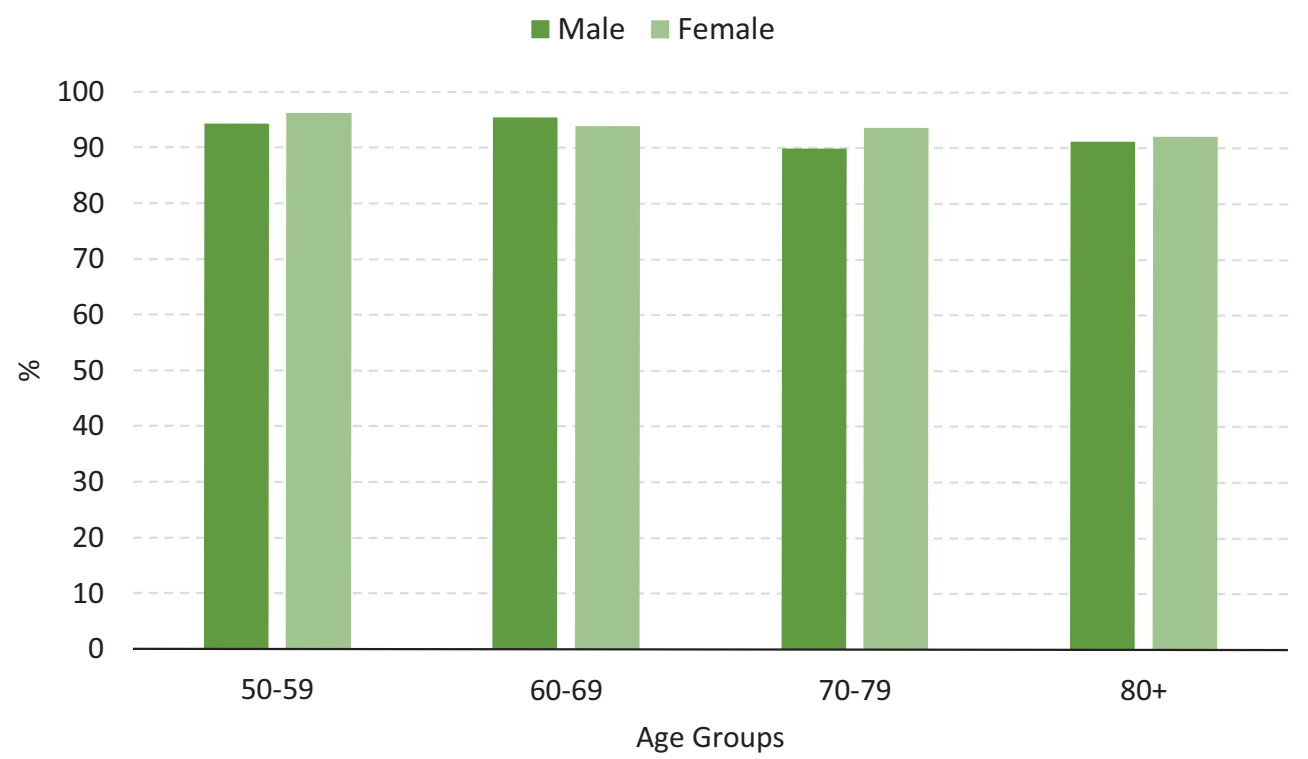

Figure 3.4. Listening to music or radio weekly by sex and educational attainment

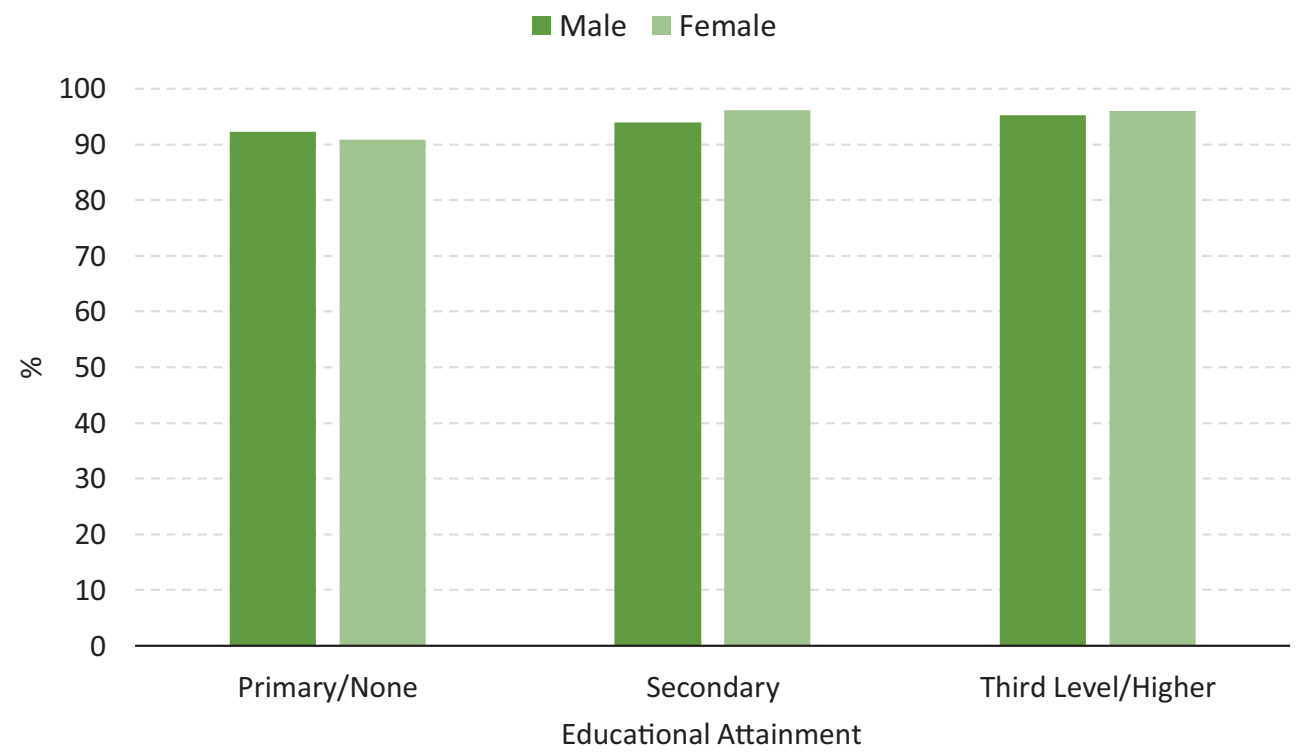


Figure 3.5 shows the proportion of older adults reading books or magazines weekly by sex and age group, while Figure 3.6 breaks this down by sex and educational attainment. In the 50-59 age group, 82.4\% of women reported reading books or magazines weekly compared to $60.7 \%$ of men. This trend remained consistent in each age group. The proportion of women reading books or magazines weekly increased from $78.4 \%$ in those with primary/none educational attainment to $89.6 \%$ in those with third/higher level education. A similar but stronger trend was apparent in men, increasing from $54 \%$ in those with primary/none educational attainment to $76.2 \%$ in those with third level or higher educational attainment.

Figure 3.5. Reading magazines or books weekly by sex and age group

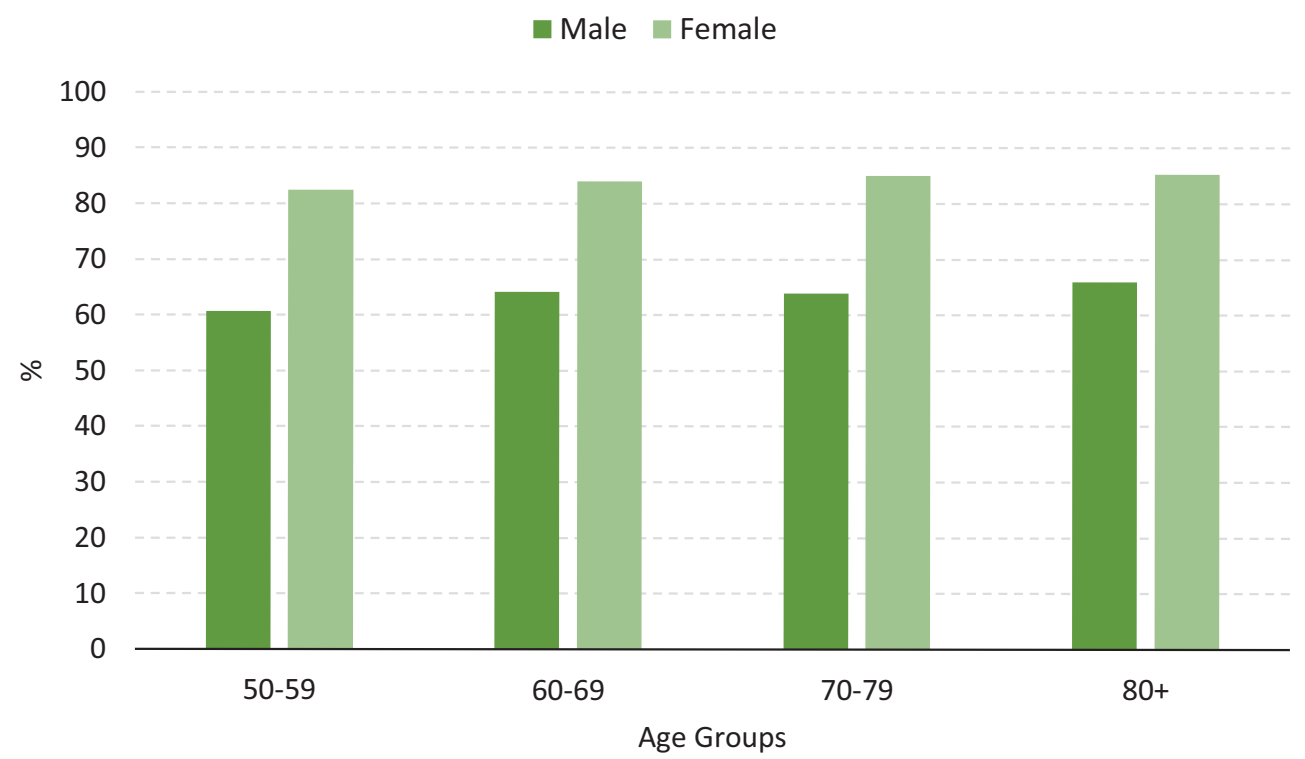

Figure 3.6. Reading magazines or books weekly by sex and educational attainment

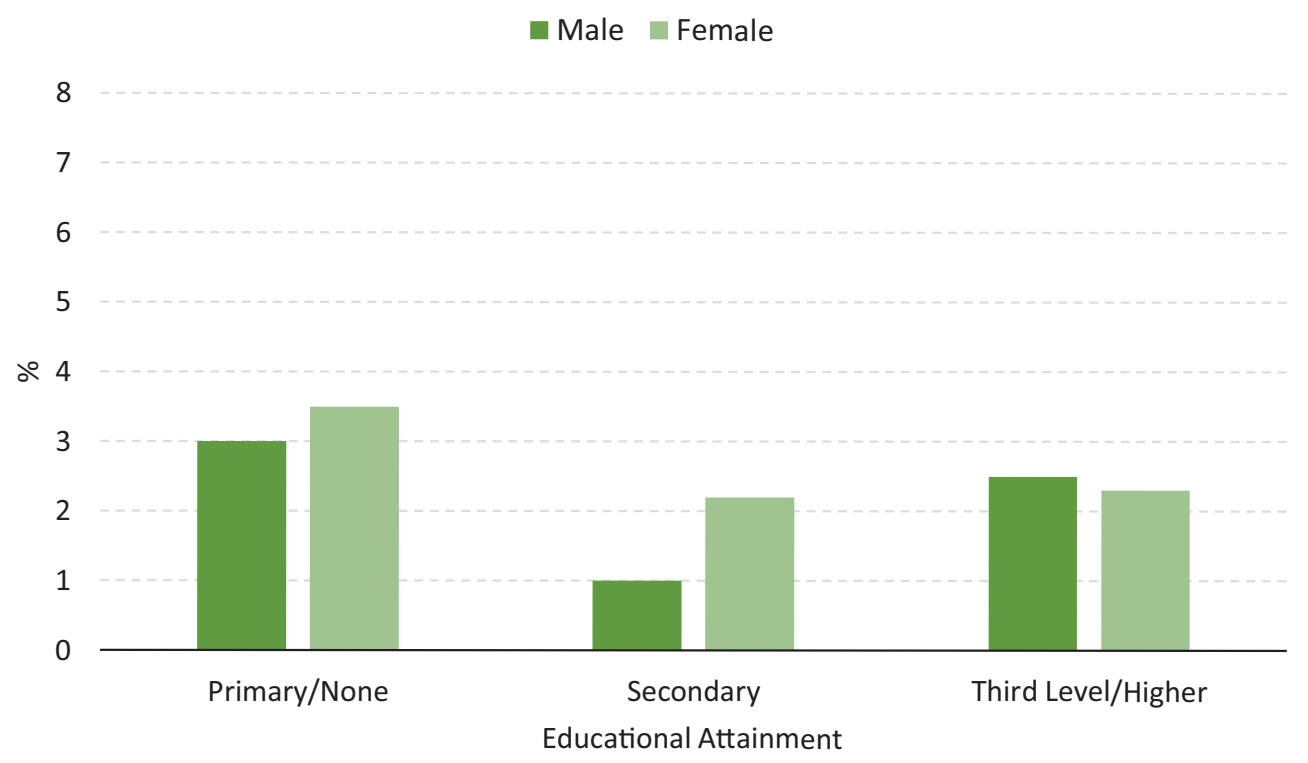


Figure 3.8 shows the proportion of older adults spending time on creative hobbies or activities weekly by sex and age group, while Figure 3.9 breaks this down by sex and educational attainment. The proportion spending time weekly was similar in both men and women. Weekly involvement was highest in age groups 50-59 years (Men: 55.1\%; Women: $57.4 \%$ ) and $70-79$ years (Men: 60.4\%; Women: 50.4\%). Weekly involvement dropped to $40.1 \%$ and $36.7 \%$ respectively for men and women aged 80 years and older. An educational attainment gradient in involvement was visible. Just $47.8 \%$ of men with primary/none educational attainment reported weekly involvement in creative activities and hobbies, compared to $59.9 \%$ of those with third level or higher educational attainment. In women the proportion increased from $39.6 \%$ in the primary/none group to $66.8 \%$ in those with third level/higher education.

Figure 3.7. Spending time on creative hobbies or activities by sex and age group

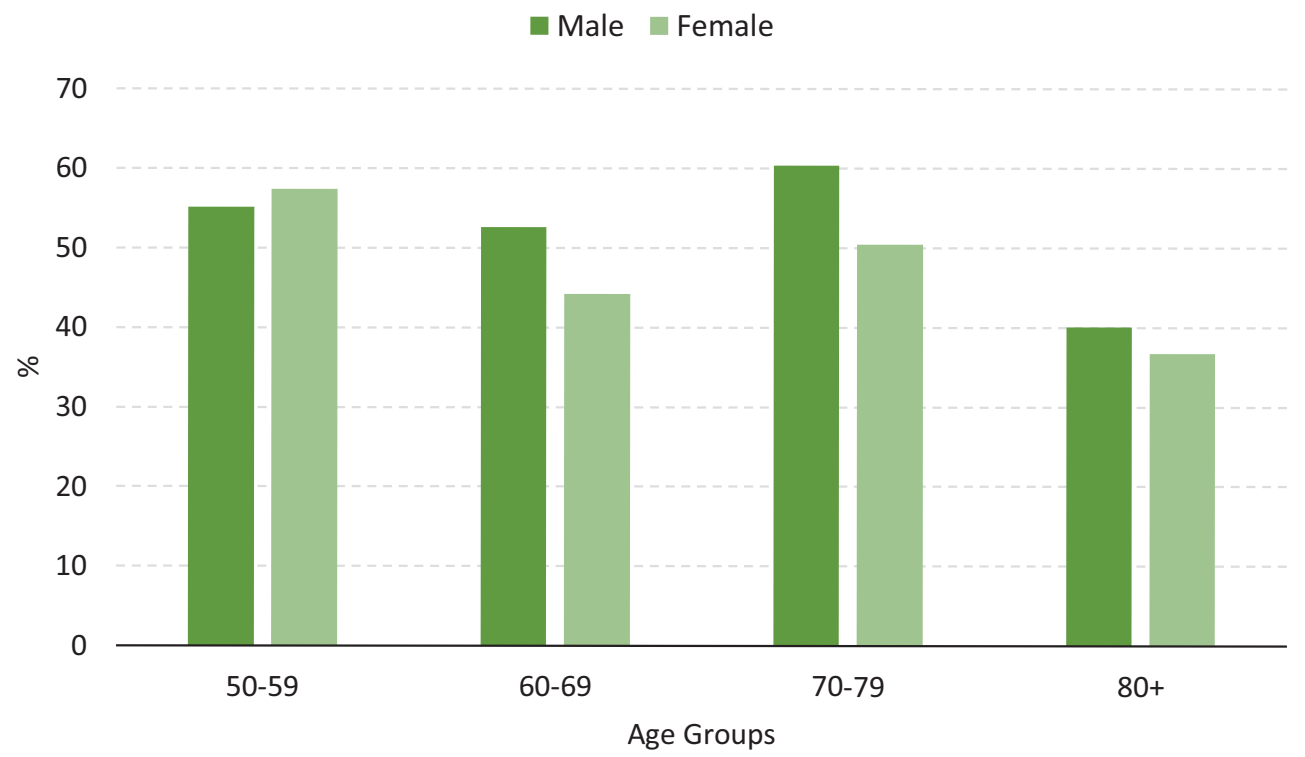

Figure 3.8. Spending time on creative hobbies or activities by sex and educational attainment

Male Female

70

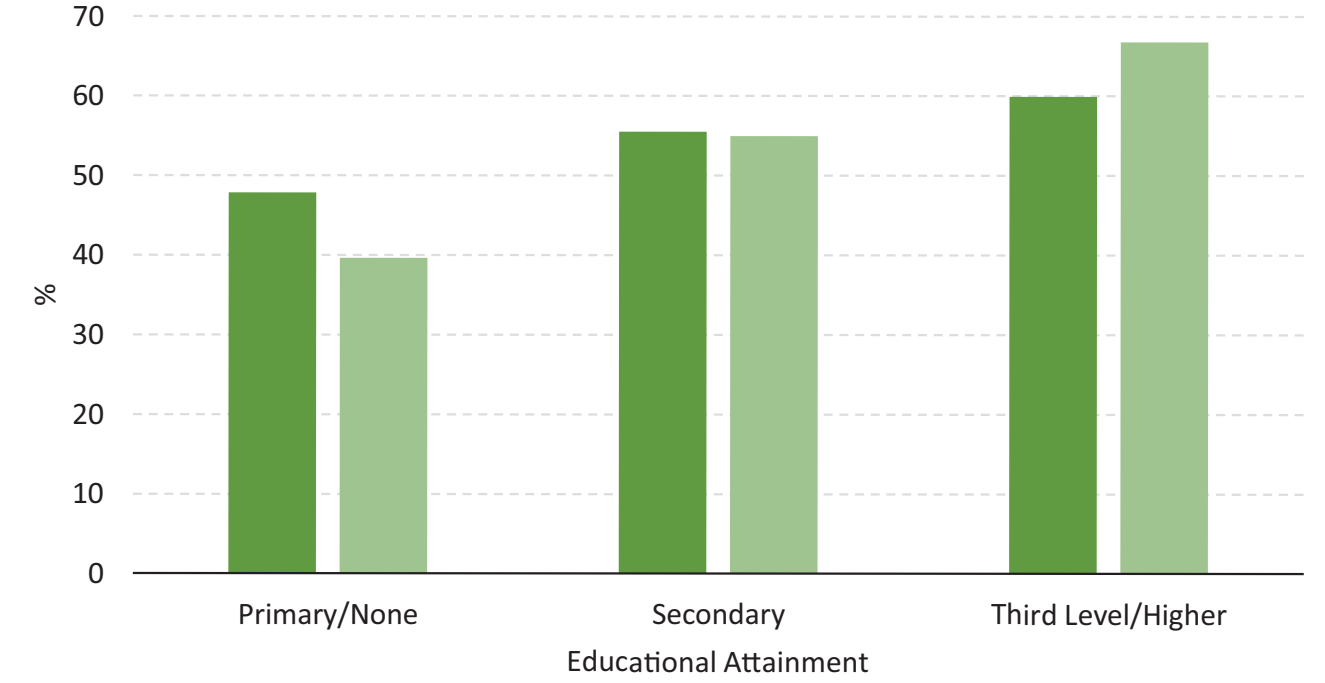


Figure 3.8 shows the proportion of older adults going to see films, concerts or plays weekly by sex and age group, while Figure 3.9 breaks this down by sex and educational attainment. No sex differences in the proportion of older adults who went to see films, concerts or plays weekly were found between ages 50-69 years (2.3\%-2.5\%). However, the proportion of men reporting weekly involvement was just $1.2 \%$ in ages $70-79$ and $0.8 \%$ in 80 years and older, while the proportion in women increased to $3.4 \%$ and $2.6 \%$ in these respective age groups. No sex differences were apparent in the proportions among those with primary/none or third level/higher educational attainment, while just $1 \%$ of men with secondary level education reported going to see films, concerts or plays weekly compared to $2.2 \%$ of women.

Figure 3.9. Going to see films, concerts or plays weekly by sex and age group

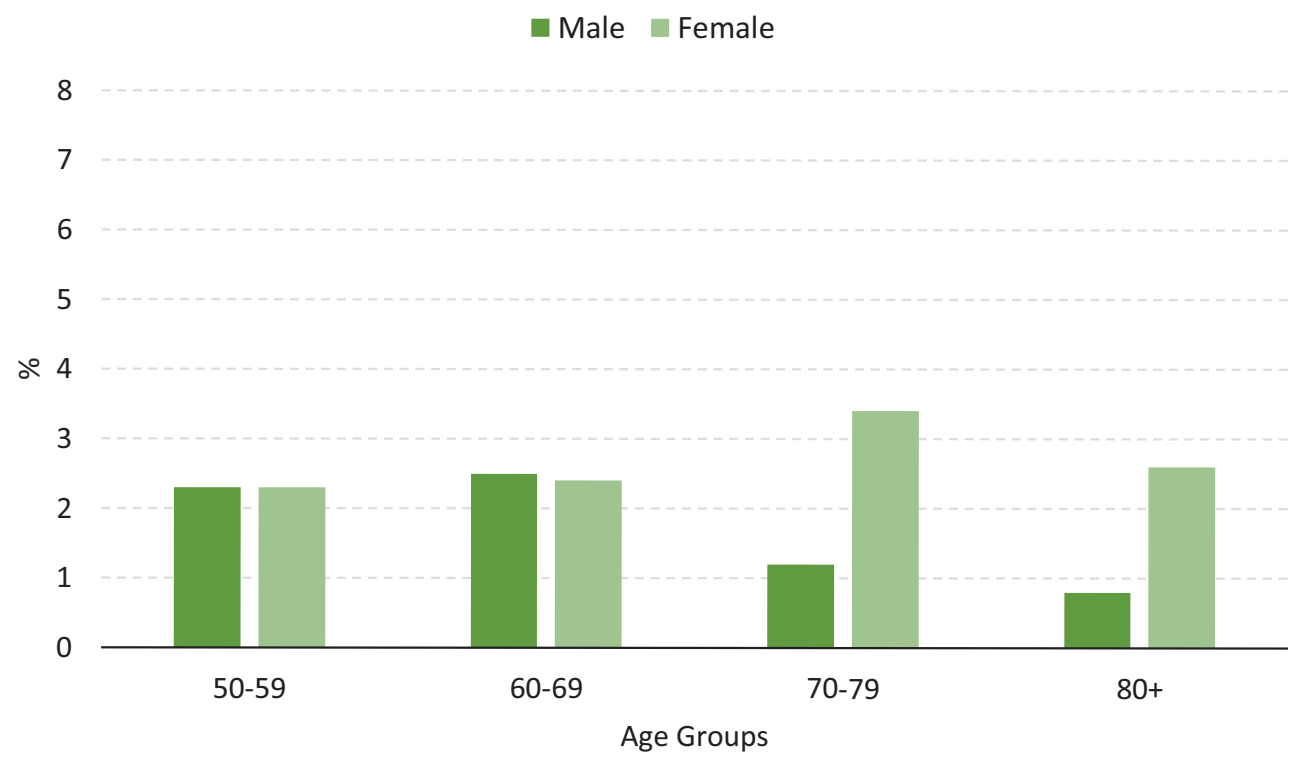

Figure 3.10. Going to see films, concerts or plays weekly by sex and educational attainment

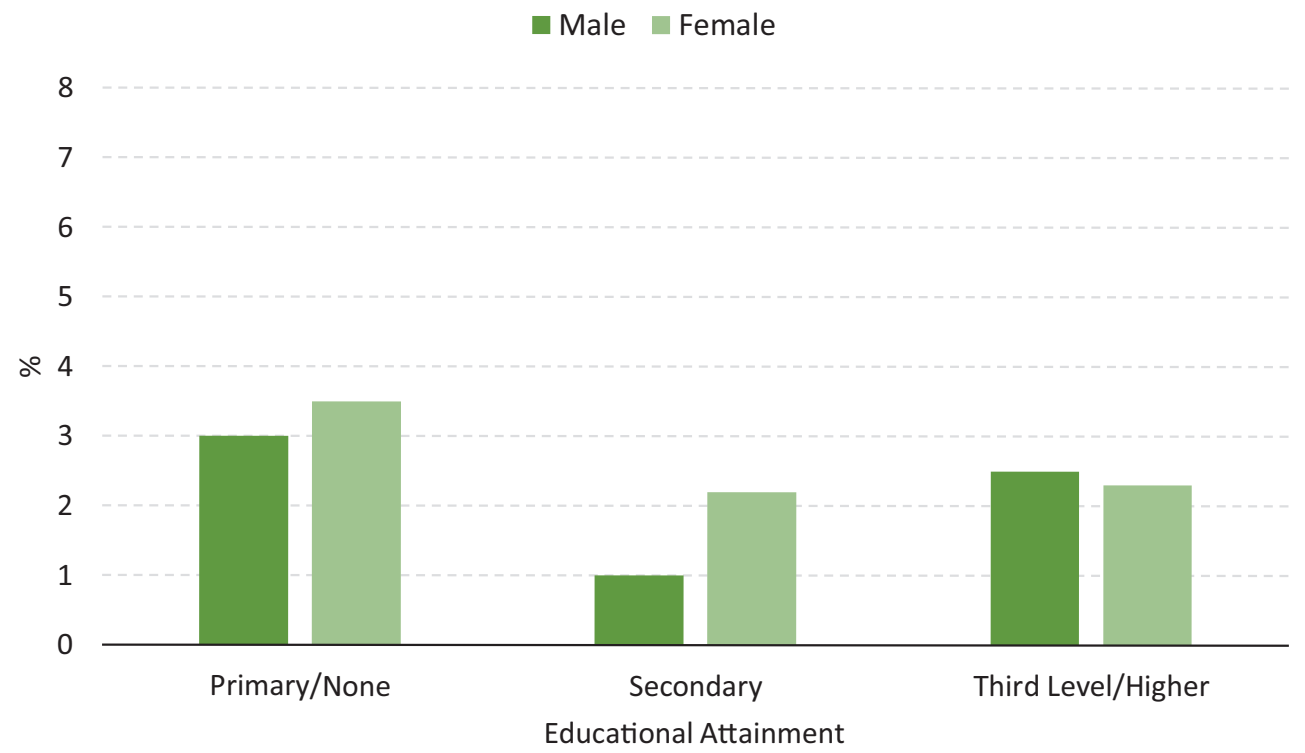


Table 3.1 presents a logistic regression model showing the associations between each creative activity by age, sex, educational attainment and location of residence (urban or rural). A positive association between age and reading books or magazines for pleasure was found, while this association was negative for listening to music or radio, suggesting that adults are more likely to read weekly in older ages and become less likely to listen to music or radio weekly. Associations with sex were limited, but the model showed that women are three times more likely than men to read books or magazines for pleasure weekly.

Educational attainment was the strongest predictor of weekly involvement in all activities. Positive associations between secondary and third level/higher education were found with reading books or magazines for pleasure, listening to music or radio, and spending time on hobbies or creative activities. Older adults with third level/higher educational attainment were three times more likely than those with primary/none to read books or magazines for pleasure weekly, and twice as likely to spend time on hobbies or creative activities weekly. In contrast, a negative association was apparent between higher levels of educational attainment and going out to films, plays and concerts, showing those with secondary educational attainment to be less likely than those with primary/none to go out to films, plays or concerts weekly.

Location of residence was not a strong driving factor for most activities with the exception of going out to films, plays and concerts, where those living in a rural area compared to an urban area were significantly less likely to do this weekly. In the highest household income quintile, there were also positive associations with reading books or magazines for pleasure, listening to music/radio and spending time on hobbies or creative activity.

Table 3.1. Logistic regression model showing associations with weekly involvement in creative activities

\begin{tabular}{|c|c|c|c|c|}
\hline & $\begin{array}{c}\text { Going out to films, plays } \\
\text { and concerts }\end{array}$ & $\begin{array}{c}\text { Reading books or magazines } \\
\text { for pleasure }\end{array}$ & Listening to music, radio & $\begin{array}{c}\text { Spending time on hobbies or } \\
\text { creative activities }\end{array}$ \\
\hline & OR $[95 \% \mathrm{Cl}]^{1}$ & OR $[95 \% \mathrm{Cl}]^{1}$ & OR $[95 \% \mathrm{Cl}]^{1}$ & OR $[95 \% \mathrm{Cl}]^{1}$ \\
\hline Age & $0.98[0.95-1.01]$ & $1.02[1.01-1.03]^{* * *}$ & $0.98[0.96-0.99]^{*}$ & $0.99[0.98-1.00]^{\dagger}$ \\
\hline \multicolumn{5}{|l|}{ Sex } \\
\hline Male & Ref & Ref & Ref & Ref \\
\hline Female & $1.04[0.64-1.70]$ & $3.12[2.60-3.75]^{* * *}$ & $1.29[0.91-1.84]$ & $0.96[0.83-1.11]$ \\
\hline Primary/None & Ref & Ref & Ref & Ref \\
\hline Secondary & $0.49[0.26-0.90]^{* *}$ & $1.67[1.34-2.07]^{* * *}$ & $1.41[0.93-2.13]^{*}$ & $1.35[1.12-1.64]^{* *}$ \\
\hline Third Level/Higher & $0.64[0.32-1.31]$ & $2.74[2.14-3.51]^{* * *}$ & $1.31[0.83-2.07]^{* *}$ & $1.89[1.52-2.35]^{* * *}$ \\
\hline \multicolumn{5}{|c|}{ Location of residence } \\
\hline Urban & Ref & Ref & Ref & Ref \\
\hline Rural & $0.57[0.34-0.98]^{*}$ & $0.89[0.75-1.07]$ & $1.00[0.70-1.41]$ & $0.95[0.81-1.12]$ \\
\hline \multicolumn{5}{|l|}{ Household Income } \\
\hline Q2 & $1.59[0.76-3.32]$ & $1.15[0.86-1.52]$ & $1.17[0.70-1.95]$ & $1.06[0.81-1.38]$ \\
\hline Q3 & $0.73[0.30-1.83]$ & $1.03[0.78-1.37]$ & $1.25[0.74-2.11]$ & $1.24[0.96-1.60]$ \\
\hline Q4 & $0.79[0.34-1.88]$ & $1.19[0.90-1.56]$ & $1.60[0.90-2.82]$ & $1.30[1.00-1.67]^{*}$ \\
\hline Q5 (Highest) & $0.68[0.24-1.78]$ & $1.34[0.99-1.81]^{\dagger}$ & $1.76[0.95 .3 .24]^{\dagger}$ & $1.28[0.97-1.68]^{\dagger}$ \\
\hline
\end{tabular}

1 The odds ratio represents the odds of weekly involvement for each creative activity in each demographic compared to the reference group. Odds ratios below or above 1 mean this demographic is less or more likely to be involved in this creative activity weekly. 


\subsection{Creative activity score}

Assessing involvement in creative activity using a composite score, where higher scores represent a greater frequency of involvement across multiple activities, we found that the average creative activity score was 18.3 (range 0-28).

To understand inflection points of lower creative activity involvement, figure 3.11 displays mean creative activity scores by five-year age bands of older adults. Scores remained consistent from ages 50 to 74 years, before beginning to decline in ages more rapidly from ages 75 years onwards.

Figure 3.11. Creative activity score by five-year age bands

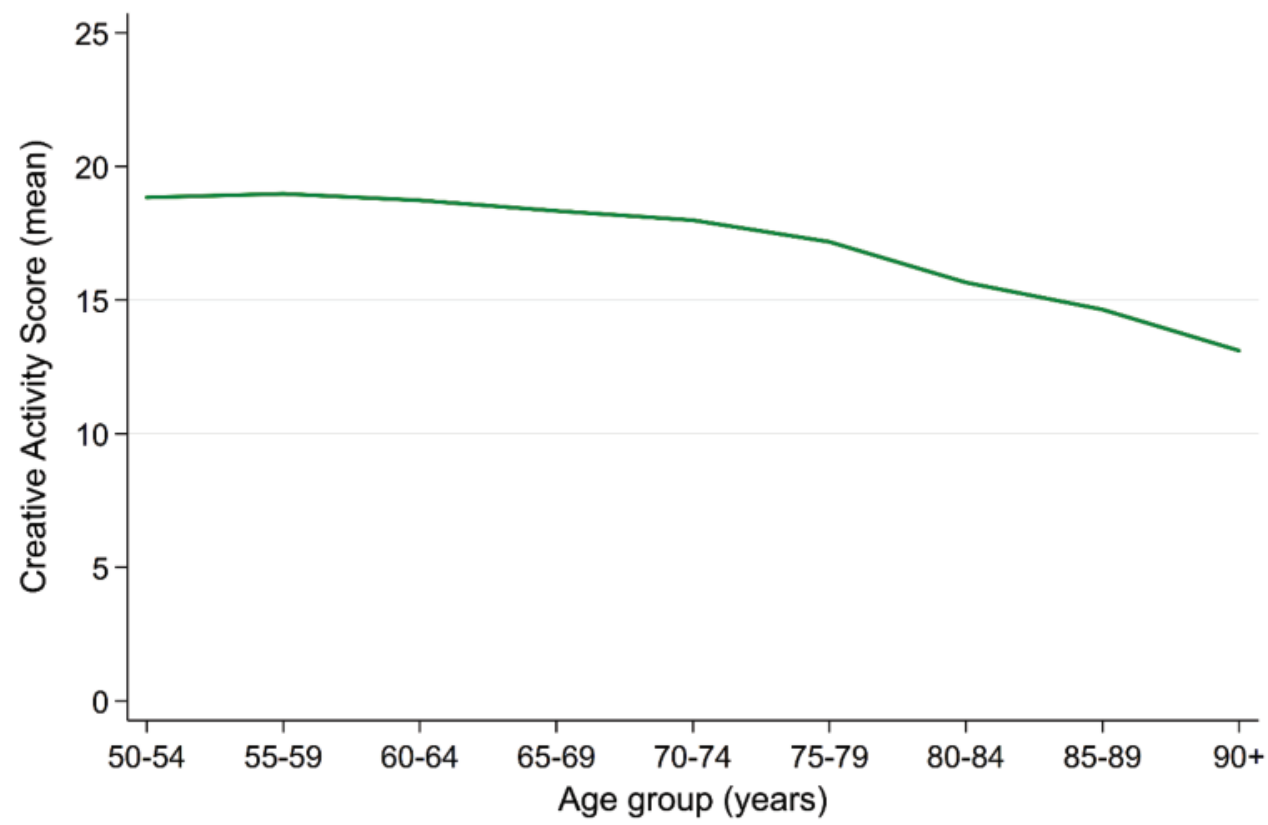

These changes are broken down by demographics in Figure 3.12, which shows mean creative activity score by sex, age group and educational attainment.

Mean score was lowest in older adults aged 80 years and older with primary/none educational attainment in both men (mean=13.7) and women (mean=14.3). Scores were consistent across all other age groups, with the highest scores for both sexes found in those aged 60-69 with third level/higher educational attainment (men: 20.3; women: 21.2 
Figure 3.12. Creative activity score by sex, age group and educational attainment

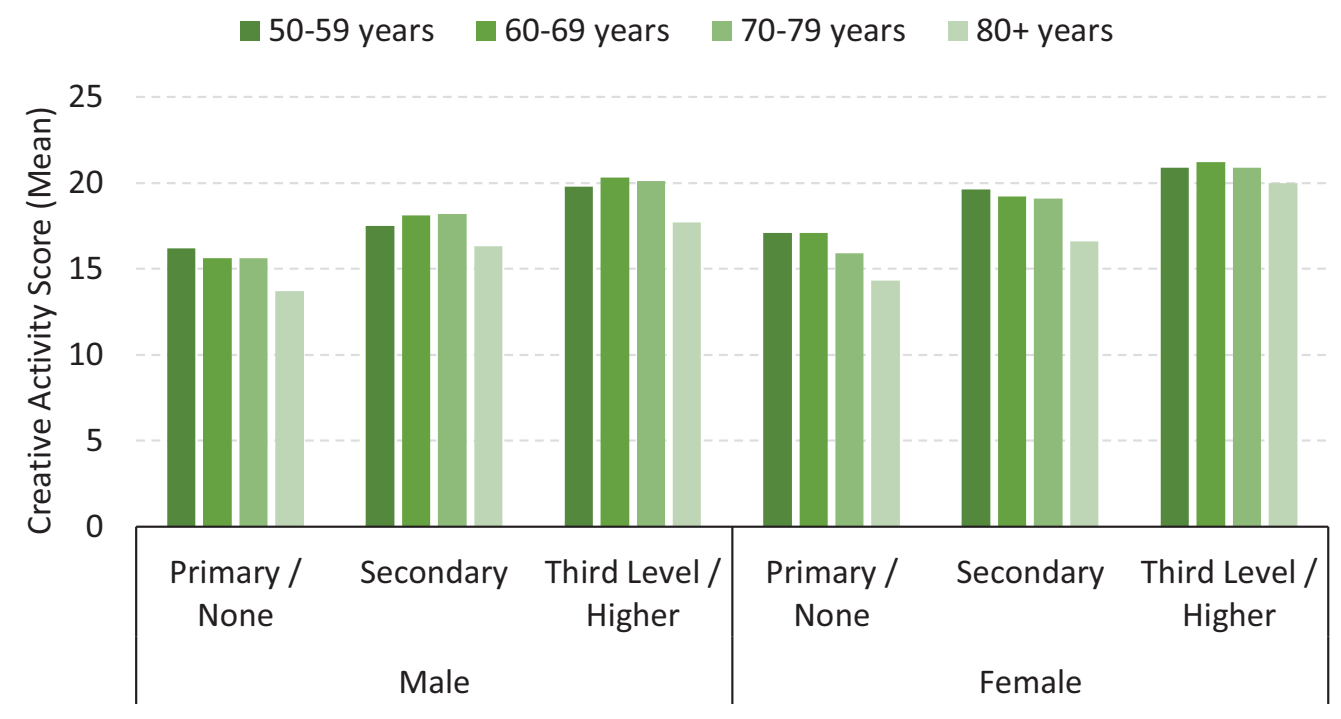

Table 3.2 presents a linear regression model showing associations between creative activity score and age, sex, educational attainment, location of residence and household income quintiles. Each of the demographics were significant driving factors in creative activity scores. Age was negatively associated with creative activity score, showing that as age increased, creative activity score declined. Similarly, those living in a rural area were more likely to have lower scores than those living in an urban area. Women, meanwhile, were more likely to have higher creative activity scores compared to men, and those with both secondary level and third level / higher educational attainment compared to older adults with primary / none. Scores were positively associated with higher household income, with a significantly increasing positive trend in the third, fourth and fifth quintiles.

\section{Table 3.2.}

Linear regression model showing associations with weekly involvement in creative activities activity score. Positive numbers reflect a positive relationship, negative numbers a negative relationship. For age, the coefficient shows the relationship as age increases. For demographic groups, the coefficient shows the relationship relative to the reference group. A positive number suggests this group had higher creative activity scores compared to the reference group.

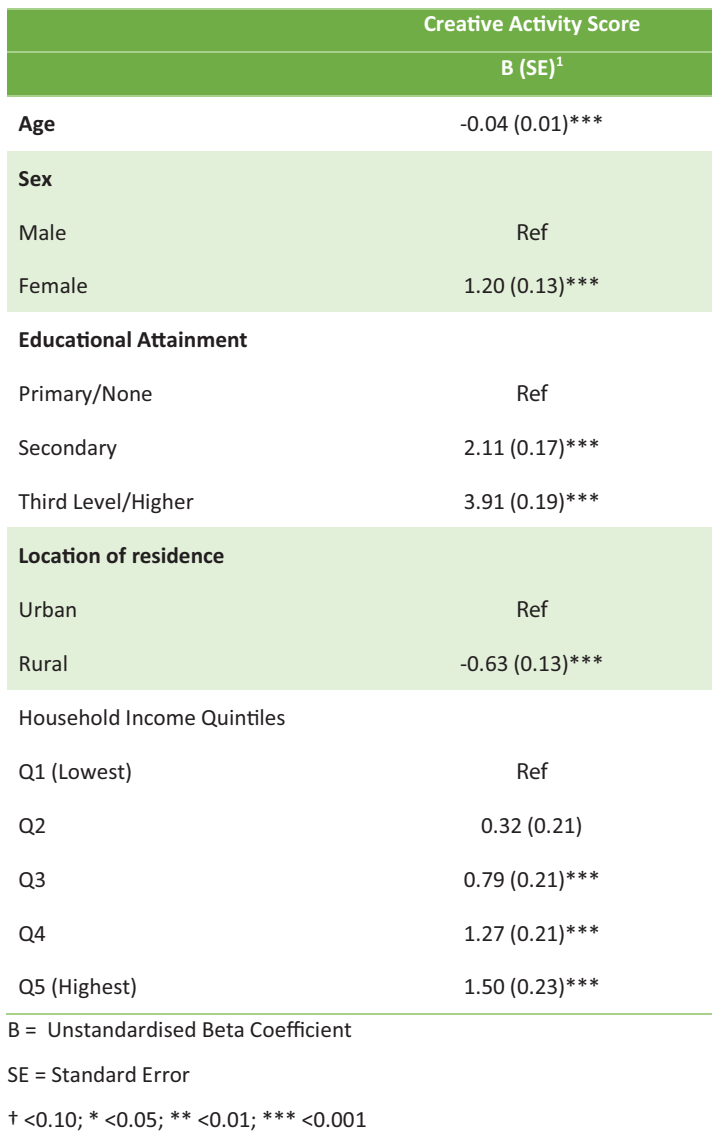




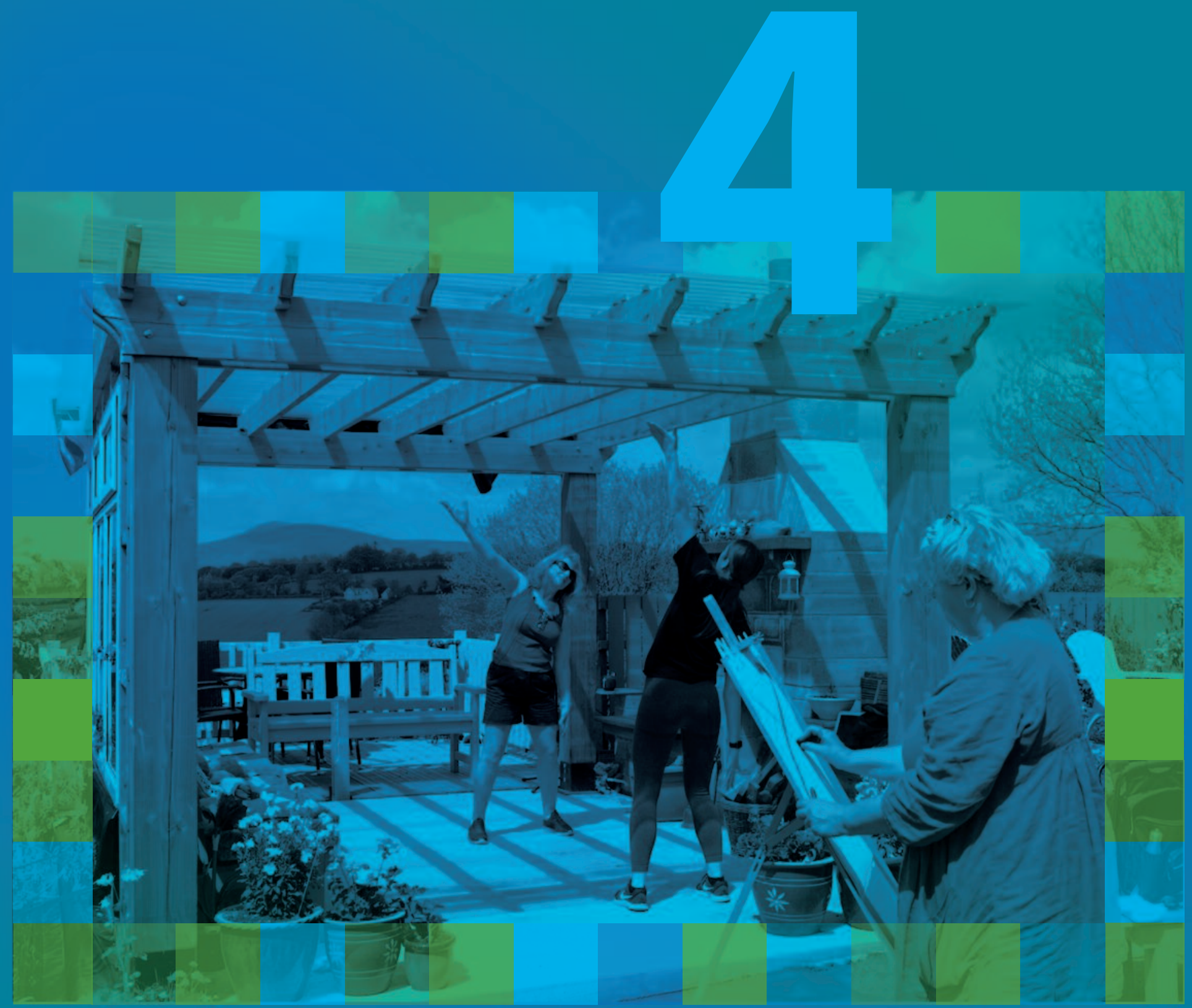

Doorstep Dances, VISUAL Carlow, in collaboration with Roisin Whelan Dance Company, Creative Ireland.

\section{Changes in participation from 2009-2018}

tilda.tcd.ie 


\section{Chapter 4 Changes in participation from 2009-2018}

At each wave of data collection, TILDA repeats the questions on creative activity, allowing us to gain a better understanding of changes as the study population ages. This chapter presents changes in levels of participation in creative activity among study participants in 2009 (wave 1) and again in 2018 (Wave 5).

\subsection{Creative activity participation}

The mean age of participants was 61.9 years (range=50-89 years) in 2009-2011 and 70.4 years (range 58-98 years) in 2018. Involvement in creative activity remained high over the nine-year period, with $52.2 \%$ of older adults spending time on hobbies or creative activities weekly (Table 4.1).

The proportion of those reporting that they go out to films, plays or concerts, or read books or magazines for pleasure, increased in over 70's, while in contrast, listening to music/radio or spending time on hobbies or creative activities was highest between 59-69. Proportions were similar in both men and women with the exception of those who read books or magazines for pleasure, with $81.2 \%$ of women reporting they do this weekly compared with $55.5 \%$ of men. In Wave 5 , proportions were consistently higher in third level/higher educational attainment, while proportions increased consistently in household income quintiles for all activities except going out to films, plays or concerts. Those reporting spending time weekly on hobbies or creative activities increased from $44.3 \%$ in the lowest household income quintile to $61.7 \%$ in the highest income quintile.

Table 4.1 Proportion of older adults participating weekly in creative activities in Wave 5 of TILDA

\begin{tabular}{|c|c|c|c|c|}
\hline & $\begin{array}{l}\text { Going out } \\
\text { to films, } \\
\text { plays and } \\
\text { concerts }\end{array}$ & $\begin{array}{l}\text { Reading books or } \\
\text { magazines for } \\
\text { pleasure }\end{array}$ & $\begin{array}{l}\text { Listening to } \\
\text { music, radio }\end{array}$ & $\begin{array}{c}\text { Spending time } \\
\text { on hobbies or } \\
\text { creative } \\
\text { activities }\end{array}$ \\
\hline & $\%$ & $\%$ & $\%$ & $\%$ \\
\hline Overall & 1.3 & 70.1 & 92.5 & 52.2 \\
\hline \multicolumn{5}{|l|}{ Age Group } \\
\hline 58-59 years & 0.7 & 64.0 & 94.9 & 47.6 \\
\hline $60-69$ years & 1.1 & 66.2 & 94.0 & 55.9 \\
\hline 70-79 years & 1.5 & 73.8 & 92.3 & 52.7 \\
\hline $80+$ years & 1.9 & 76.2 & 88.0 & 42.5 \\
\hline \multicolumn{5}{|l|}{ Sex } \\
\hline Male & 1.2 & 55.5 & 91.2 & 50.8 \\
\hline Female & 1.5 & 81.2 & 92.8 & 53.4 \\
\hline \multicolumn{5}{|c|}{ Educational Attainment } \\
\hline Primary/None & 1.3 & 62.6 & 89.4 & 41.2 \\
\hline Secondary & 1.0 & 68.8 & 92.8 & 51.9 \\
\hline Third Level/Higher & 1.9 & 76.8 & 95.1 & 63.0 \\
\hline \multicolumn{5}{|c|}{ Household Income Quintiles } \\
\hline Q1 (Lowest) & 2.4 & 64.6 & 89.7 & 44.3 \\
\hline Q2 & 0.8 & 66.7 & 91.5 & 45.7 \\
\hline Q3 & 1.7 & 67.4 & 92.8 & 49.1 \\
\hline Q4 & 1.2 & 71.0 & 95.1 & 57.0 \\
\hline Q5 (Highest) & 1.0 & 75.3 & 93.4 & 61.7 \\
\hline
\end{tabular}


Figure 4.1 presents the proportion of older adults who reported a change in the frequency they are engaged with each respective creative activity between 2009 to 2018 . Older adults with decreased activity reported weekly involvement during the first Wave of TILDA but responded that their involvement was less than weekly by Wave 5. Increased involvement represents older adults who did not engage in the activity at least weekly in Wave 1 but report that they are now involved weekly by Wave 5 .

Across each activity, the proportion of those who changed their involvement from weekly to a less frequent amount was greater than those who had since taken up the activity on a weekly basis (Figure 4.1). Little change was apparent in going to see films, plays or concerts, with just $1.9 \%$ reporting decreased activity and $1.2 \%$ reporting increased activity. $17.6 \%$ reported that they no longer spend time weekly on hobbies or creative activities, while $13.1 \%$ of older adults who did not do so in Wave 1 reported in Wave 5 that they now spend time weekly. The largest change was in reading magazines or books for pleasure, with $12.9 \%$ reporting decreased activity compared to $7.9 \%$ reporting increased activity.

Figure 4.1 Changes in weekly involvement in creative activity between 2009 - 2018

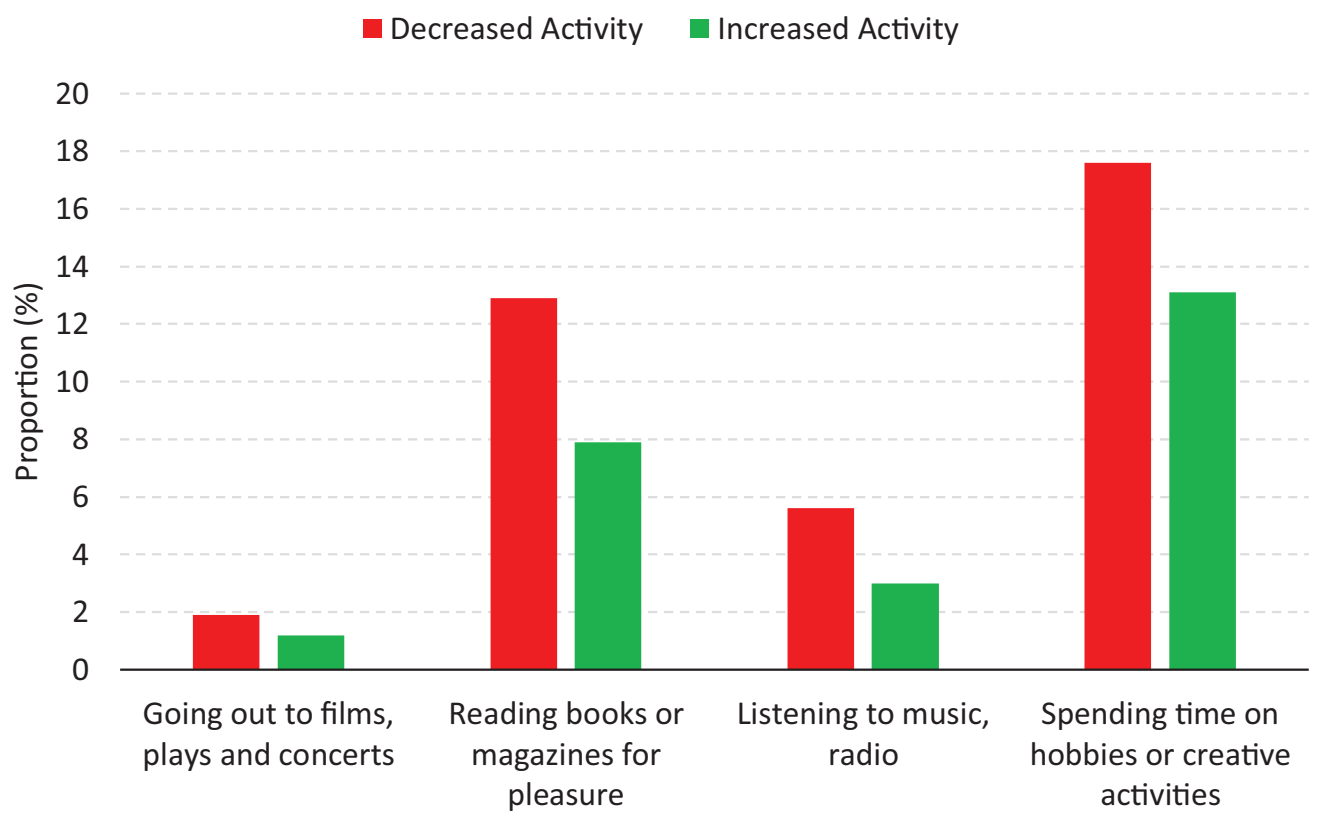




\subsection{Creative activity score}

Overall, the mean creative activity score showed little difference between 2009 and 2018, dropping from 19.1 to 18.5. We derived tertiles of creative activity showing low, moderate and high activity at each timepoint (Table 4.2). These were used to assess shifts in overall activity in older adults from 2009-2018 and to assess demographics which may drive these changes.

Table 4.2. Creative activity score by tertiles of low, moderate and high activity in Wave 1 and Wave 5

\begin{tabular}{|c|c|c|c|c|}
\hline & \multicolumn{2}{|c|}{$\begin{array}{c}\text { Wave } 1 \\
(2009-2011)\end{array}$} & \multicolumn{2}{|c|}{$\begin{array}{l}\text { Wave } 5 \\
\text { (2018) }\end{array}$} \\
\hline & Mean (SD) & Range & Mean (SD) & Range \\
\hline \multicolumn{5}{|c|}{ Creative Activity Tertiles } \\
\hline Low Activity & $14.2(3.9)$ & $0-18$ & $12.7(4.4)$ & $0-17$ \\
\hline Moderate Activity & $20.7(1.1)$ & $19-22$ & $20.3(1.4)$ & $18-22$ \\
\hline High Activity & $23.9(1.0)$ & $23-28$ & $23.9(1.1)$ & $23-28$ \\
\hline
\end{tabular}

Using these tertiles, we derived categories representing each participant's group at Wave 1 and Wave 5 to assess shifts in activity. Table 4.3 shows the proportion of older adults whose creative activity score remained the same, increased or decreased. $65.7 \%$ and $14.5 \%$ of older adults remained stable with either low/moderate activity or high activity respectively between 2009 and 2018. 10.4\% of older adults shifted from a high creative activity score to a low/moderate creative activity score, while the remainder, 9.5\%, increased from a low/moderate creative activity score to a high creative activity score.

\begin{tabular}{|c|c|c|c|}
\cline { 3 - 4 } \multicolumn{2}{c|}{} & \multicolumn{2}{c|}{ Wave 5 (2018) } \\
\cline { 3 - 4 } & Low /Moderate & High \\
\hline $\begin{array}{c}\text { Wave 1 (2009- } \\
\text { 2011) }\end{array}$ & Low/Moderate & 65.7 & 9.5 \\
\cline { 2 - 4 } & High & 10.4 & 14.5 \\
\hline
\end{tabular}


Figure 4.2 presents these scores by age group and sex. Women aged 58-59 years showed the highest proportion of increased creative activity, with $15.6 \%$ who reported low/moderate creative activity in Wave 1 reporting high creative activity in Wave 5. (Note that study population ageing meant age cut-off of the original baseline sample was 58 at Wave 5.) Women aged 6069 and 70-79 years reported the most consistent high involvement in creative activity between waves (16.7\%). In comparison, among men just 4.6\% aged 58-59 years reported an increase between waves from low/moderate to high creative activity. Meanwhile, $79.4 \%$ of men aged $80+$ years reported low/moderative activity at both waves, compared to $70.4 \%$ of women.

Figure 4.2. Changes in creative activity score tertiles from Wave 1 (2009-2011) to Wave 5 (2018) by Wave 5 age groups and sex

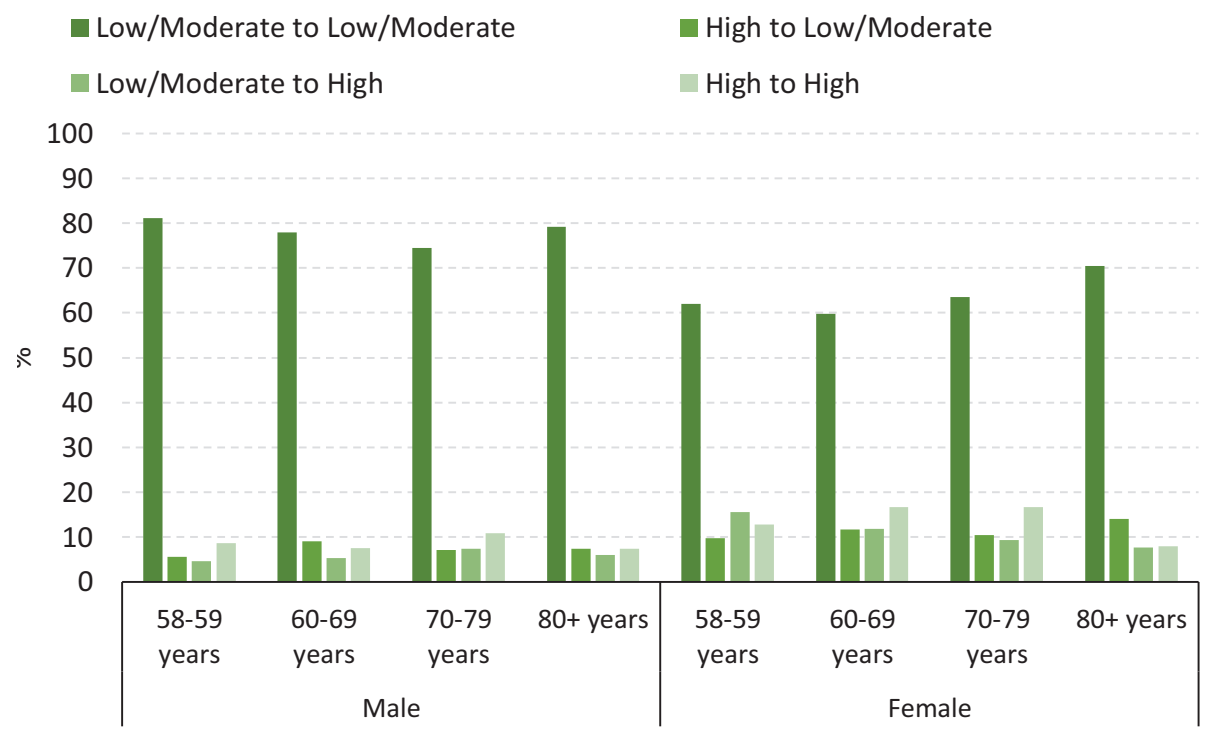

Figure 4.3 presents these scores by educational attainment and sex. Women with third level or higher educational attainment showed the highest proportion of increased creative activity, with $13.0 \%$ who reported low/moderate creative activity in Wave 1 reporting high creative activity in Wave 5, while 25.9\% remained consistent in high creative activity between the two waves. Just 3.2\% of men with primary/none educational attainment reported an increase from low/moderate to high creative activity between waves; $4.2 \%$ reported high creative activity at both waves, while $88.8 \%$ reported low/moderate creative activity in both waves.

Figure 4.3. Changes in creative activity score tertiles from Wave 1 (2009-2011) to Wave 5 (2018) by educational attainment and sex

- Low/Moderate to Low/Moderate $\square$ High to Low/Moderate $\square$ Low-Moderate to High $\square$ High to High

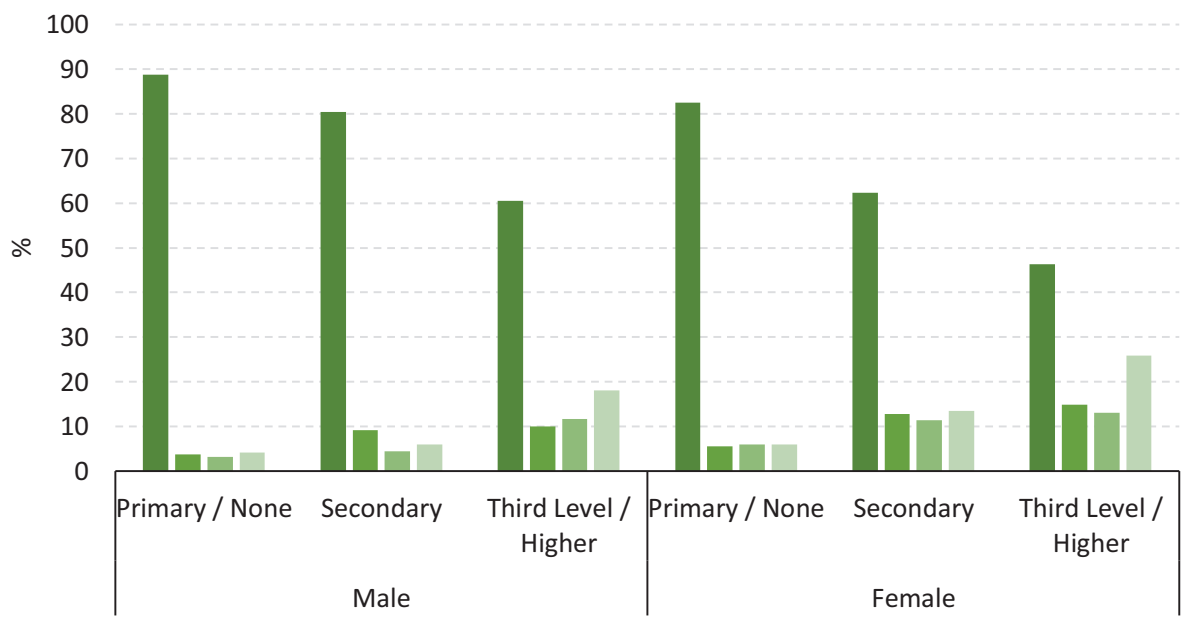




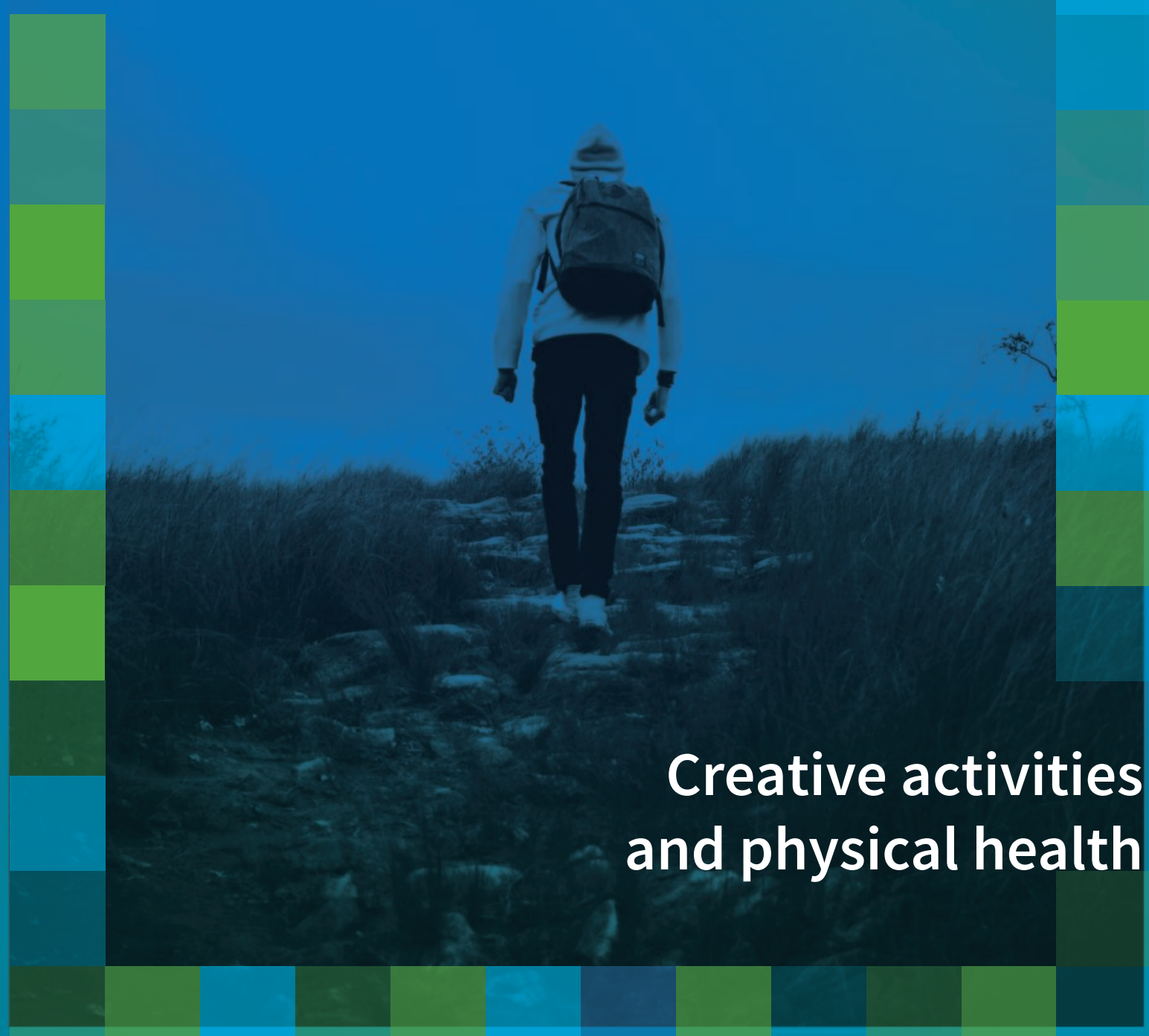

tilda.tcd.ie 


\section{Chapter 5 Creative activities and physical health}

\subsection{Creative activity by health, vision, hearing and disability}

\section{Self-Rated Health}

Overall, those with higher creative activity mean scores self-rated their health as excellent/very good/good (figure 5.1). The largest differences were in women aged 60-69 and 70-79, with mean scores of 19.6 and 18.9 respectively in those reporting excellent/very good/good health, compared to 16.5 and 16.1 respectively in those reporting fair/poor health.

Figure 5.1. Self-rated health by creative activity score in Wave 1

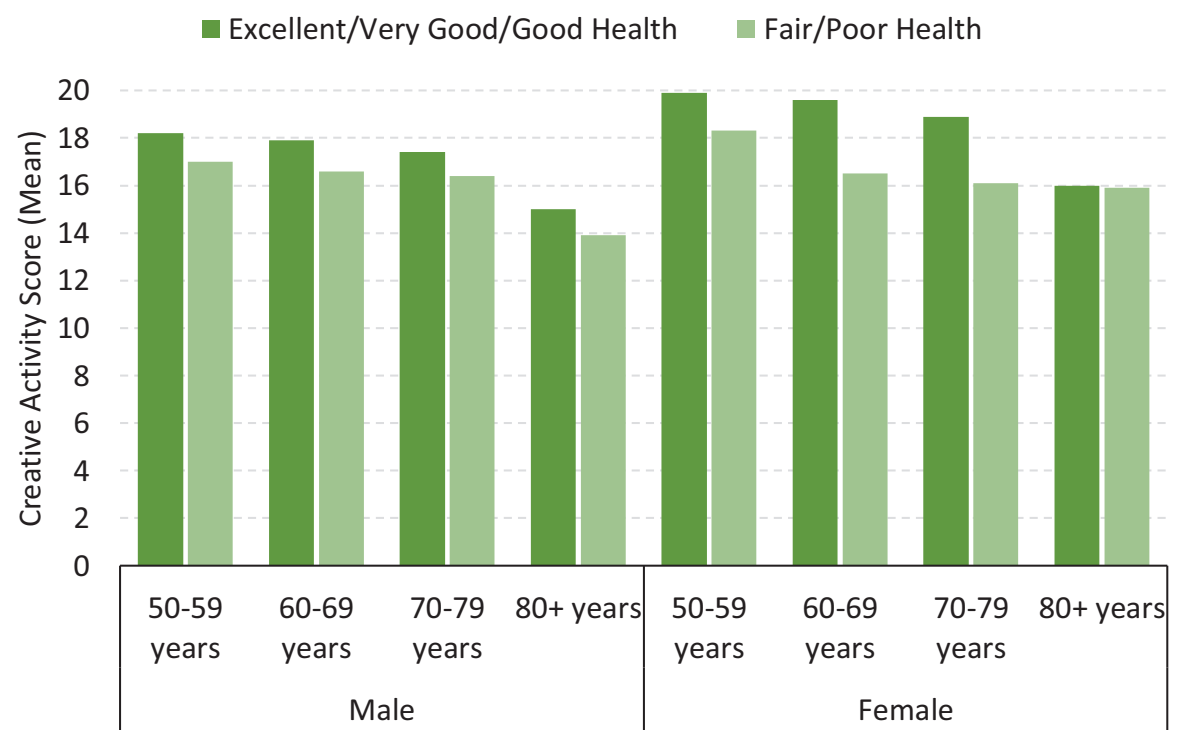

Vision

Scores were lower on average in those reporting fair/poor vision (figure 5.2) in both sexes across all age groups; however, differences in men aged 70-79 and 80+ years were just 0.9 on average. In comparison, the largest creative score differences among women comparing those with excellent/very good/good vision to those with fair/good vision were in age group 7079 years at 18.4 compared to 15.1 , and in age group $80+$ years at 16.5 compared to 14.2 .

Figure 5.2. Self-rated vision by creative activity score in Wave 1

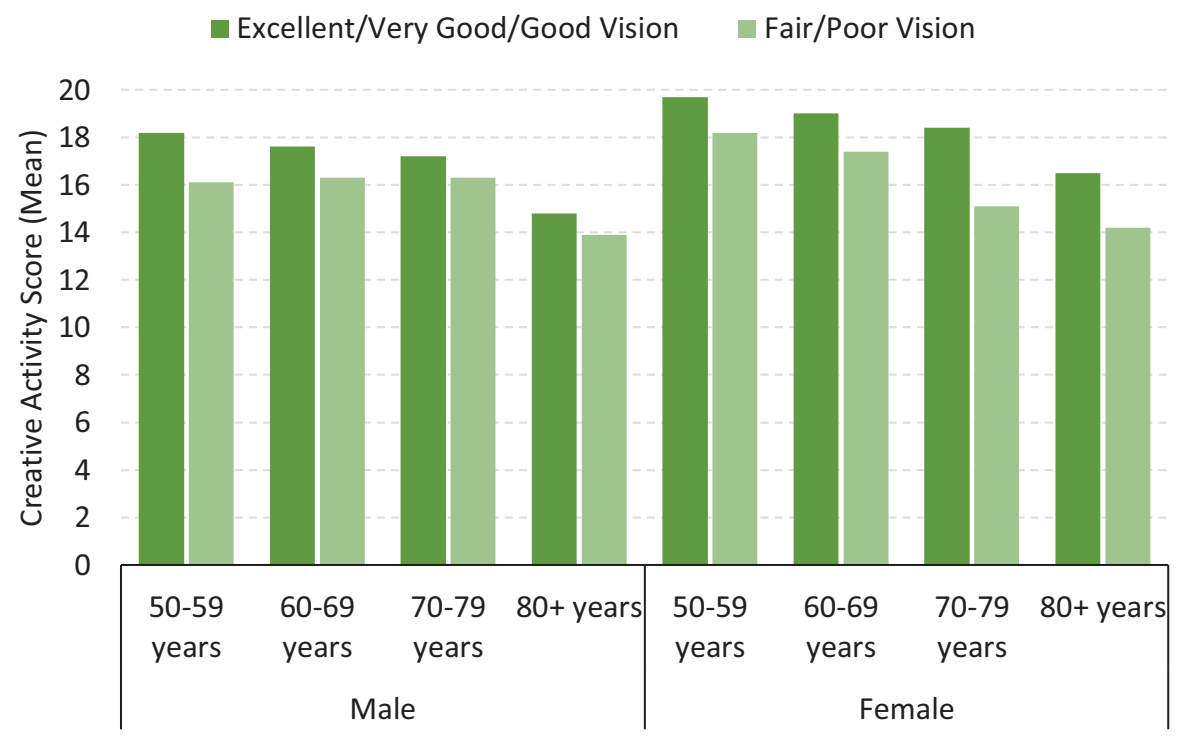


Hearing

Differences in mean scores among men with excellent/very good/good hearing (Figure 5.3) compared to fair/poor hearing were largest in those aged 60-69 years (17.9 vs 15.8). In women, the largest discrepancies in mean scores were in those aged 60-69 years (excellent/very/good: 19.1 vs fair/poor: 16.8) and in those aged 70-79 years (excellent/very/good: 18.2 vs fair/poor: 16.5).

Figure 5.3. Self-rated hearing by creative activity score in Wave 1

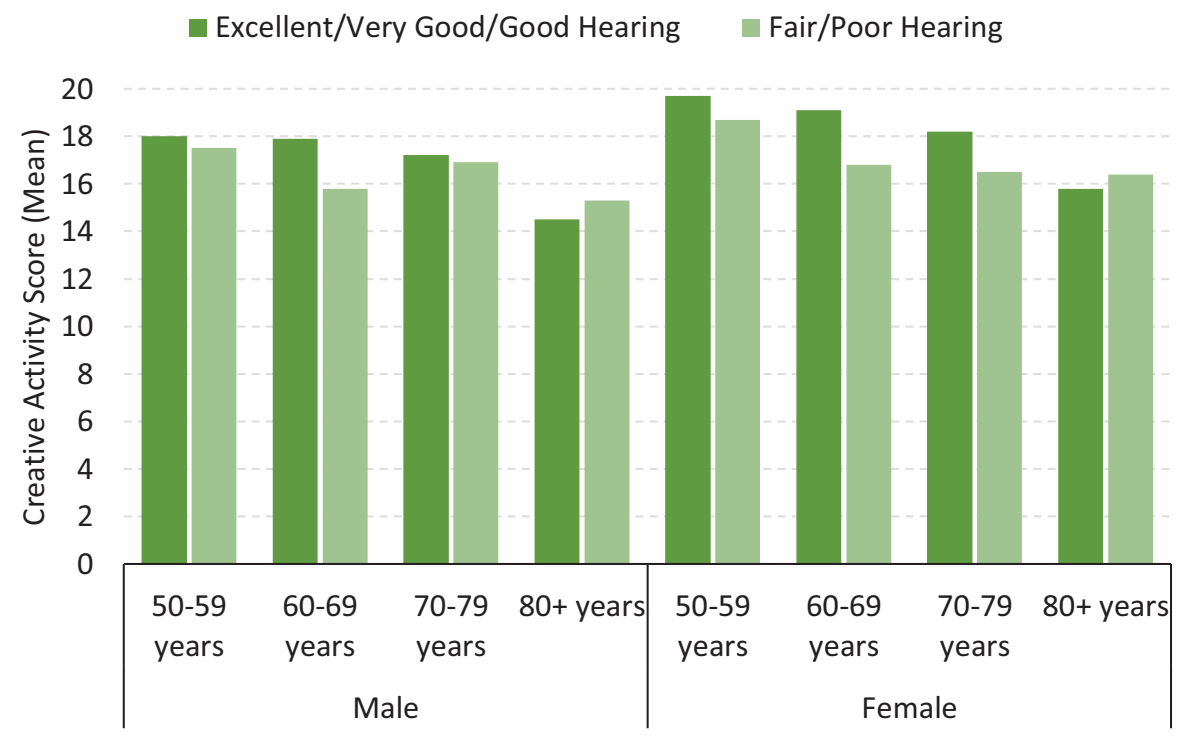

Disability

Among men, scores were similar between those reporting a disability and those without across all age groups (Figure 5.4). In women, however, larger differences were apparent. Mean scores for those aged 60-69 years reporting no disability were 19.1 compared to 16.3 in those with a disability. Similarly, in those aged $70-79$ years, those with no disability had a mean score of 18.6 compared to 15.1 .

Figure 5.4. Disability by creative activity score in Wave 1

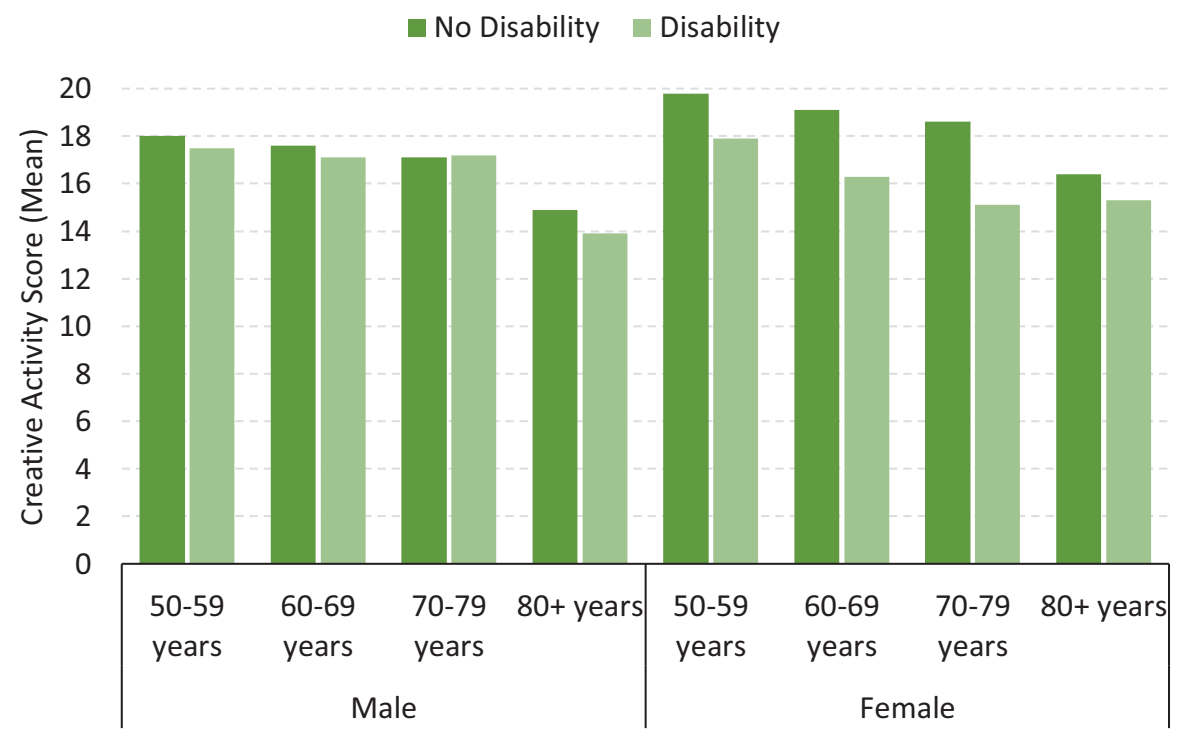




\section{Chronic conditions}

Little difference in scores between those with no chronic condition and those with $\geq 1$ chronic condition was found in women aged in the 50 to 79 age groups (Figure 5.5). In women aged $80+$ years, mean scores were 18.3 in those reporting no chronic conditions compared to 15.9 in those with $\geq 1$ chronic condition. Among men, those aged $70-79$ years with $\geq 1$ chronic condition had higher mean scores (17.7) than those with no chronic condition (14.7). In line with observed differences among women, however, those aged 80+ with no chronic conditions had a mean score of 16.7 compared to 14.4 in those with $\geq 1$ chronic condition.

\section{Figure 5.5. Chronic condition by creative activity score in Wave 1}

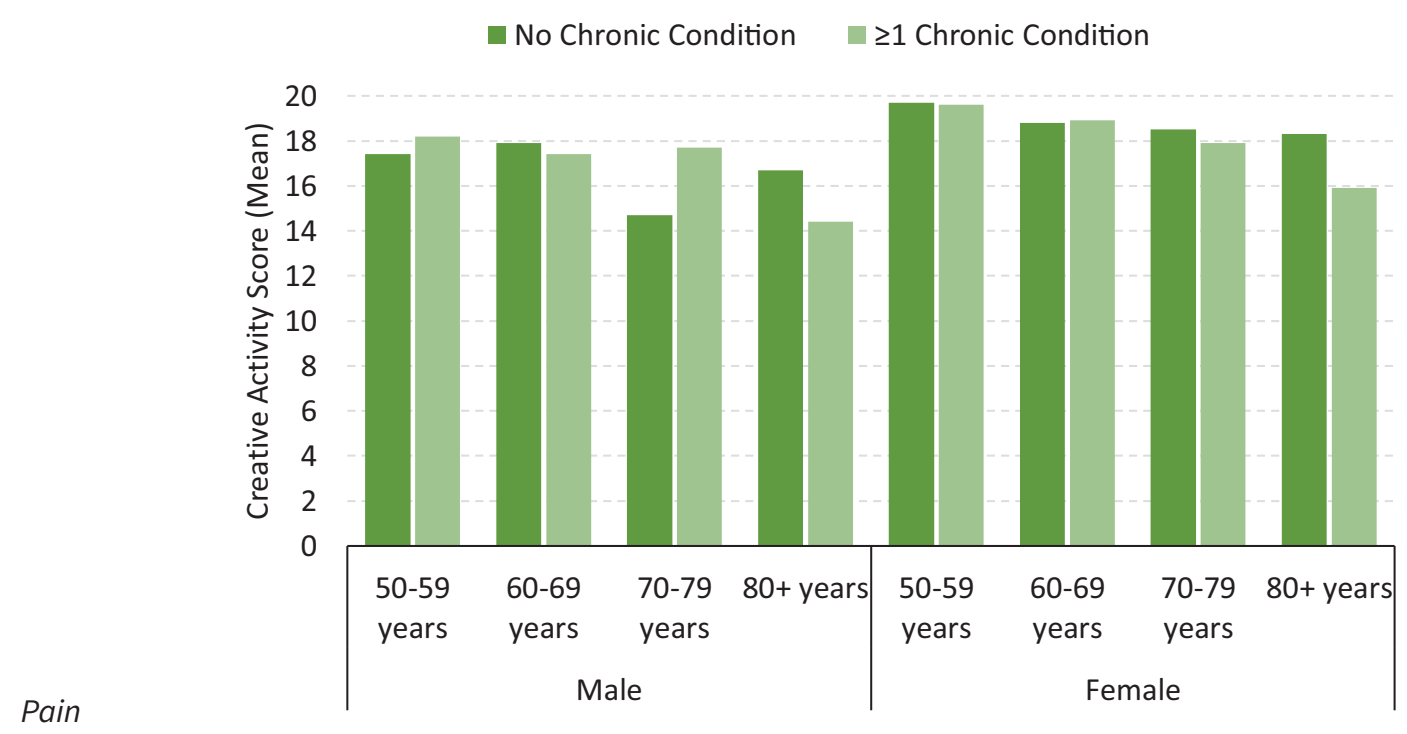

Creative activity scores in women aged in the 50 to 79 age groups were marginally lower in those reporting moderate/severe pain compared to those reporting none/mild pain, with no differences in the $80+$ years group (Figure 5.6). Among men, few differences were found with the exception of the 60-69 years age group, where mean scores were 18.8 in those reporting none/mild pain compared to 16.6 in those with moderate/severe pain.

Figure 5.6. Experience of pain by creative activity score in Wave 1

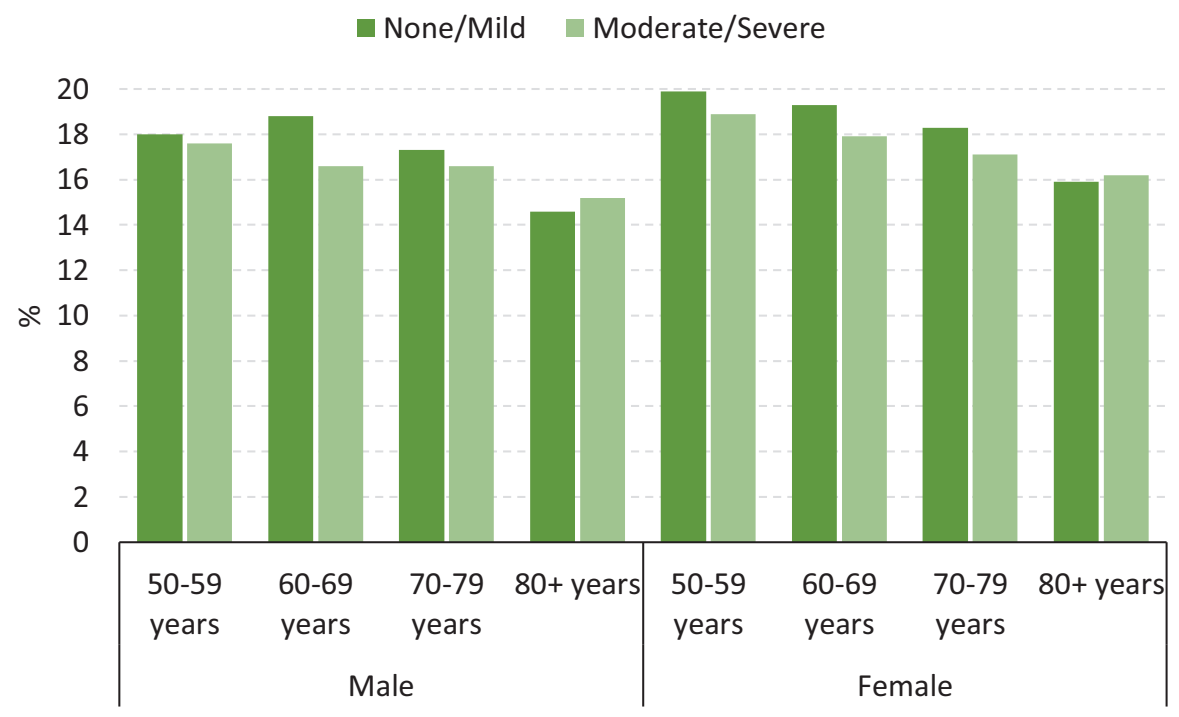


Table 5.2 presents a linear regression model showing associations between creative activity score, self-rated health, hearing, vision, disability chronic condition and reported pain while controlling for sociodemographic factors including age, sex, educational attainment, location of residence and household income quintiles. Fair/poor self-rated health and vision remained negatively associated with creative activity score compared with excellent/very good/good health and vision.

Those reporting a disability also had significantly lower creative activity scores than those with no disability. Report of $\geq 1$ chronic conditions had a positive association with creative activity scores. There were no significant differences in scores between those reporting excellent/very good/good hearing and those reporting fair/poor hearing.

Table 5.2. Linear regression model showing associations between creative activity score and self-rated health, vision, hearing and disability

\begin{tabular}{|c|c|}
\hline & Creative Activity Score \\
\hline & $\mathrm{B}(\mathrm{SE})^{1}$ \\
\hline \multicolumn{2}{|l|}{ Self-Rated Health } \\
\hline Excellent/Very Good/Good & Ref \\
\hline Fair/Poor & $-0.51(0.29) \dagger$ \\
\hline \multicolumn{2}{|l|}{ Self-Rated Vision } \\
\hline Excellent/Very Good/Good & Ref \\
\hline Fair/Poor & $-1.06(0.39)^{* *}$ \\
\hline \multicolumn{2}{|l|}{ Self-Rated Hearing } \\
\hline Excellent/Very Good/Good & Ref \\
\hline Fair/Poor & $-0.41(0.31)$ \\
\hline \multicolumn{2}{|l|}{ Disability } \\
\hline No Disability & Ref \\
\hline Reported Disability & $-0.96(0.37)^{*}$ \\
\hline \multicolumn{2}{|l|}{ Chronic Condition } \\
\hline No Chronic Condition & Ref \\
\hline$\geq 1$ Chronic Condition & $0.65(0.24)^{* *}$ \\
\hline \multicolumn{2}{|l|}{ Reported Pain } \\
\hline None/Mild & Ref \\
\hline Moderate/Severe & $0.15(0.24)$ \\
\hline
\end{tabular}

1 The unstandardised beta coefficient represents the relationship of between each health characteristic with the creative activity score. Positive numbers reflect a positive relationship, negative numbers a negative relationship. For each group, the coefficient shows the relationship relative to the reference group. A positive number suggests this group had higher creative activity scores compared to the reference group.

Model adjusted for age, sex, educational attainment, location of residence and household income quintiles

$$
\begin{aligned}
& \mathrm{B}=\text { Unstandardised Beta Coefficient } \\
& \mathrm{SE}=\text { Standard Error } \\
& \dagger<0.10 ;^{\star}<0.05 ;^{\star \star}<0.01 ;{ }^{\star \star \star}<0.001
\end{aligned}
$$




\subsection{Differences in physical health between Wave 1 and Wave 5}

Figures 5.7-5.9 present the proportions of those reporting fair/poor self-rated health, vision or hearing at Wave 1 and Wave 5 broken down by creative activity involvement groups among those who completed both waves $(n=3,857)$.

Those reporting fair/poor health in Wave 1 decreased by Wave 5 potentially reflecting that these participants were in better health and more likely to remain as participants of the study from 2009-2011 to 2018. Those reporting fair/poor vision or hearing increased.

Only men in the high to low/moderate group had an increase in the proportion of fair/poor self-rated health, while women in this group and those in the high to high group also increased. Among adults who reported low/moderate to low/moderate group, the proportion of fair/poor self-rated vision and hearing increased. The proportion of fair/poor self rated health, vision and hearing was highest among both men and women in the low/moderate to low/moderate group by Wave 5.

Figure 5.7. Proportion of older adults rating their physical health as fair/poor between Wave 1 to Wave 5 by sex and creative activity involvement groups

a Fair/Poor Health in Wave $1 \quad$ Fair/Poor Health in Wave 5

30

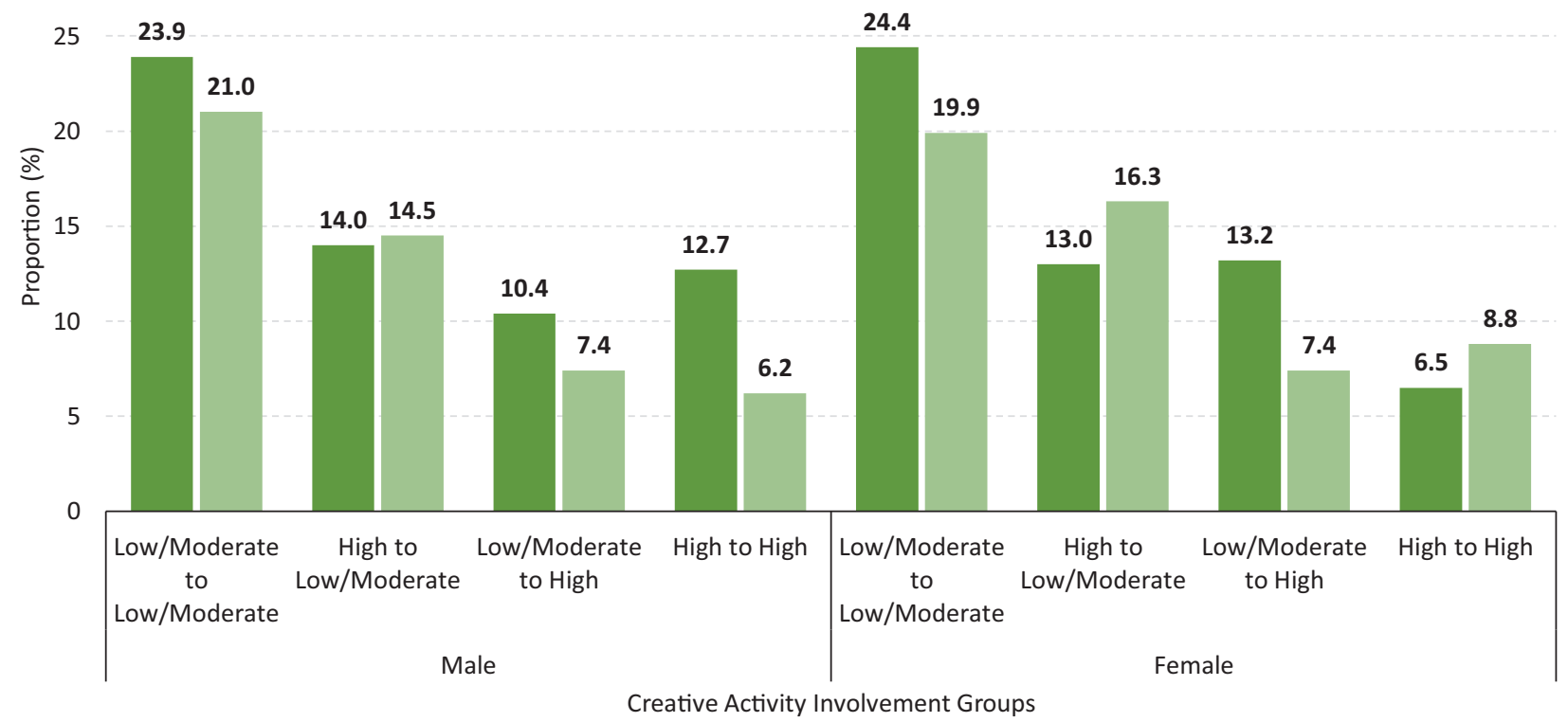


Figure 5.8. Proportion of older adults rating their vision as fair/poor between Wave 1 to Wave 5 by sex and creative activity involvement groups

Fair/Poor Vision in Wave $1 \quad$ Fair/Poor Vision in Wave 5

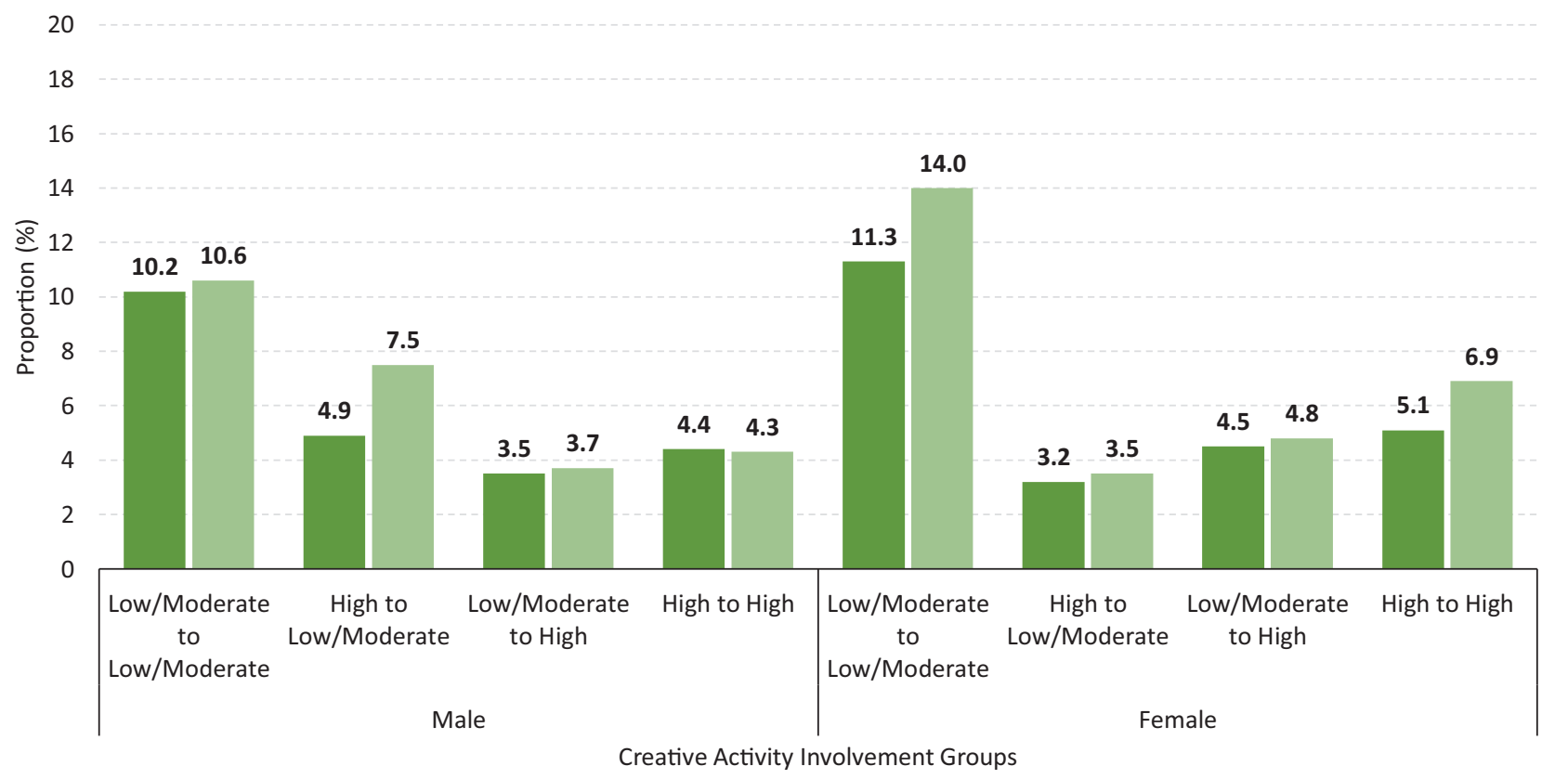

Figure 5.9. Proportion of older adults rating their hearing as fair/poor between Wave 1 to Wave 5 by sex and creative activity involvement groups

Fair/Poor Hearing in Wave $1 \quad$ Fair/Poor Hearing in Wave 5

30

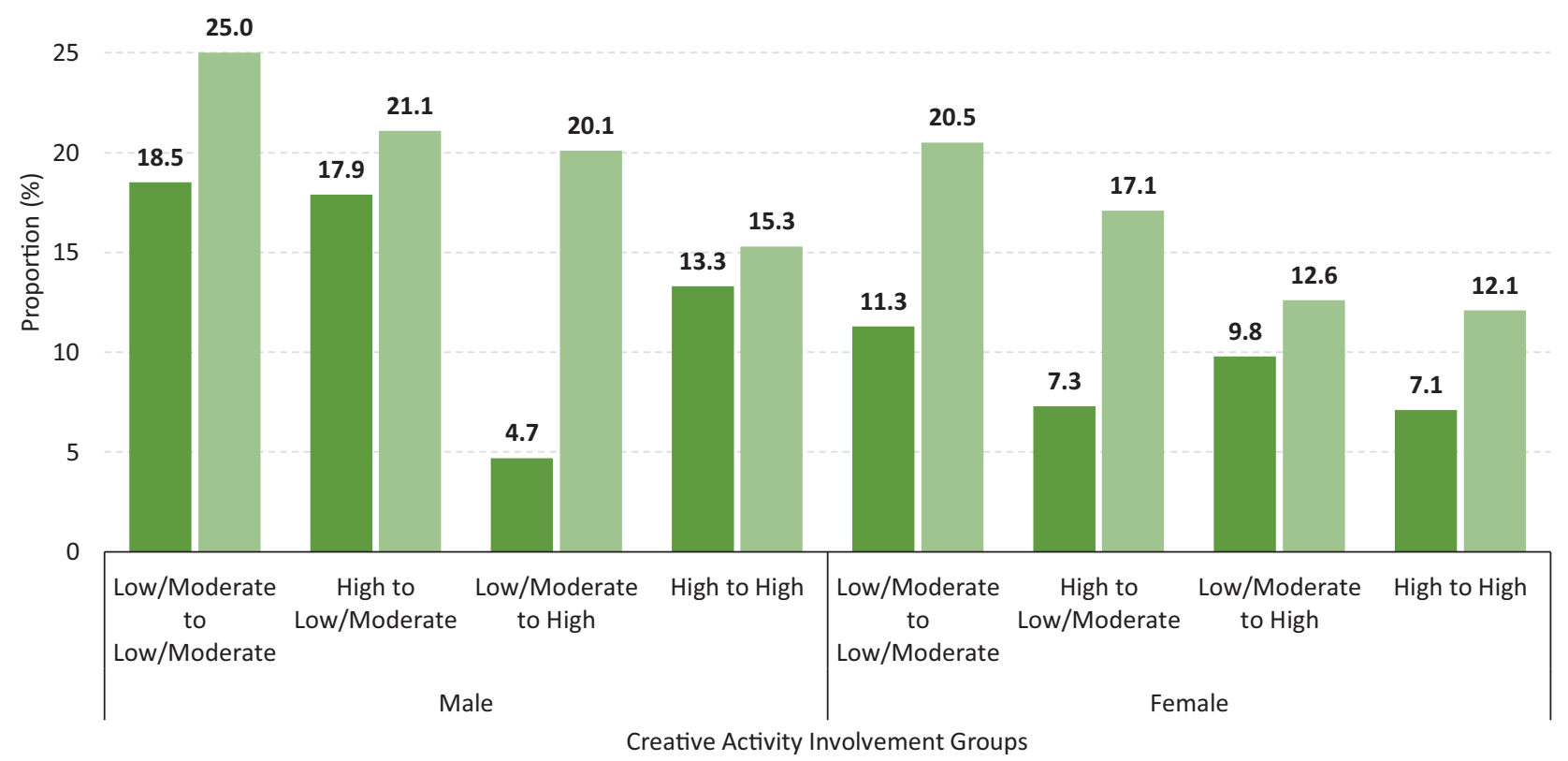


Figures 5.10-5.12 present the proportions of those reporting a disability, $\geq 1$ chronic conditions or moderate/severe pain at Wave 1 and Wave 5 broken down by creative activity involvement groups in those who completed both waves ( $n=3,857$ ).

The proportion of those reporting a disability or $\geq 1$ chronic condition increased between Wave 1 and Wave 5, while reporting moderate/severe pain remained consistent. Women in the high to low/moderate group had the largest increases in reporting a disability or moderate/severe pain.

Figure 5.10. Proportion of older adults reporting a disability between Wave 1 to Wave 5 by sex and creative activity involvement groups

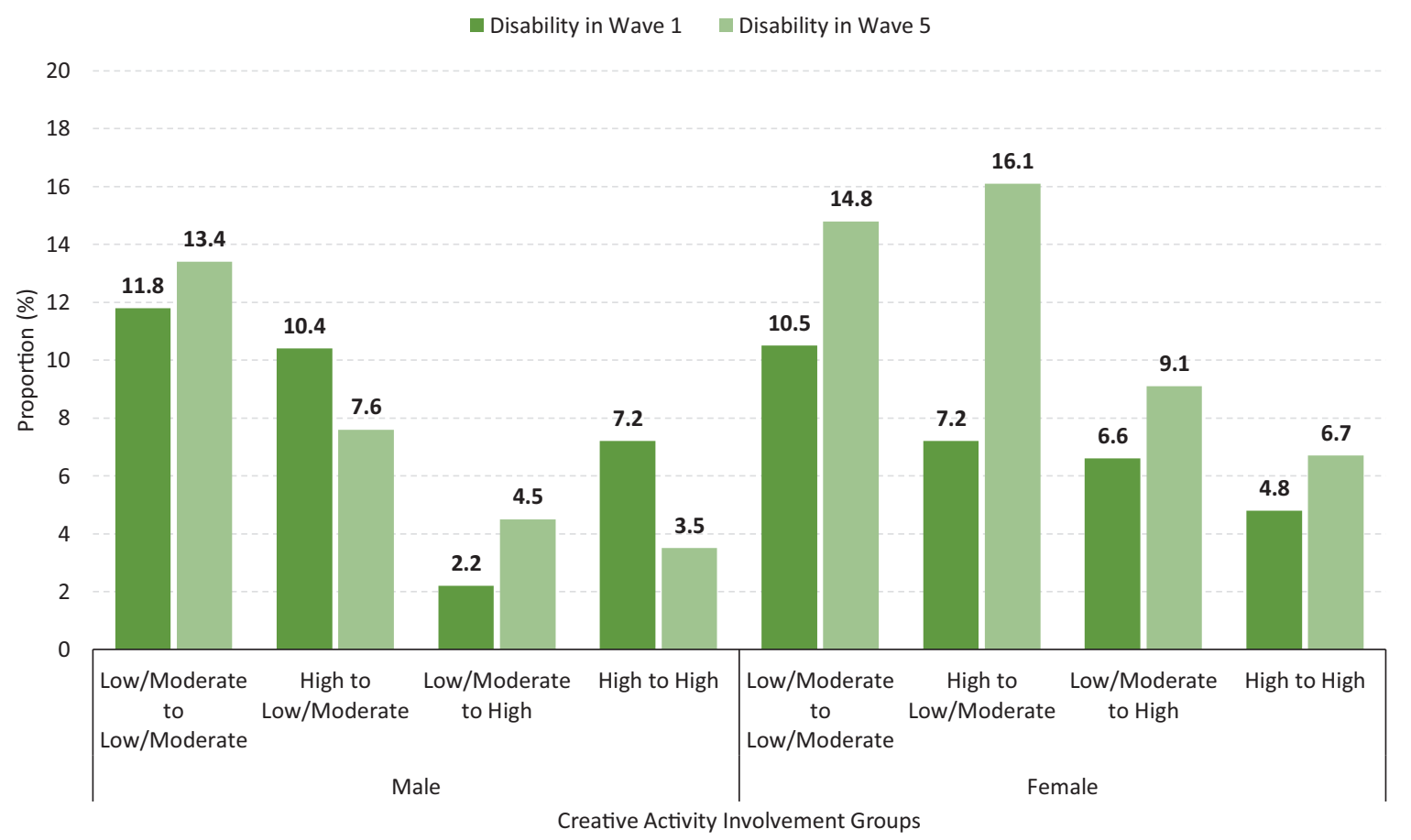

Figure 5.11. Proportion of older adults reporting a chronic condition between Wave 1 to Wave 5 by sex and creative activity involvement groups

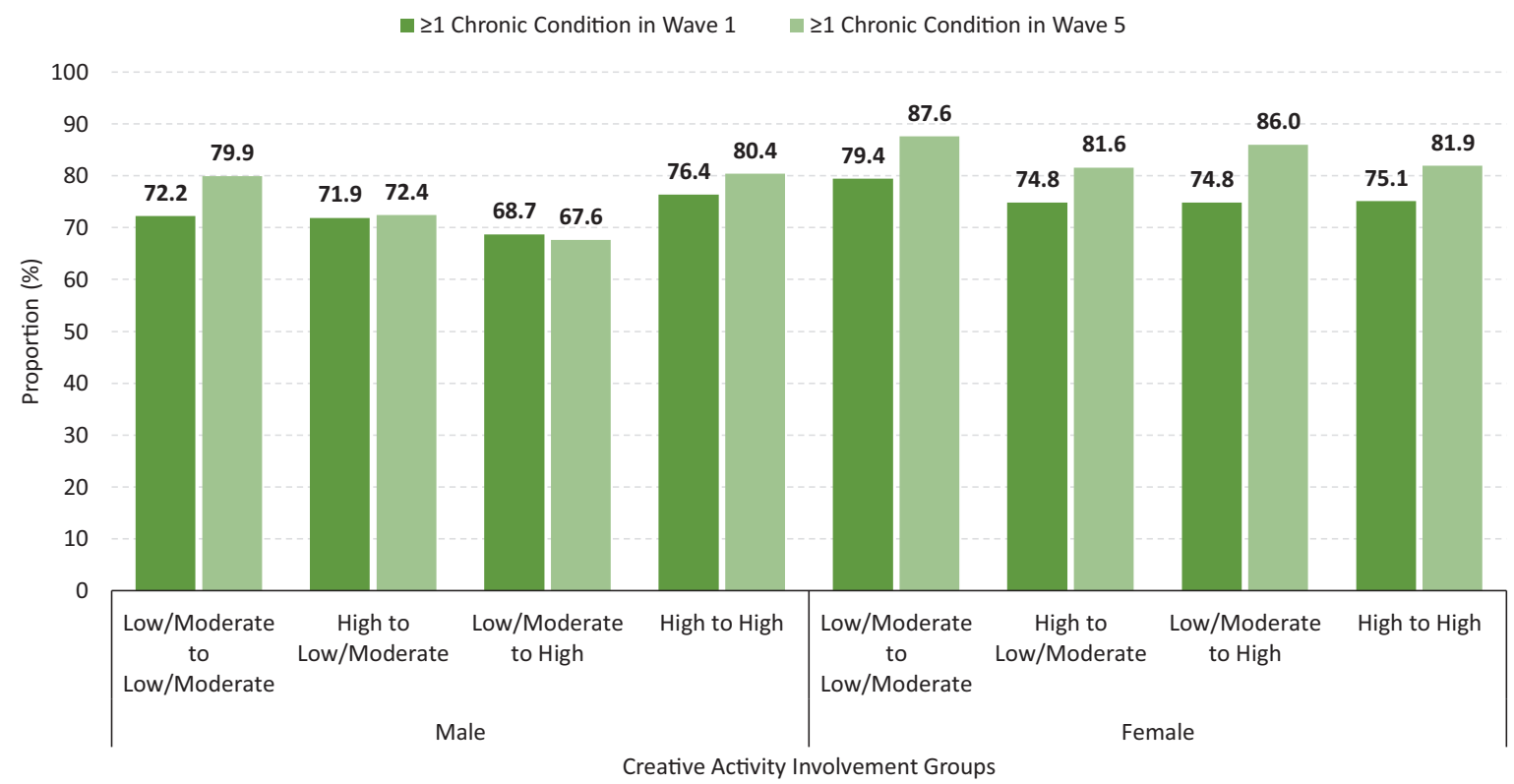


Figure 5.12. Proportion of older adults reporting moderate/severe pain between Wave 1 to Wave 5 by sex and creative activity involvement groups

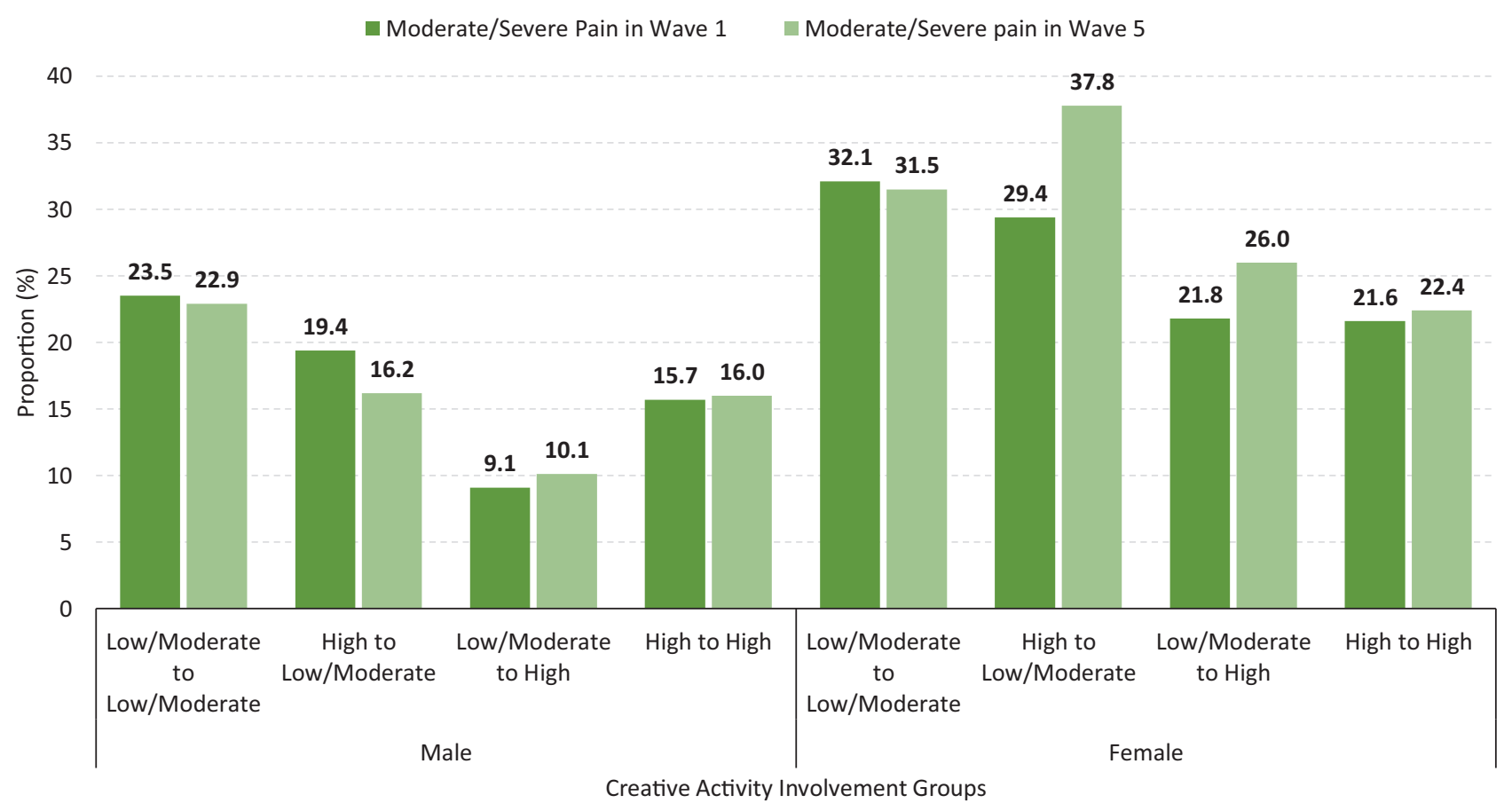




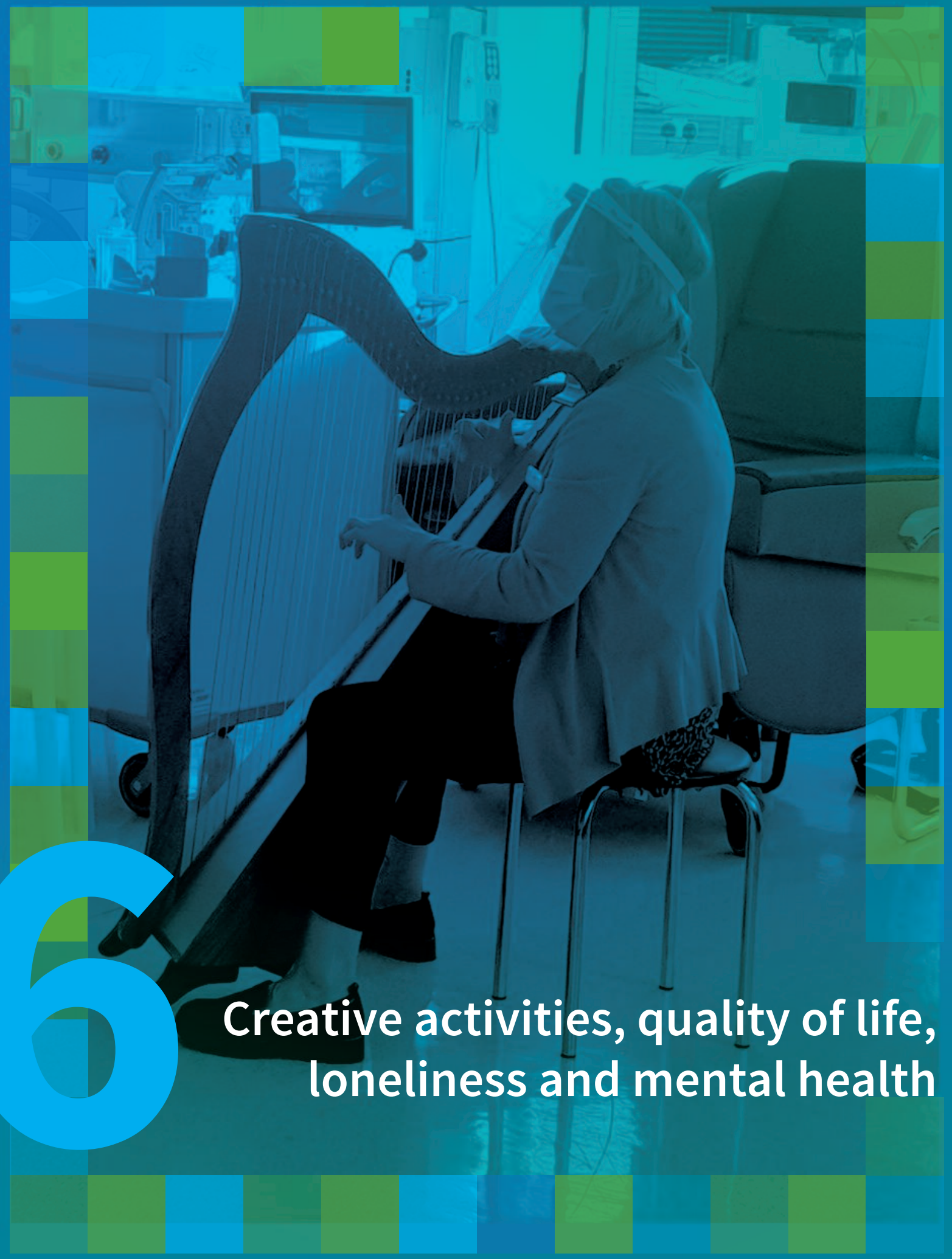

tilda.tcd.ie 


\section{Chapter 6 Creative activities, quality of life, loneliness and mental health}

This chapter examines associations between creative activities and reported quality of life, feelings of loneliness and measures of mental health including depression, stress and worry.

\subsection{Creative activity and quality of life}

Figure 6.1 presents quality of life scores by creative activity group, age group and sex. The overall mean quality of life score was 27.7 (range: 3-36). In women, those reporting high levels of creative activity reported the highest quality of life scores in all age groups. The largest difference was in women aged 50-59, where those reporting high creative activity had a mean quality of life score of 31.2, compared to 25.5 in those reporting low creative activity. In men, mean scores were similar across each creative activity group, with the largest quality of life difference between high and low creative activity found in those aged 50-59 years, at 28.3 compared to 26.4 respectively. In those aged $80+$ years, little difference was apparent, with mean scores of $24.8,25.8$ and 25.8 for those reporting low, moderate and high creative activity respectively.

Figure 6.1. Quality of life scores by creative activity group

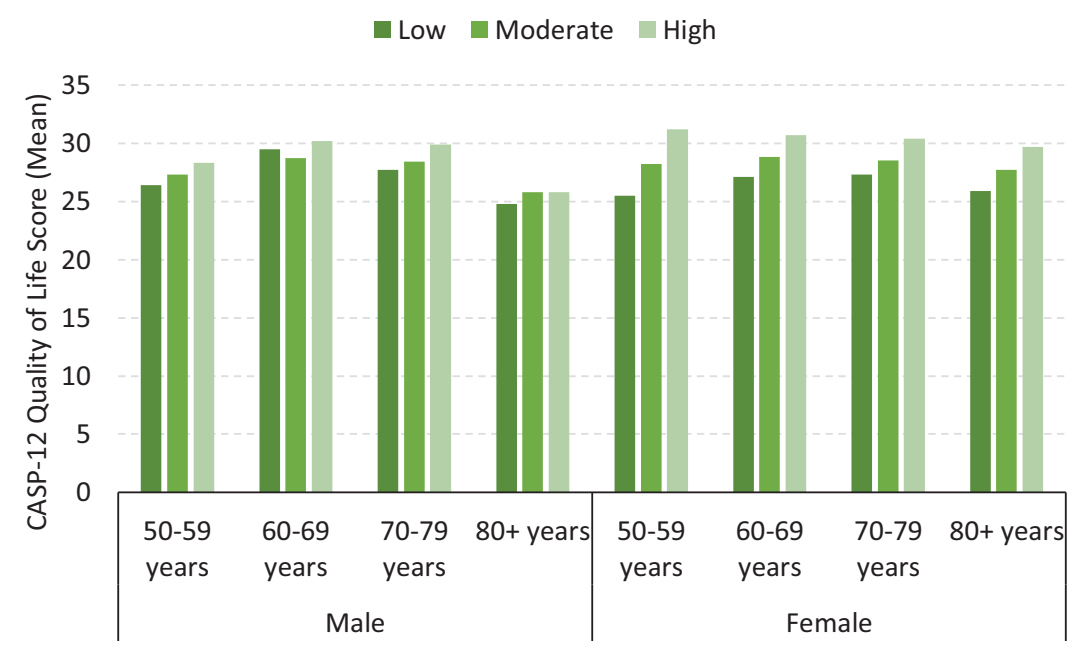

\subsection{Creative activity and loneliness}

The overall mean loneliness score was 2.1 (range: 0-10). Mean loneliness (figure 6.2) was consistently lower in both sexes reporting high creative activity across all age groups. Women aged 50-59 reporting low creative activity had a mean score of 2.7, compared to 1.7 in those reporting high creative activity. Similar differences were apparent in the oldest age group, with mean scores of 1.2 in women reporting high creative activity compared to 2.1 in low creative activity. Similar trends were found in men, with loneliness scores consistently lower in men reporting high creative activity compared to low creative activity.

Figure 6.2. Loneliness scores by creative activity group

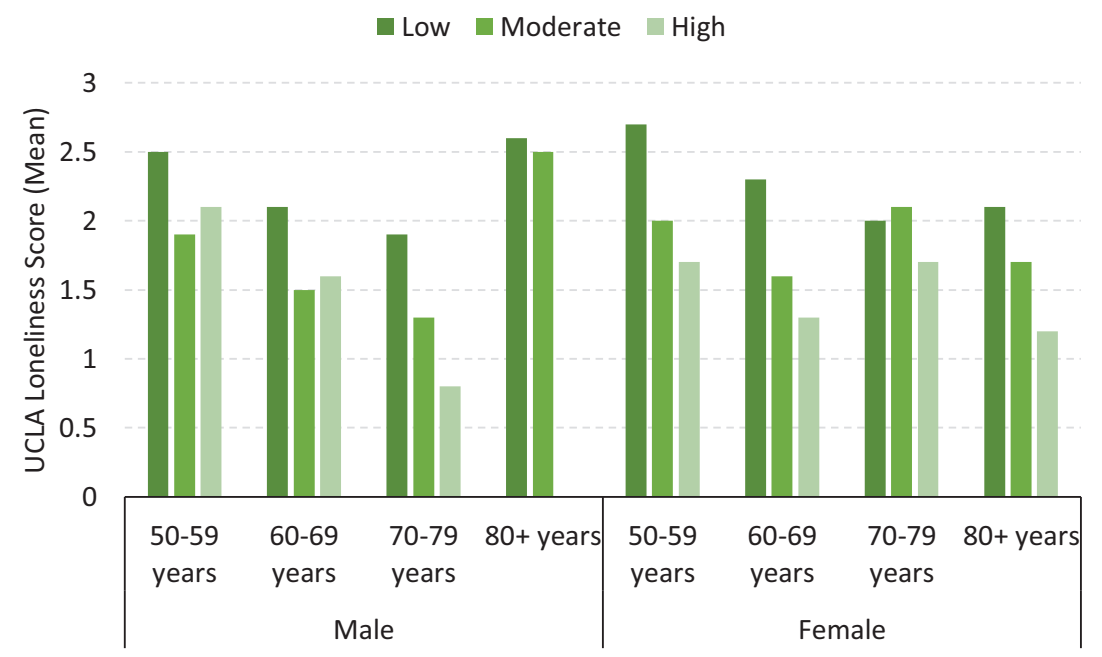




\subsection{Creative activity and mental health}

\section{Depression}

The overall mean depression score was 3.1 (range: 0-24). Among women, mean depression was lower in those reporting high creative activity compared to low activity in all age groups, with the largest difference in those aged 70-79 years, at a mean score of 4.0 compared to 2.1. There were little differences among men in the age groups between 50 to 69 . However, in men aged 70-79 reporting high creative activity, mean depression was lower compared to those reporting low creative activity.

\section{Figure 6.3. Depression scores by creative activity group}

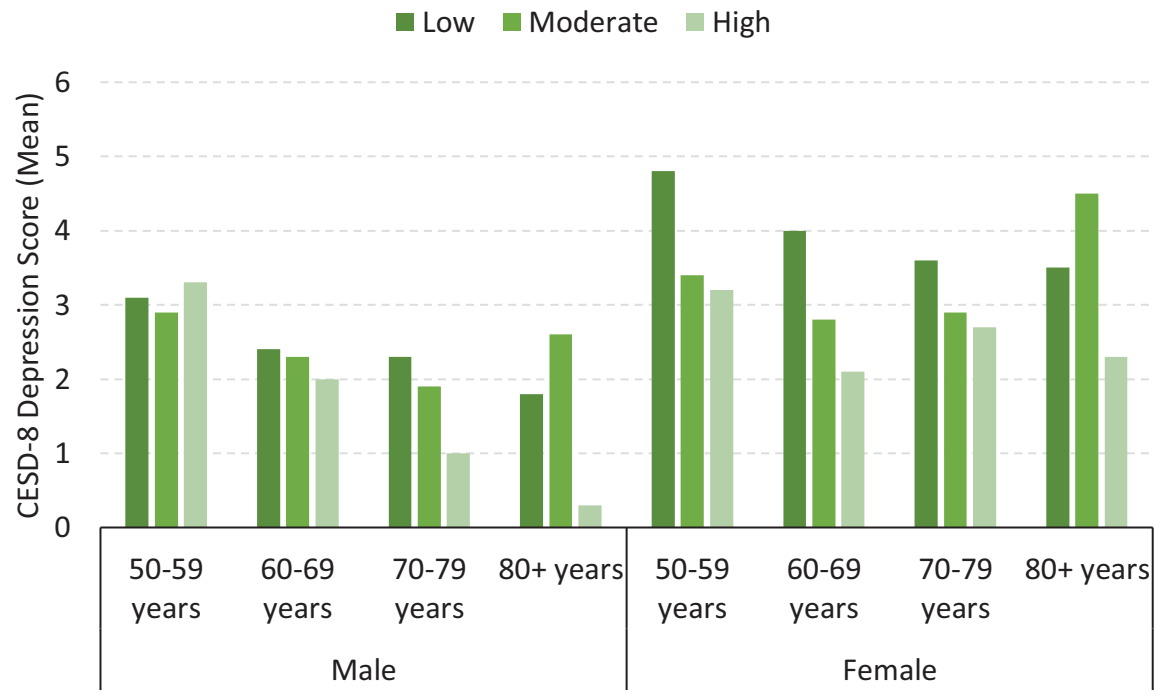

Worry

The overall mean worry score was 7.7 (range: 0-32).There was a consistent decline in mean worry across all age groups with increased creative activity (figure 6.4). Mean differences between low creative activity and high creative activity groups were largest among women aged 50-59 (low creative activity: 13.0 vs high creative activity: 8.8) and 60-69 years (low creative activity: 10.3 vs high creative activity: 6.0 ). Differences were not as large in men older adults, though mean worry scores were consistently lower in those reporting high creative activity compared to low creative activity.

Figure 6.4. Worry scores by creative activity group

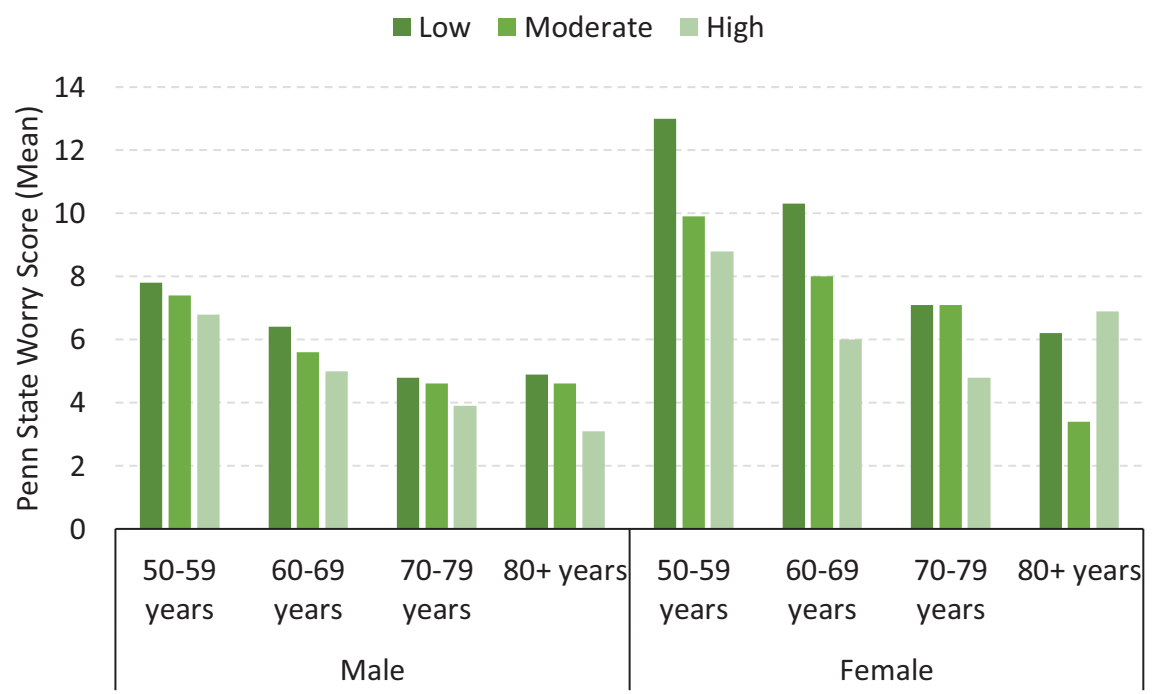


The overall mean stress score was 4.4 (range: $0-16$ ). Women aged between 50 to 79 reporting high creative activity had lower mean perceived stress scores compared to those reporting low creative activity (figure 6.5). The discrepancy was largest in those aged 60-69 years, with mean scores of 4.9 compared to 2.9 respectively. Scores levelled out in those aged $80+$ years, with no differences between low and high activity groups apparent. Among men, mean scores remained consistently lower in high creative activity groups compared to low activity groups across all ages. Mean stress scores among men aged 60-69 reporting high activity were just 2.5 compared to 4.5 in those reporting low creative activity.

Figure 6.5. Perceived stress scores by creative activity group

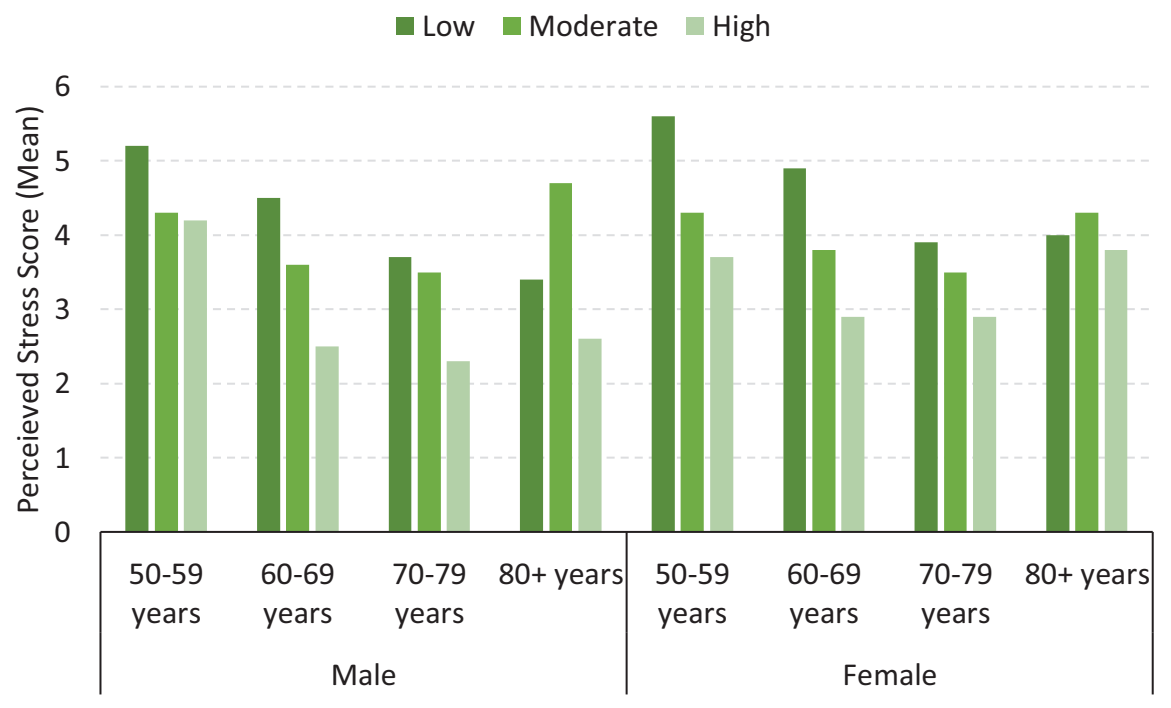

Table 6.1 presents a set of linear regression models showing associations between quality of life, loneliness, depression, worry and perceived stress scores and between creative activity group. Sociodemographic factors including age, sex, educational attainment, location of residence and income quintiles are controlled for. Independent of sociodemographic factors, reporting moderate or high creative activity was significantly positively associated with higher quality of life, and with lower loneliness, depression, worry and perceived stress.

Table 6.1. Linear regression models predicting quality of life, loneliness and mental health outcomes by creative activity groups

\begin{tabular}{|c|c|c|c|c|c|}
\hline & $\begin{array}{l}\text { Quality of life } \\
\text { B (SE) }\end{array}$ & $\begin{array}{l}\text { Loneliness } \\
\qquad \text { B (SE) }{ }^{1}\end{array}$ & $\begin{array}{l}\text { Depression } \\
\text { B (SE) })^{1}\end{array}$ & $\begin{array}{l}\text { Worry } \\
\text { B (SE) }\end{array}$ & $\begin{array}{c}\text { Perceived Stress } \\
\text { B (SE) }\end{array}$ \\
\hline \multicolumn{6}{|c|}{ Creative Activity Group } \\
\hline Low & Ref & Ref & Ref & Ref & Ref \\
\hline Moderate & $1.14(0.29)^{* * *}$ & $-0.46(0.12)^{* * *}$ & $-0.39(0.20)^{*}$ & $-0.84(0.40)^{*}$ & $-0.71(0.17)^{* * *}$ \\
\hline High & $2.20(0.30)^{* * *}$ & $-0.51(0.14)^{* * *}$ & $-0.57(0.21)^{* *}$ & $-1.33(0.46)^{* *}$ & $-1.15(0.17)^{* * *}$ \\
\hline
\end{tabular}

Model adjusted for age, sex, educational attainment, location of residence and household income quintiles

$B=$ Unstandardised Beta Coefficient

$\mathrm{SE}=$ Standard Error

$+<0.10 ; *<0.05 ; * *<0.01 ; * * *<0.00$

1 The unstandardised beta coefficient represents the relationship of between each creative activity group with quality of life, loneliness, depression, worry or perceived stress. Positive numbers reflect a positive relationship, negative numbers a negative relationship. For each creative activity group, the coefficient shows the relationship relative to the reference group: Low creative activity. A positive number suggests this group had higher scores for each measure compared to the low creative activity group. 


\subsection{Differences in quality of life, loneliness and mental health between Wave 1 and Wave 5}

Figures 6.6-6.9 present mean quality of life, loneliness and mental health scores at Wave 1 and Wave 5 broken down by creative activity involvement groups between waves in those who completed both waves $(n=3,857)$.

Overall mean quality of life, loneliness, depression, worry and stress remained consistent between waves, with marginal decreases in quality of life, loneliness and worry, and a marginal increase in depression. Both men and women moving from high to low/moderate creative activity across waves had the largest decrease in quality of life, and among just women a slight increase in stress. Men who moved from low/moderate activity to high creative activity had almost no change in quality of life, depression or loneliness, and a decrease in both worry and stress scores. Similarly, for women in this group, quality of life, loneliness and stress remained consistent, while worry decreased. Both men and women who reported low/moderate to low/moderate creative activity had the lowest quality of life, and highest loneliness, worry and stress scores by Wave 5.

Figure 6.6. Wave 1 and Wave 5 mean quality of life scores by creative activity involvement groups

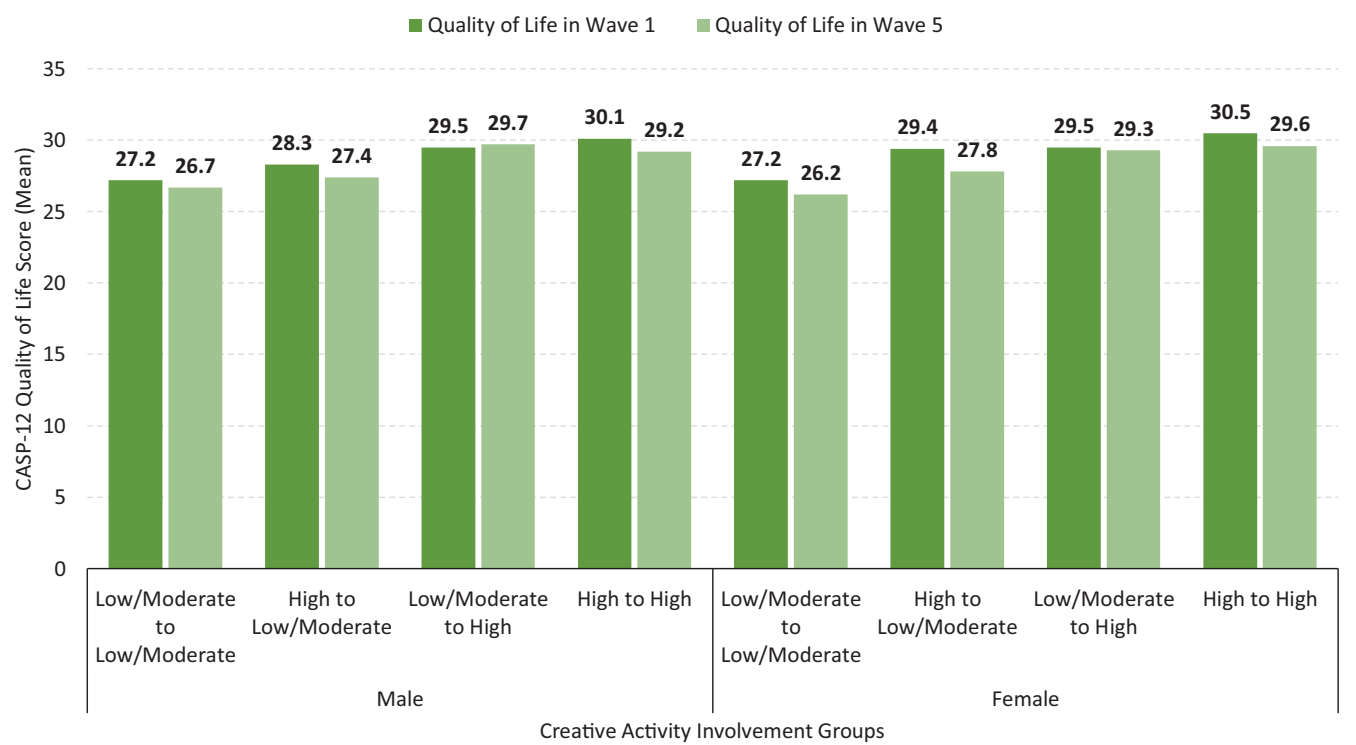

Figure 6.7. Wave 1 and Wave 5 mean loneliness scores by creative activity involvement groups

- Loneliness in Wave 1 Loneliness in Wave 5

$$
2.5
$$

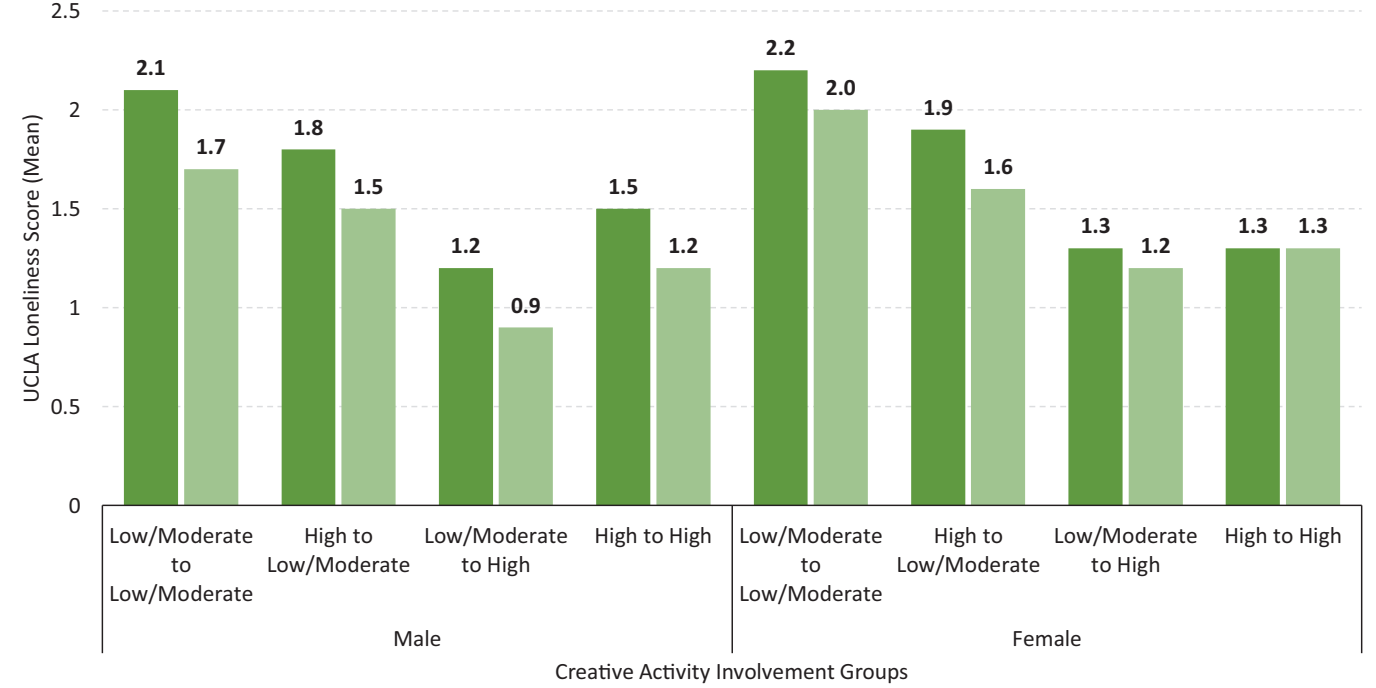


Figure 6.8. Wave 1 and Wave 5 mean depression scores by creative activity involvement groups

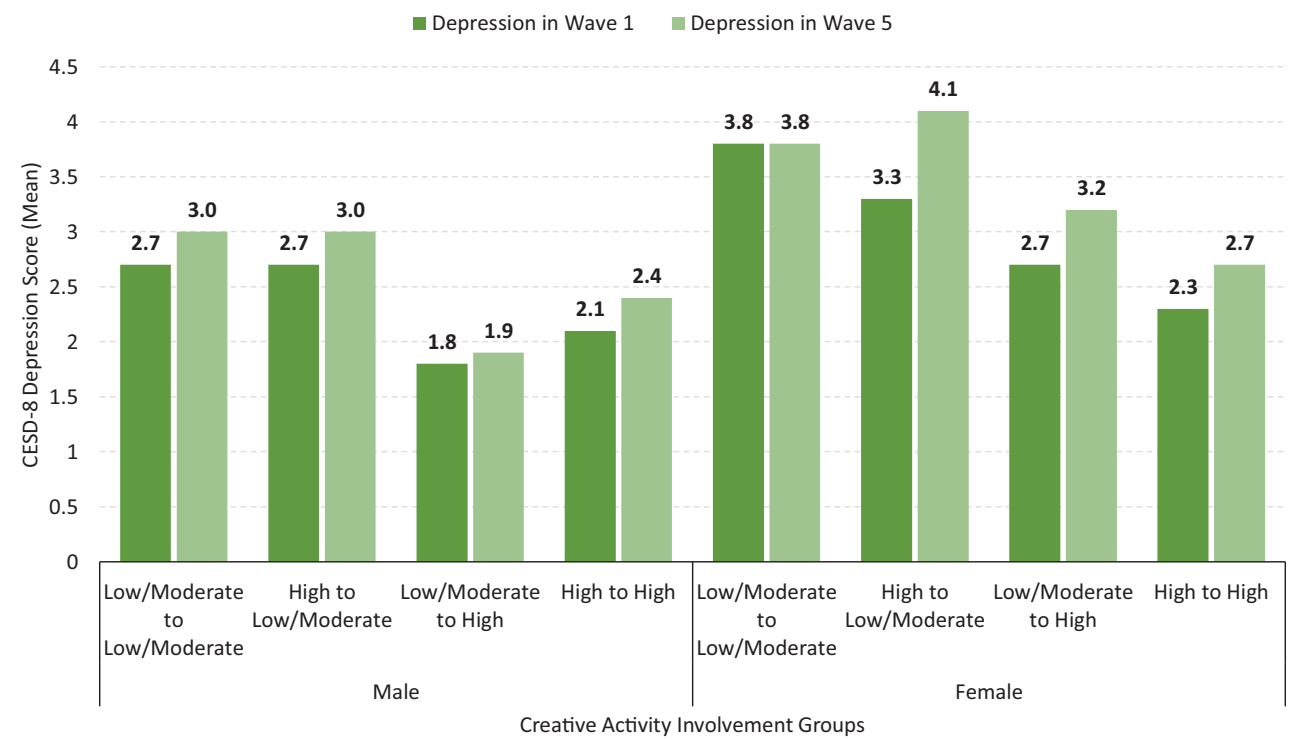

Figure 6.9. Wave 1 and Wave 5 mean worry scores by creative activity involvement groups

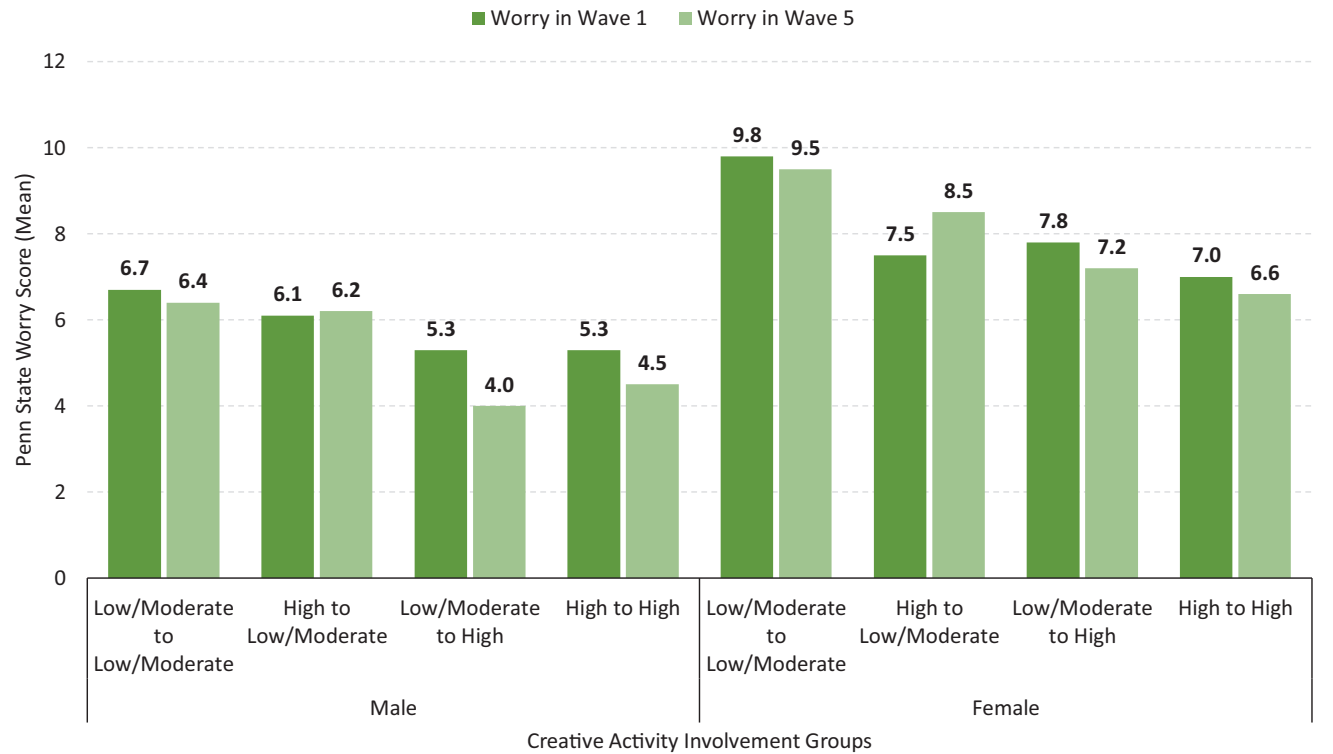


Figure 6.10. Wave 1 and Wave 5 mean stress scores by creative activity involvement groups

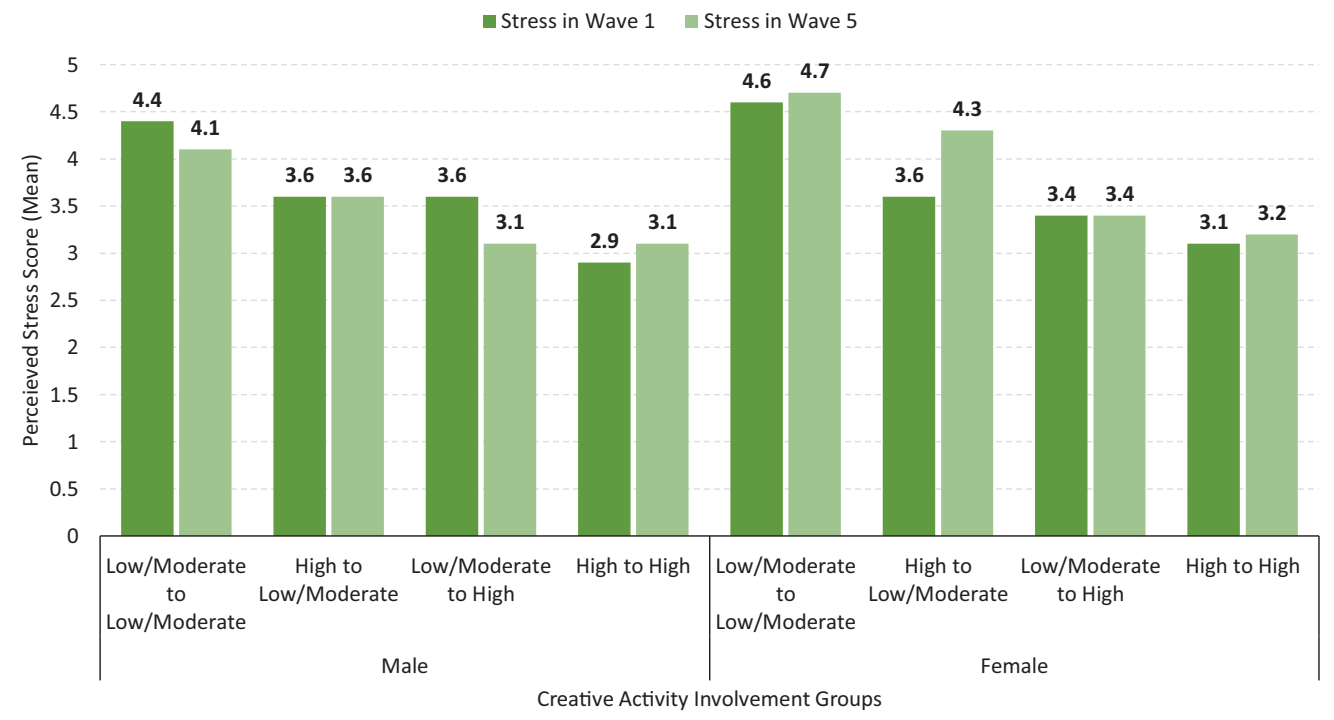




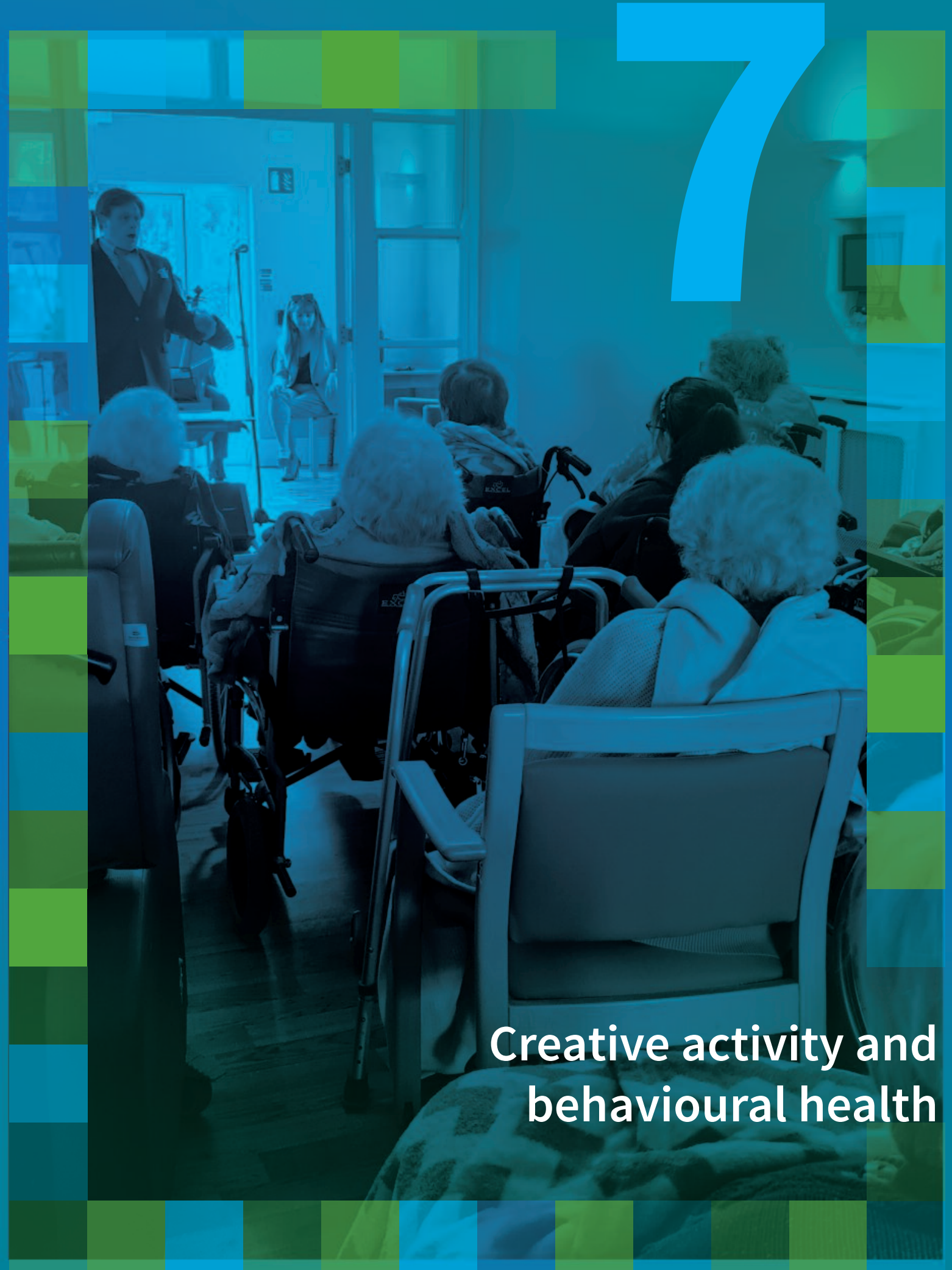




\section{Chapter 7 Creative activity and behavioural health}

This chapter explores creative activity involvement and behavioural health patterns, focusing on physical activity and smoking.

\subsection{Creative activity and physical activity}

Figure 7.1 shows the proportion of adults who report low, moderate and high physical activity within creative activity groups. The proportion of men reporting high physical activity was highest among those also reporting high creative activity (47.9\%), with just $13.7 \%$ reporting low physical activity. In men reporting low creative activity, $41.2 \%$ reported high physical activity, with $30.6 \%$ reporting low physical activity. In women, $41.4 \%$ in the low creative activity group also reported low physical activity. This proportion decreased to $22.8 \%$ among women in the high creative activity group.

Figure 7.1. Proportion of physical activity groups within creative activity groups by sex at Wave 1

$$
\text { - Low Physical Activity } \quad \text { Moderate Physical Activity } \quad \text { High Physical Activity }
$$

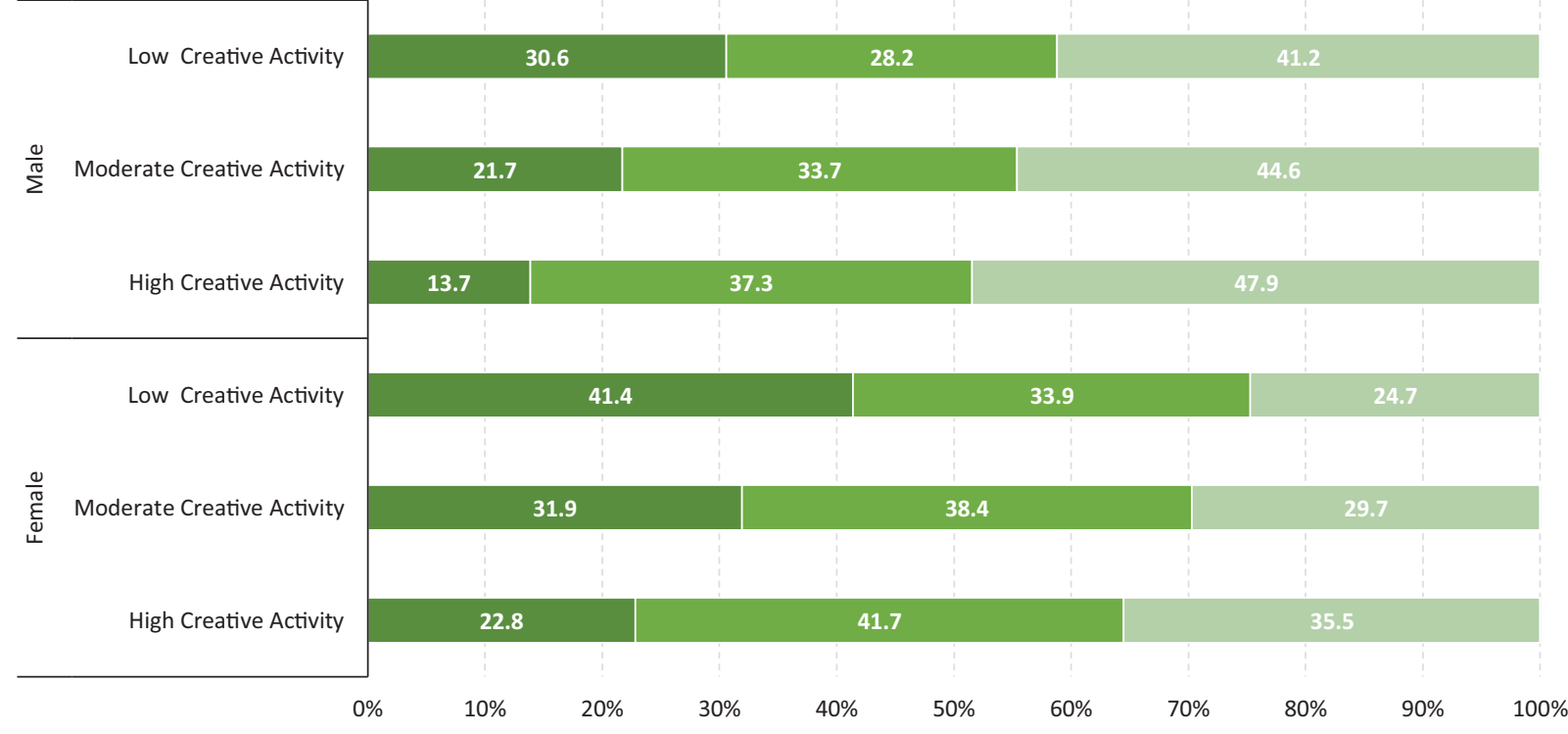

Table 7.1 presents a multinomial logistic regression model showing the odds of members of each creative activity groups reporting moderate or high physical activity compared to low physical activity while controlling for sociodemographic factors including age, sex, educational attainment, location of residence and household income quintiles. Significant positive associations with moderate and high physical activity were found for those in either the moderate or high creative activity groups. Adults in the high creative activity group were over twice as likely to report high physical activity compared with those in the low creative activity group while accounting for sociodemographic factors.

Table 7.1. Multinomial logistic regression model of associations between creative activity groups and physical activity group

\begin{tabular}{|c|c|c|}
\hline & $\begin{array}{c}\text { Moderate Physical } \\
\text { Activity } \\
\text { RRR }[95 \% \mathrm{Cl}]^{1}\end{array}$ & $\begin{array}{l}\text { High Physical } \\
\text { Activity } \\
\text { RRR }[95 \% \mathrm{Cl}]^{1}\end{array}$ \\
\hline \multicolumn{3}{|c|}{ Creative Activity Group } \\
\hline $\begin{array}{l}\text { Low } \\
\text { Moderate } \\
\text { High }\end{array}$ & $\begin{array}{c}\text { Ref } \\
1.56[1.20-2.04]^{* *} \\
2.22[1.63-3.02]^{* * *}\end{array}$ & $\begin{array}{c}\text { Ref } \\
1.53[1.19-1.98]^{* *} \\
2.77[2.05-3.73]^{* * *}\end{array}$ \\
\hline
\end{tabular}

Model adjusted for age, sex, educational attainment, location of residence and household income quintiles

RRR = Relative Risk Ratio

$\mathrm{Cl}=$ Confidence Interval

$\dagger<0.10 ;^{\star}<0.05 ;^{\star \star}<0.01 ;{ }^{\star \star \star}<0.001$

1 The odds ratio represents the odds of an being a current smoker in each group compared to the reference group; low physical activity. Odds ratios below or above 1 mean this group is less or more likely to be a current smoker respectively. 


\subsection{Creative activity and smoking status}

Overall, $19.2 \%$ of adults reported being current smokers compared to $80.8 \%$ reporting being never/past smokers in 2009 2011. Figure 7.2 shows the proportion of adults who report being current or never/past smokers within creative activity groups. In women, $21.2 \%$ in the low creative activity group reported being current smokers (21.2\%) compared to $11.2 \%$ in the high creative activity group. The proportion of men reporting being current smokers compared to never/past smokers was highest among those in the low (18.2\%) creative activity groups. Just $13.0 \%$ of men reported being current smokers in the high creative activity group.

Figure 7.2. Creative activity groups by smoker status in Wave 1

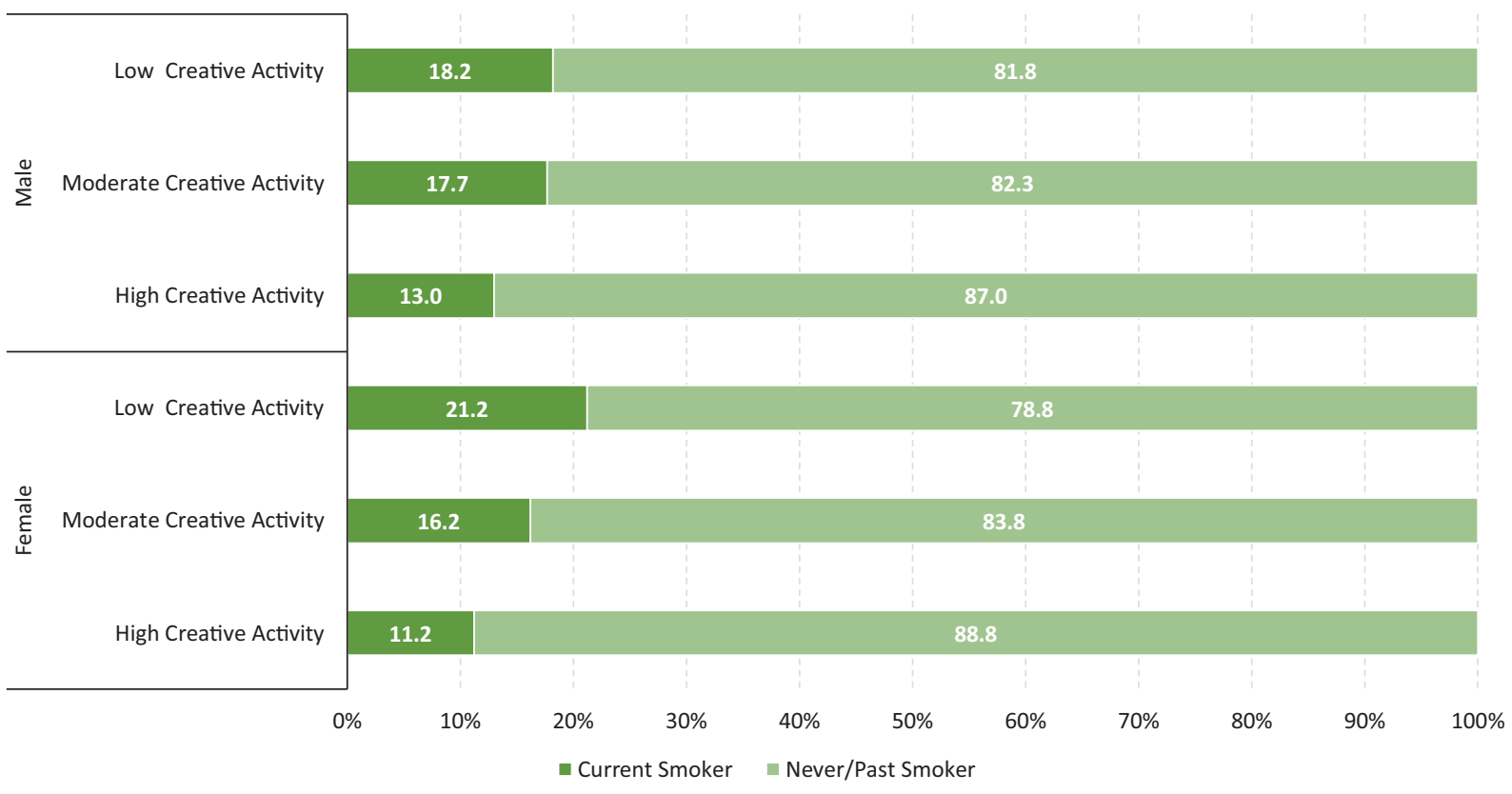

Table 7.2 presents a logistic regression model showing the odds of members of each creative activity group reporting being a current smoker compared to a never/past smoker while controlling for sociodemographic factors including age, sex, educational attainment, location of residence and household income quintiles. No associations were found for those in the moderate creative activity group, while those in the high creative activity group were less likely to be current smokers. 
Table 7.2 presents a logistic regression model showing the odds of members of each creative activity group reporting being a current smoker compared to a never/past smoker while controlling for sociodemographic factors including age, sex, educational attainment, location of residence and household income quintiles. No associations were found for those in the moderate creative activity group, while those in the high creative activity group were less likely to be current smokers.

Table 7.2. Logistic regression model of associations between creative activity groups and smoker status

\begin{tabular}{lc} 
& $\begin{array}{c}\text { Current Smoker } \\
\text { OR }[95 \% \mathrm{Cl}]^{1}\end{array}$ \\
\hline Creative Activity Group & \\
\hline Low & Ref \\
Moderate & $0.94[0.69-1.27]$ \\
High & $0.69[0.46-1.03]^{\dagger}$ \\
\hline
\end{tabular}

Model adjusted for age, sex, educational attainment, location of residence and household income quintiles

OR = Odds Ratio

$\mathrm{Cl}=$ Confidence Interval

$\dagger<0.10 ;{ }^{\star}<0.05 ;{ }^{\star \star}<0.01 ;{ }^{\star \star \star}<0.001$

\subsection{Differences in behavioural health between Wave 1 and Wave 5}

Figures 7.3 and 7.4 present the proportions of adults reporting high physical activity and current smokers respectively at Wave 1 and Wave 5 broken down by creative activity involvement groups in those who completed both waves ( $n=3,857$ ).

High physical activity decreased overall during the nine-year period. The largest decrease was among both men and women were among those reporting high to low/moderate creative activity (Figure 7.3). The proportion of high physical activity was highest among those reporting low/moderate to high creative activity among both men and women by Wave 5 .

Current smokers also decreased overall, but the proportion of current smokers remained highest among those reporting low/moderate to low/moderate creative activity in both men and women (Figure 7.4). The lowest proportion of current smokers were in those low/moderate to high creative activity by Wave 5.

Figure 7.3. Proportion of older adults reporting high physical activity at Wave 1 and Wave 5 by creative activity involvement groups

High Physical Activity in Wave $1 \quad$ High Physical Activity in Wave 5

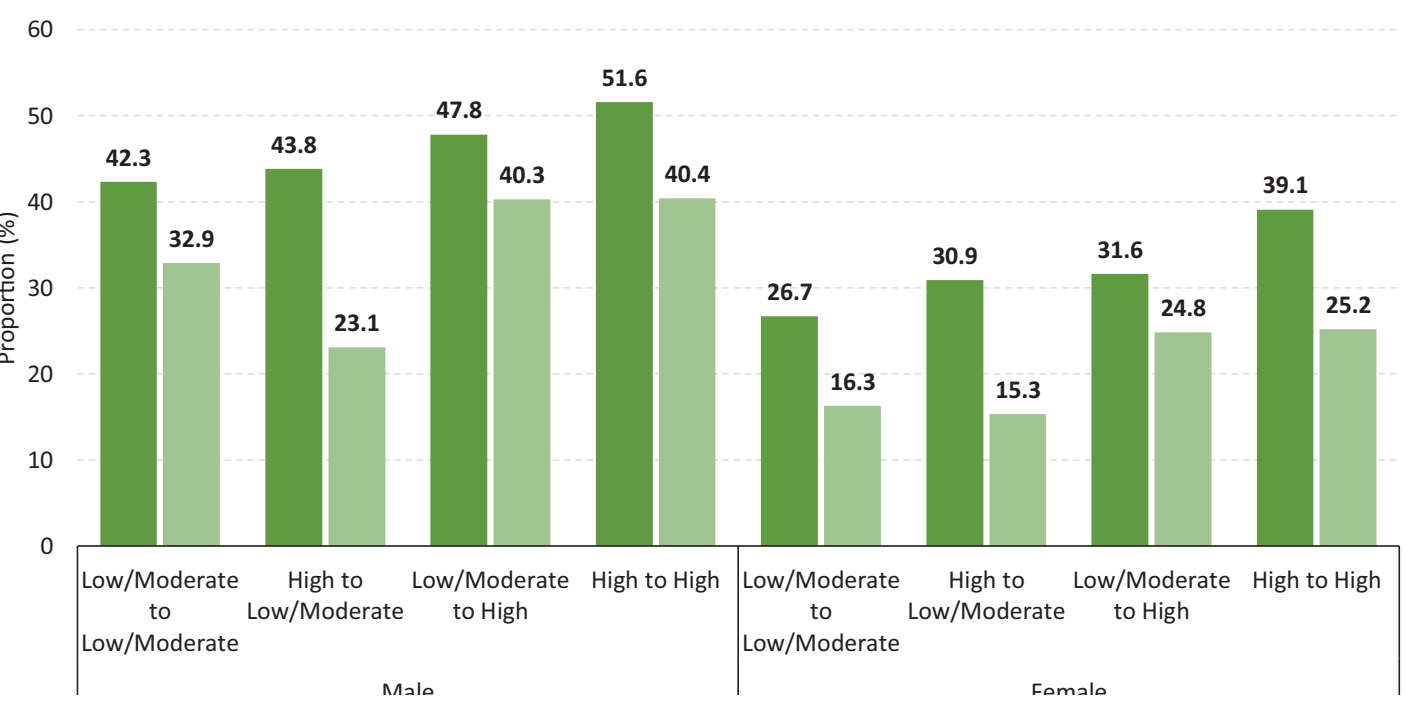

1 The odds ratio represents the odds of an being a current smoker in each group compared to the reference group; low physical activity. Odds ratios below or above 1 mean this group is less or more likely to be a current smoker respectively. 
Figure 7.4. Proportion of current smokers at Wave 1 and Wave 5 by creative activity involvement groups

25

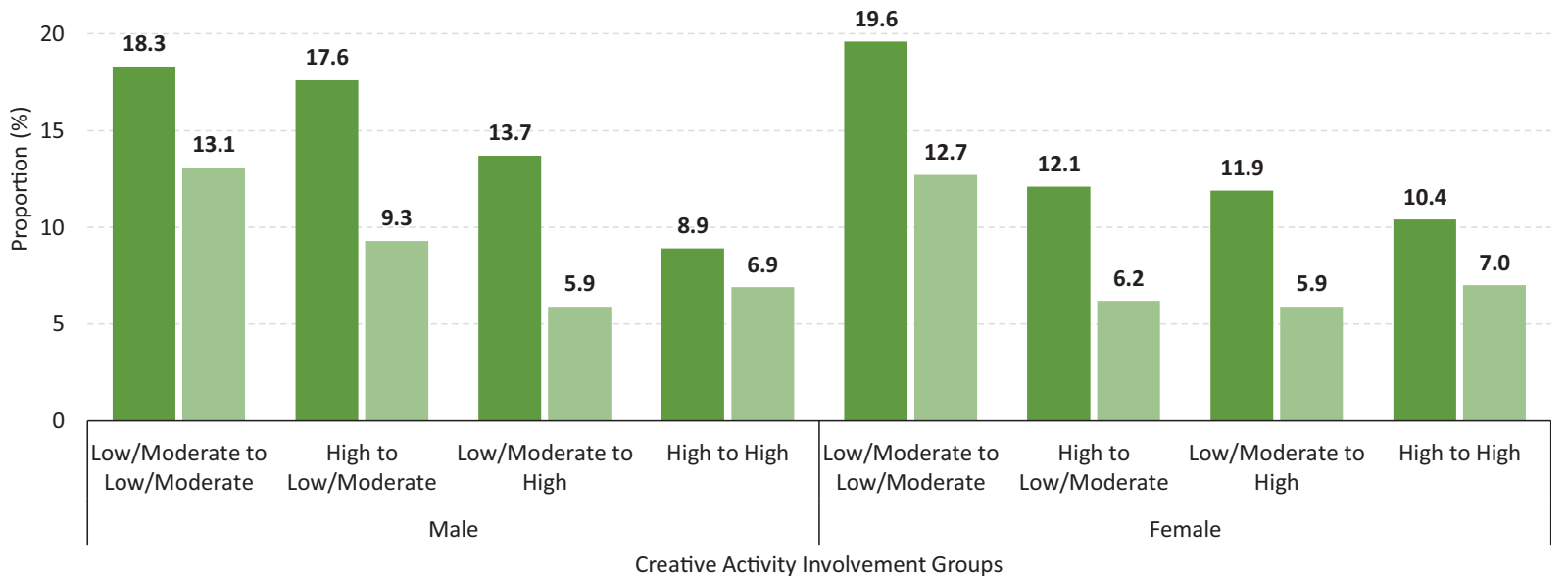




\section{Creative Activity during the COVID-19 restrictions}




\section{Chapter 8 Creative Activity during the COVID-19 restrictions}

Shortly after the COVID-19 pandemic began, TILDA sent a self-completion questionnaire to all participants to capture information on their experiences during the lockdown period. Participants were asked about how often they did a number of activities, including reading books, magazines or newspapers, watching TV, Netflix, streaming movies or shows, and also doing hobbies, crafts or puzzles, compared to before the COVID-19 outbreak. This chapter describes involvement in creative activity during the first lockdown period of the COVID-19 era. We explore differences in involvement by sociodemographic characteristics, and the impact of involvement on quality of life, loneliness, depression and perceived stress.

\subsection{Involvement in creative activity during the COVID-19 restrictions}

Table 8.1. presents the sociodemographic characteristics of the COVID-19 SCQ sample. The mean age of the sample was 71.7 years (range 61-98 years). 55.4\% were women, $41.0 \%$ had completed third level/higher education, while $55.9 \%$ resided in an urban location. Compared with before the COVID-19 pandemic, the majority (68.3\%) reported that their financial situation was about the same, $2.5 \%$ reported it was much worse off, while $2.1 \%$ reported that they were much better off.

Table 8.1. Sociodemographic characteristics of COVID-19 Questionnaire baseline sample $(n=3,596)$

\begin{tabular}{lc}
\hline Age, mean (SD) & $71.7(7.5)$ \\
\hline Age Group, \% (n) & \\
\hline $60-69$ years & $44.5(1,600)$ \\
\hline $70+$ years & $55.5(1,996)$ \\
Sex, \% (n) & \\
Male & $44.6(1,598)$ \\
Female & $55.4(1,985)$ \\
Educational Attainment, \% (n) & \\
Primary/None & $19.4(683)$ \\
Secondary & $39.7(1,398)$ \\
Third Level/Higher & $41.0(1,445)$ \\
Location of residence, \% (n) & \\
Urban & $55.9(1,971)$ \\
Rural & $44.1(1,554)$ \\
\hline Financial Situation, \% (n) & \\
I am much worse off & $2.5(88)$ \\
I am a little worse off & $331(9.5)$ \\
I am about the same & $2,369(68.3)$ \\
I am a little better off & $608(17.5)$ \\
I am much better off & $73(2.1)$ \\
\hline
\end{tabular}

The majority of participants responded that the time they spent reading books, magazines, or newspapers, and watching TV, Netflix, streaming movies or shows remained about the same compared with before the COVID-19 pandemic (55.3\% and $52.3 \%$ respectively) (Figure 8.1 ). 5.0\% stated they read books, magazines or newspapers less often and $37.8 \%$ stated they read more often. $6.4 \%$ stated they watched TV, Netflix, streamed movies or shows less often while $34.8 \%$ said this occurred more often.

Just over one quarter of participants (26.0\%) stated they did hobbies, crafts or puzzles more often compared with before the COVID-19 pandemic, while $10.2 \%$ said they did these less often. 
Figure 8.1. Level of involvement in creative activities during the COVID-19 lockdown

Read books, magazines, or newspapers

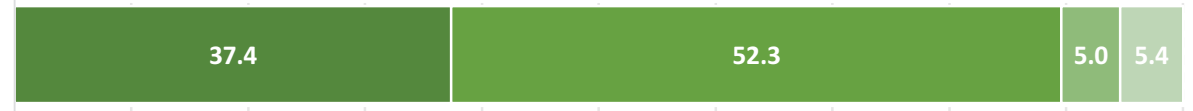

Watch TV, Netflix, stream movies, or shows

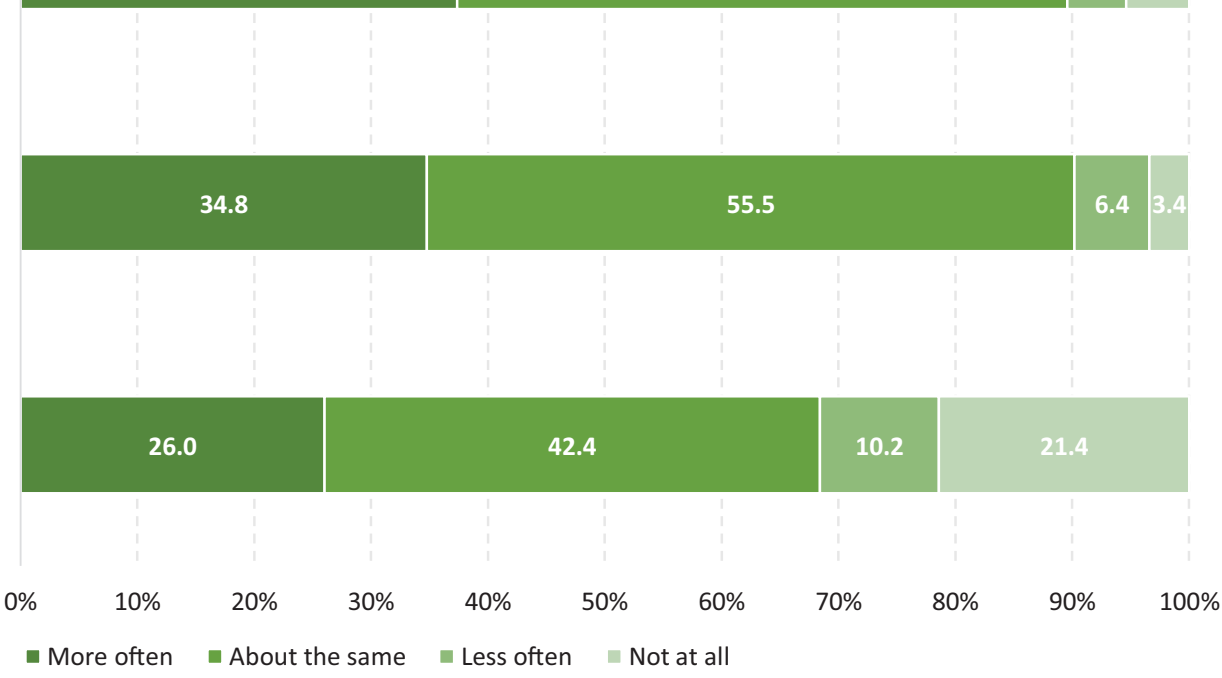

Do hobbies, crafts, or puzzles

\subsection{Reading books, magazines, or newspapers}

The majority of men (59.1\%) stated the time they spent reading books, magazines or newspapers remained the same, while $28.4 \%$ read more often. In comparison, $44.7 \%$ of women adults stated they read books, magazines or newspapers more often. A higher proportion of those with third level/higher educational attainment also stated they read books, magazines or newspapers more often than those with primary/none educational attainment (43.2\% vs $29.2 \%$ ), while a higher proportion of adults living in an urban area compared with those living in a rural area reported the same (40.6\% vs $33.2 \%)$. 


\begin{tabular}{|c|c|c|c|c|}
\hline & Readii & ks, magazin & r newspapers (in I & or online) \\
\hline & Not at all & Less often & About the same & More often \\
\hline & $\%$ & $\%$ & $\%$ & $\%$ \\
\hline Sex & & & & \\
\hline Male & 6.9 & 5.6 & 59.1 & 28.4 \\
\hline Female & 4.2 & 4.5 & 46.7 & 44.7 \\
\hline Age Group & & & & \\
\hline $60-69$ years & 5.5 & 4.1 & 51.2 & 39.4 \\
\hline $70+$ years & 5.5 & 5.7 & 53.1 & 35.6 \\
\hline $\begin{array}{l}\text { Educational } \\
\text { Attainment }\end{array}$ & & & & \\
\hline Primary/None & 12.9 & 7.3 & 50.7 & 29.2 \\
\hline Secondary & 5.5 & 5.0 & 54.3 & 35.1 \\
\hline Third/Higher & 1.8 & 3.9 & 51.2 & 43.2 \\
\hline Location of residence & & & & \\
\hline Urban & 4.5 & 4.7 & 50.2 & 40.6 \\
\hline Rural & 6.4 & 5.4 & 55.0 & 33.2 \\
\hline Financial Situation & & & & \\
\hline I am much worse off & 12.8 & 4.7 & 37.2 & 45.4 \\
\hline I am a little worse off & 5.5 & 6.1 & 50.0 & 38.3 \\
\hline I am about the same & 5.7 & 4.7 & 54.2 & 35.3 \\
\hline I am a little better & 1.7 & 4.0 & 49.9 & 44.5 \\
\hline I am much better off & 5.8 & 4.4 & 50.7 & 39.1 \\
\hline
\end{tabular}

Table 8.3 presents a multinomial logistic regression model showing sociodemographic driving factors for spending time reading books, magazines or newspapers not at all, less often, or more often compared with spending about the same amount of time.

Women compared with men were more likely to state they read books, magazines or newspapers more often, as were those in third level/higher educational attainment compared with primary/none, and those who stated their financial situation was either a little worse off or a little better off compared with remaining the same. Only those living in a rural area were less likely to report reading more often. Those with higher educational attainment were also less likely to report reading less often or not at all, while those who stated their financial situation was a little worse off had the highest odds of responding "not at all" to time spent reading books, magazines or newspapers. 
Table 8.3. Multinomial logistic regression showing associations between sociodemographic characteristics and time spent reading books, magazines or newspapers

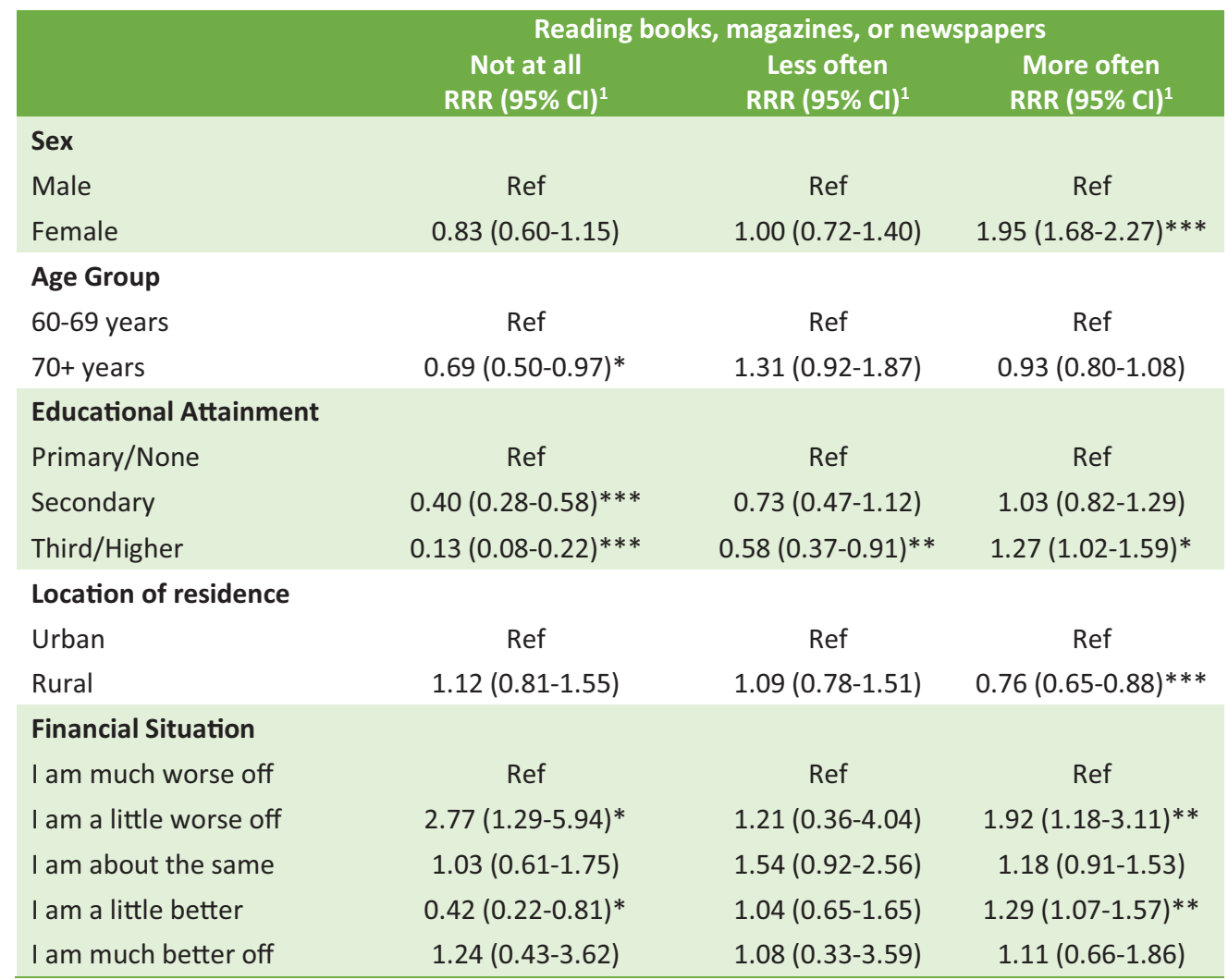

Reference Category: About the same

RRR = Relative Risk Ratio

$\mathrm{Cl}=$ Confidence Interval

$\dagger<0.10 ; *<0.05 ; * *<0.01 ; * * *<0.001$

1 The relative risk ratio represents the likelihood of reporting reading books, magazines or newspapers 'not at all', 'less often' or 'more often' relative to 'about the same' for each demographic compared to their reference group. Relative risk ratios below or above 1 mean this demographic is less or more likely to report this time spent reading books, magazines or newspapers.

Figure 8.2 presents mean quality of life, loneliness, depression and perceived stress by time spent reading books, magazines or newspapers.

Adults who spent time reading books, magazines or newspapers more often or about the same compared with before the COVID-19 pandemic had the highest quality of life. Men spending more time reading had a mean quality of life score of 27.9 compared with 25.6 for those who spent less time. For women, those spending more time reading had a mean score of 27.4 , compared with 24.5 for those spending less time.

Similar trends were apparent for loneliness, depression and perceived stress scores, with lower mean scores for each among those spending time reading more often compared with those spending time reading less often or not at all. In women, mean loneliness scores were 4.5 in those spending time reading more often compared with a mean score of 5.1 in those spending time less often, while for depression, mean scores were 5.5 and 7.3 in these groups respectively. For perceived stress, the largest discrepancy in mean scores was for men who reported spending time reading more often (mean=4.2) compared with those spending time less often (mean=5.5). 
Figure 8.2. Quality of life, loneliness, depression and perceived stress mean scores by time spent reading books, magazines or newspapers during COVID-19 restrictions

$\square$ Not at all Less often $\square$ About the same $\square$ More often

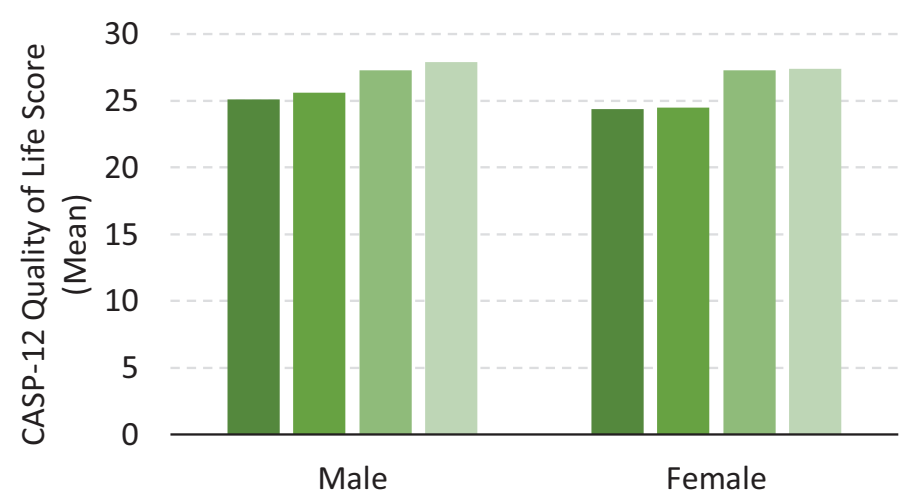

Not at all Less often $\square$ About the same $\square$ More often

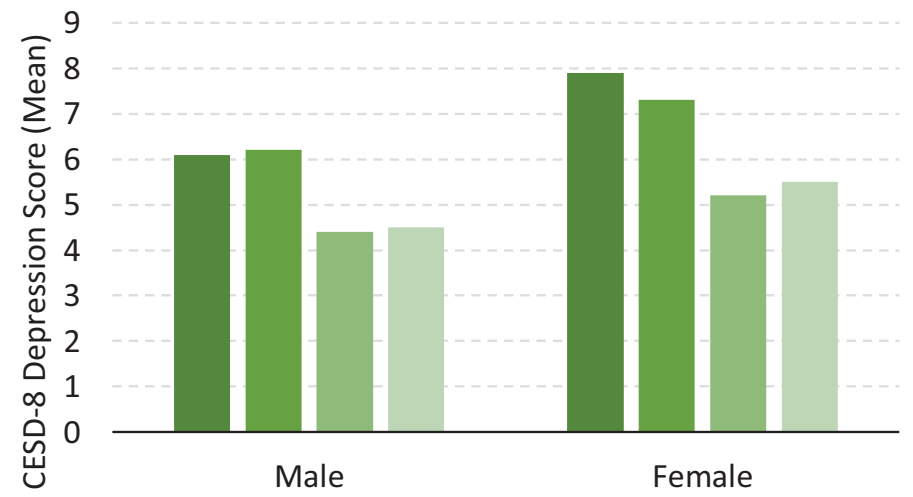

$\square$ Not at all Less often $\square$ About the same $\square$ More often

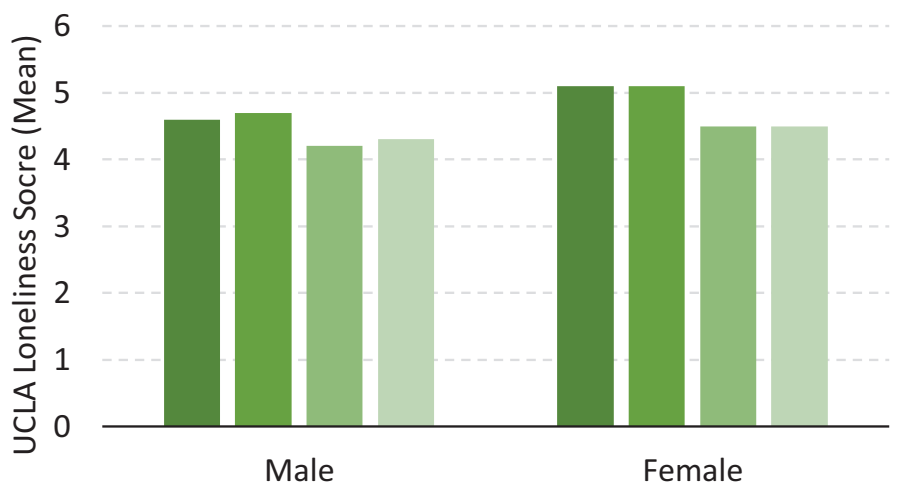

Not at all Less often $\square$ About the same $\square$ More often

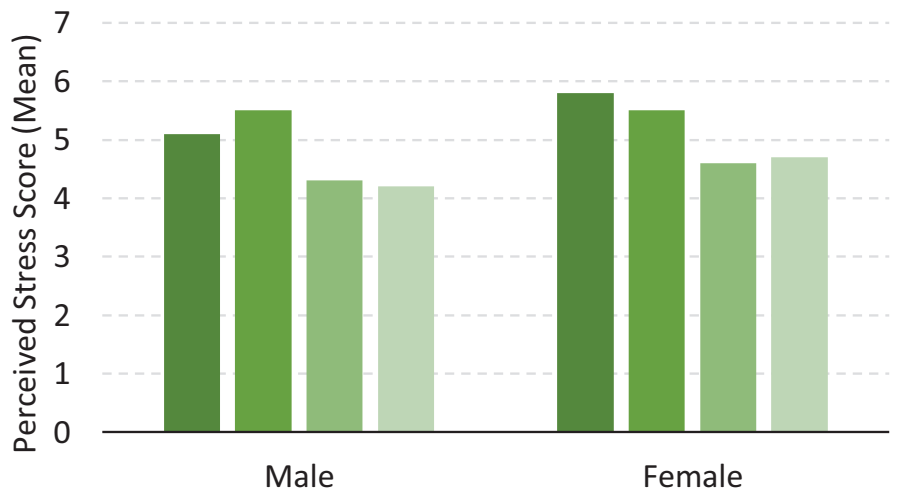

Table 8.4 presents a set of linear regression models showing associations between time spent reading books, magazines or newspapers during COVID-19 restrictions and quality of life, loneliness, depression, and perceived stress scores.

Spending time reading more often compared with before the COVID-19 era showed no associations with any of the measures compared with spending about the same amount of time. However, those reporting they spent time reading less often or not at all had significantly lower quality of life, and higher loneliness, depression and stress scores when compared with those who reported they spent about the same amount of time. 
Table 8.4. Linear regression models predicting quality of life, loneliness and depression and perceived stress by frequency of reading books, magazines or newspapers during COVID-19 restrictions

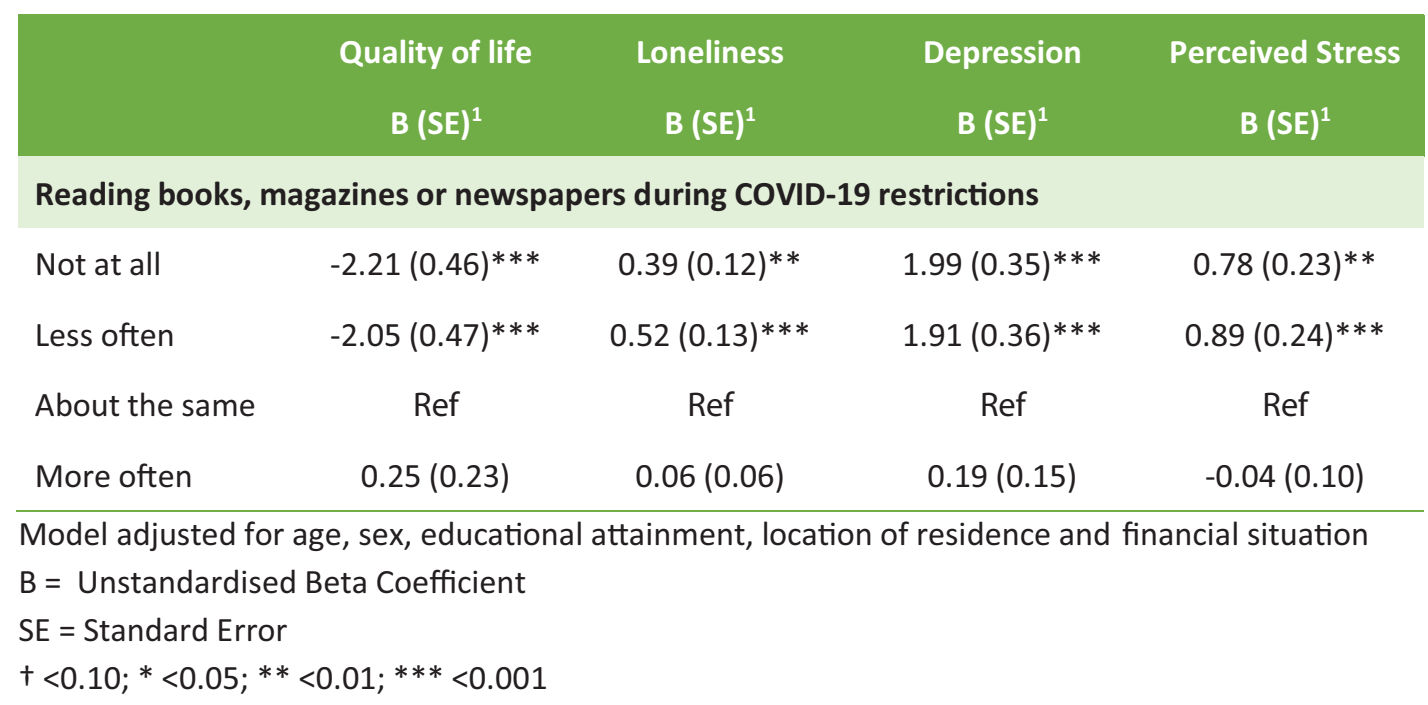

\subsection{Watching TV, Netflix, streaming movies, or shows}

We next looked at sociodemographic characteristics and associations with watching TV, Netflix, streaming movies or shows during the COVID-19 restrictions compared with prior to the COVID-19 era (Table 8.5). A higher proportion of women reported spending time watching TV, Netflix, streaming movies or shows more often (37.3\%) compared with men (31.8\%), as did those aged 60-69 years (37.9\%) compared with those aged $70+$ years $(32.1 \%)$. Proportions were similar among educational attainment groups, while $39.2 \%$ of adults living in an urban area reported spending time more often compared with $29.4 \%$ living in a rural area. Regarding financial situations, the highest proportion of those spending time more often stated they were much worse off (44.7\%), with $5.9 \%$ of this group spending time less often; $8.6 \%$ of those reporting they were much better off stated they spent time less often.

1 The unstandardised beta coefficient represents the relationship between time reading books, magazines or newspapers with quality of life, loneliness, depression, worry or perceived stress. Positive numbers reflect a positive relationship, negative numbers a negative relationship. For each 'time spent' group, the coefficient shows the relationship relative to the reference group: 'About the same'. A positive number suggests this group had higher scores for each measure compared to those who reported time spent was 'about the same'. 


\begin{tabular}{|c|c|c|c|c|}
\hline & \multicolumn{4}{|c|}{ Watching TV, Netflix, streaming movies, or shows } \\
\hline & Not at all & Less often & About the same & More often \\
\hline & $\%$ & $\%$ & $\%$ & $\%$ \\
\hline \multicolumn{5}{|l|}{ Sex } \\
\hline Male & 3.6 & 6.6 & 58.1 & 31.8 \\
\hline Female & 3.3 & 6.2 & 53.3 & 37.3 \\
\hline \multicolumn{5}{|l|}{ Age Group } \\
\hline $60-69$ years & 2.8 & 5.9 & 53.3 & 37.9 \\
\hline $70+$ years & 3.8 & 6.7 & 57.3 & 32.1 \\
\hline \multicolumn{5}{|l|}{$\begin{array}{l}\text { Educational } \\
\text { Attainment }\end{array}$} \\
\hline Primary/None & 4.5 & 7.6 & 54.9 & 33.0 \\
\hline Secondary & 2.8 & 6.2 & 55.7 & 35.3 \\
\hline Third/Higher & 3.5 & 6.0 & 55.2 & 35.3 \\
\hline \multicolumn{5}{|l|}{ Location of residence } \\
\hline Urban & 2.8 & 4.6 & 53.4 & 39.2 \\
\hline Rural & 4.2 & 8.6 & 57.9 & 29.4 \\
\hline \multicolumn{5}{|l|}{ Financial Situation } \\
\hline I am much worse off & 1.8 & 5.9 & 44.7 & 44.7 \\
\hline I am a little worse off & 1.8 & 5.8 & 52.0 & 40.4 \\
\hline I am about the same & 3.6 & 6.0 & 57.1 & 33.3 \\
\hline I am a little better & 2.7 & 6.3 & 53.6 & 37.5 \\
\hline I am much better off & 8.6 & 8.6 & 47.1 & 35.7 \\
\hline
\end{tabular}

Table 8.6 presents a multinomial logistic regression model showing sociodemographic driving factors for time spent watching TV, Netflix, streaming movies, or shows not at all, less often, or more often compared with spending about the same amount of time. Age was a significant driving factor in time spent, with adults aged $70+$ years compared with adults aged 60-69 years less likely to report they spent time more often. Location was also a strong predictor, with those living in a rural area compared with an urban area significantly more likely to report they spent time less often watching TV, Netflix, streaming movies or shows. 
Table 8.6. Multinomial logistic regression showing associations between sociodemographic characteristics and time spent watching TV, Netflix, streaming movies, or shows during COVID-19 restrictions

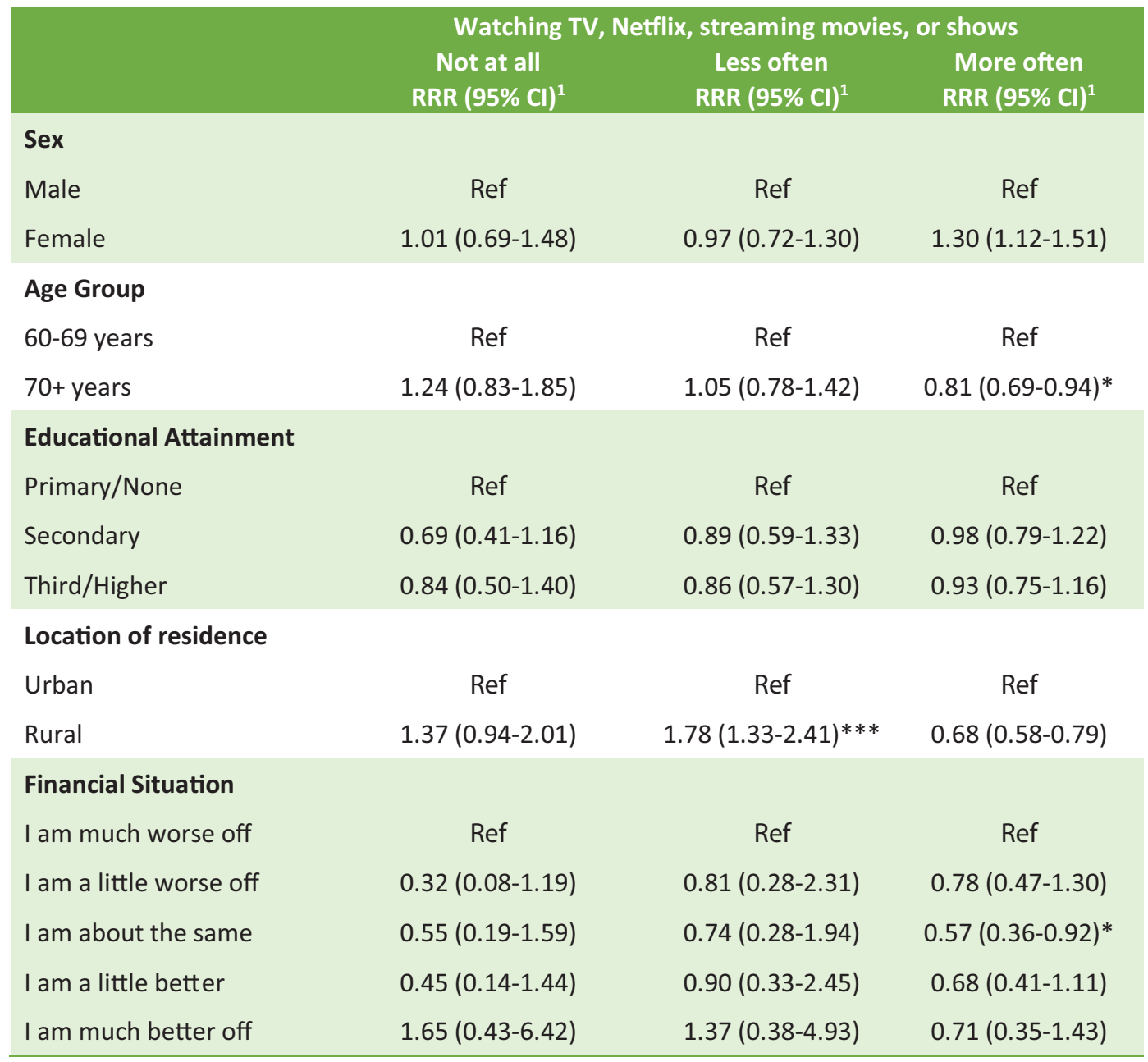

Reference Category: About the same

RRR = Relative Risk Ratio

$\mathrm{Cl}=$ Confidence Interval

$\dagger<0.10$; $^{*}<0.05 ; * *<0.01 ; * * *<0.001$

Little difference in quality of life or loneliness mean scores were found relative to time spent watching TV, Netflix, streaming movies or shows (Figure 8.3). Women reporting they spent time more often had the highest depression (mean=6.3) and perceived stress (5.1) scores.

1 The relative risk ratio represents the likelihood of reporting watching TV, Netflix, streaming movies 'not at all', 'less often' or 'more often' relative to 'about the same' for each demographic compared to their reference group. Relative risk ratios below or above 1 mean this demographic is less or more likely to report this time spent watching TV, Netflix, streaming movies or shows. 
Figure 8.3. Quality of life, loneliness, depression and perceived stress mean scores by time spent watching TV, Netflix, streaming movies, or shows during COVID-19 restriction
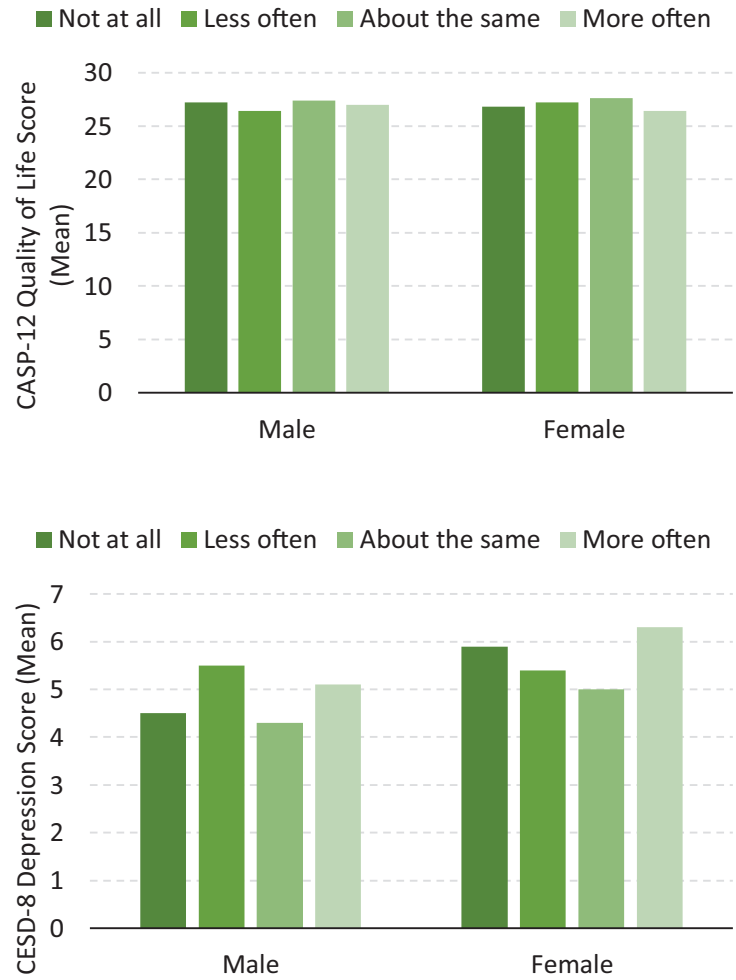
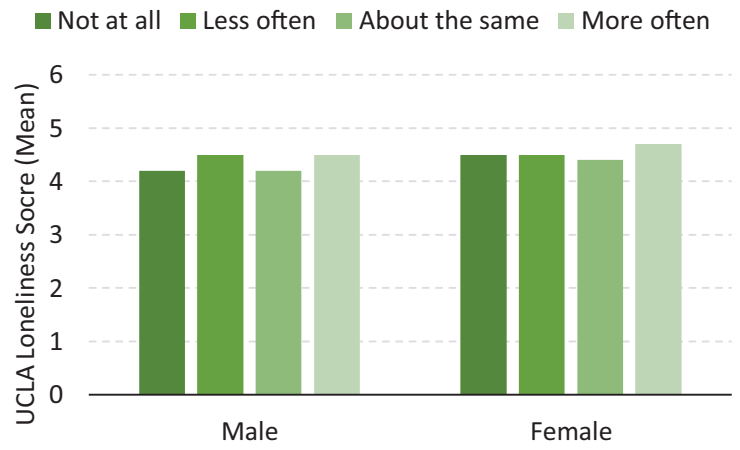

$\square$ Not at all $\square$ Less often $\square$ About the same $\square$ More often

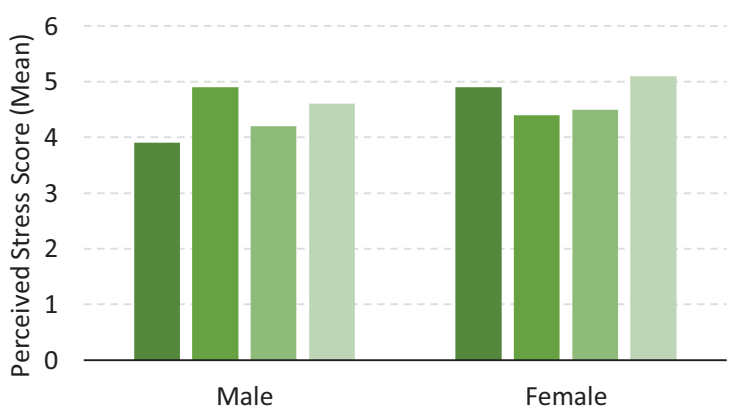

Table 8.7 presents a set of linear regression models showing associations between time spent watching TV, Netflix, streaming movies or shows during COVID-19 restrictions and quality of life, loneliness, depression, and perceived stress scores. Spending time more often compared with before the COVID-19 era was associated with lower quality of life and with higher loneliness, depression and perceived stress.

Table 8.7. Linear regression models predicting quality of life, loneliness and depression and perceived stress by time spent watching TV, Netflix, streaming movies, or shows during COVID-19 restrictions

\begin{tabular}{|c|c|c|c|c|}
\hline & $\begin{array}{c}\text { Quality of life } \\
\text { B (SE) }\end{array}$ & $\begin{array}{l}\text { Loneliness } \\
\qquad \text { B (SE) }\end{array}$ & $\begin{array}{l}\text { Depression } \\
\text { B (SE) }\end{array}$ & $\begin{array}{c}\text { Perceived Stress } \\
\text { B (SE) })^{1}\end{array}$ \\
\hline \multicolumn{5}{|c|}{ Watch TV, Netflix, stream movies, or shows } \\
\hline Not at all & $-0.40(0.56)$ & $-0.03(0.15)$ & $0.41(0.41)$ & $0.04(0.27)$ \\
\hline Less often & $-0.60(0.21)$ & $0.15(0.11)$ & $0.90(0.32)^{* *}$ & $0.13(0.21)$ \\
\hline About the same & Ref & Ref & Ref & Ref \\
\hline More often & $-0.88(0.21)^{* * *}$ & $0.25(0.06)^{* * *}$ & $1.04(0.16)^{* * *}$ & $0.51(0.10)^{* * *}$ \\
\hline
\end{tabular}

Model adjusted for age, sex, educational attainment, location of residence and financial situation $\mathrm{B}=$ Unstandardised Beta Coefficient

$\mathrm{SE}=$ Standard Error

$+<0.10 ; *<0.05 ; * * 0.01 ; * * *<0.001$

1 The unstandardised beta coefficient represents the relationship the time spent watching TV, Netflix, streaming movies or shows with quality of life, loneliness, depression, worry or perceived stress. Positive numbers reflect a positive relationship, negative numbers a negative relationship. For each time spent group, the coefficient shows the relationship relative to the reference group: About the same. A positive number suggests this group had higher scores for each measure compared to those who reported the time spent was about the same. 


\subsection{Doing hobbies, crafts or puzzles}

Finally, we look at associations between sociodemographic characteristics and spending time doing hobbies, crafts or puzzles during the COVID-19 restrictions compared with prior to the pandemic (Table 8.8). A higher proportion of women reported spending time doing hobbies, crafts or puzzles more often (32.3\%) compared with men (18.4). Just over a quarter of men reported they didn't spend any time (25.4\%), while just less than a quarter of adults aged 70+ years reported the same (24.4\%). Among educational attainment groups, those with third level/higher had the highest proportion of adults reporting they spent time more often (30.8\%), while $36.0 \%$ of those with primary/none stated they did not spend any time. $38.2 \%$ of adults with a financial situation much better off spent time more often on hobbies, crafts or puzzles, while just over a quarter of those much worse off (26.4\%) did not spend any time.

\section{Table 8.8. Sociodemographic characteristics of time spent doing hobbies, crafts or puzzles}

\begin{tabular}{|c|c|c|c|c|}
\hline & \multicolumn{4}{|c|}{ Do hobbies, crafts or puzzles } \\
\hline & $\begin{array}{c}\text { Not at all } \\
\%\end{array}$ & $\begin{array}{c}\text { Less often } \\
\%\end{array}$ & $\begin{array}{c}\text { About the same } \\
\%\end{array}$ & $\begin{array}{c}\text { More often } \\
\%\end{array}$ \\
\hline \multicolumn{5}{|l|}{ Sex } \\
\hline Male & 25.4 & 11.3 & 45.0 & 18.3 \\
\hline Female & 18.3 & 9.3 & 40.2 & 32.3 \\
\hline \multicolumn{5}{|l|}{ Age Group } \\
\hline $60-69$ years & 17.8 & 10.3 & 43.9 & 28.0 \\
\hline $70+$ years & 24.4 & 10.2 & 41.2 & 24.3 \\
\hline \multicolumn{5}{|c|}{ Educational Attainment } \\
\hline Primary/None & 36.0 & 10.8 & 34.7 & 18.5 \\
\hline Secondary & 23.2 & 10.0 & 42.1 & 24.7 \\
\hline Third/Higher & 13.2 & 10.1 & 46.0 & 30.8 \\
\hline \multicolumn{5}{|l|}{ Location of residence } \\
\hline Urban & 20.3 & 10.3 & 41.3 & 28.1 \\
\hline Rural & 22.9 & 10.0 & 43.7 & 23.5 \\
\hline \multicolumn{5}{|l|}{ Financial Situation } \\
\hline I am much worse off & 26.4 & 10.3 & 37.9 & 25.3 \\
\hline I am a little worse off & 21.4 & 12.1 & 42.1 & 24.5 \\
\hline I am about the same & 22.6 & 9.8 & 43.8 & 23.7 \\
\hline I am a little better & 15.1 & 9.5 & 41.6 & 33.8 \\
\hline I am much better off & 13.2 & 11.8 & 36.8 & 38.2 \\
\hline
\end{tabular}

The multinomial regression model in table 8.9 assesses sociodemographic driving factors for time spent doing hobbies, crafts or puzzles not at all, less often, or more often compared with spending about the same amount of time. Women were almost twice as likely as men to report spending time more often, and less likely to reporting spending no time at all. Those in a rural area were less likely to report spending time more often than those in an urban area. Compared with those with primary/none educational attainment, adults with either secondary level or third/higher were significantly less likely to report they spent no time on hobbies, crafts or puzzles. 
Table 8.9. Multinomial logistic regression showing associations between sociodemographic characteristics and time spent doing hobbies, crafts or puzzles

\begin{tabular}{|c|c|c|c|}
\hline & Do & oies, crafts or puzz & \\
\hline & Not at all & Less often & More often \\
\hline & $\operatorname{RRR}(95 \% \mathrm{Cl})^{1}$ & $\operatorname{RRR}(95 \% \mathrm{Cl})^{1}$ & $\operatorname{RRR}(95 \% \mathrm{Cl})^{1}$ \\
\hline Sex & & & \\
\hline Male & Ref & Ref & Ref \\
\hline Female & $0.82(0.69-0.99) *$ & $0.92(0.72-1.17)$ & $1.90(1.59-2.28)^{* * *}$ \\
\hline Age Group & & & \\
\hline $60-69$ years & Ref & Ref & Ref \\
\hline $70+$ years & $1.20(0.99-1.45)^{\dagger}$ & $1.02(0.80-1.31)$ & $0.97(0.81-1.15)$ \\
\hline Educational Attainme & & & \\
\hline Primary/None & Ref & Ref & Ref \\
\hline Secondary & $0.56(0.44-0.71)^{* * *}$ & $0.82(0.58-1.16)$ & $1.08(0.82-1.42)$ \\
\hline Third/Higher & $0.30(0.23-0.39)^{* * *}$ & $\begin{array}{c}0.72(0.51-1.03) \\
+\end{array}$ & $1.15(0.87-1.51)$ \\
\hline Location of residence & & & \\
\hline Urban & Ref & Ref & Ref \\
\hline Rural & $0.96(0.80-1.16)$ & $0.86(0.67-1.09)$ & $0.80(0.67-0.95)^{*}$ \\
\hline Financial Situation & & & \\
\hline I am much worse off & Ref & Ref & Ref \\
\hline I am a little worse off & $0.68(0.36-1.28)$ & $1.00(0.44-2.28)$ & $0.81(0.44-1.51)$ \\
\hline I am about the same & $0.70(0.40-1.23)$ & $0.80(0.38-1.71)$ & $0.78(0.44-1.36)$ \\
\hline I am a little better & $0.58(0.32-1.06)^{\dagger}$ & $0.81(0.36-1.80)$ & $1.12(0.63-2.00)$ \\
\hline I am much better off & $0.52(0.20-1.35)$ & $1.14(0.38-3.38)$ & $1.43(0.66-3.12)$ \\
\hline Reference Category: A & me & & \\
\hline RRR = Relative Risk Rati & & & \\
\hline $\mathrm{Cl}=$ Confidence Interva & & & \\
\hline$\dagger<0.10 ;^{*}<0.05 ; * *<0$. & 01 & & \\
\hline
\end{tabular}

11 The relative risk ratio represents the likelihood of doing hobbies, crafts or puzzles 'not at all', 'less often' or 'more often' relative to 'about the same' for each demographic compared to their reference group. Relative risk ratios below or above 1 mean this demographic is less or more likely to report this time doing hobbies, crafts or puzzles.

Figure 8.4 shows the breakdown of mean quality of life, loneliness, depression and perceived stress scores and time spent on hobbies, crafts and puzzles during COVID-19 restrictions. Mean quality of life scores were higher in those spending time more often compared with not at all among both men (mean: 28.5 vs 25.9) and women (mean: 27.8 vs 25.5). Loneliness scores were similar among both men and women regardless of time spent on hobbies, crafts and puzzles, as were depression scores among men, while women who spent time less often or not at all had the highest mean depression scores (mean: 6.4 and 7.0 respectively). For perceived stress, the largest discrepancy was between men participants reporting they spent time more often, who had a mean score of 4.0, and those who spent time less often or not at all, where each group had mean scores of 4.9. 
Figure 8.4. Quality of life, loneliness, depression and perceived stress mean scores by time spent doing hobbies, crafts or puzzles during COVID-19 restrictions

$\square$ Not at all $\square$ Less often $\square$ About the same $\square$ More often

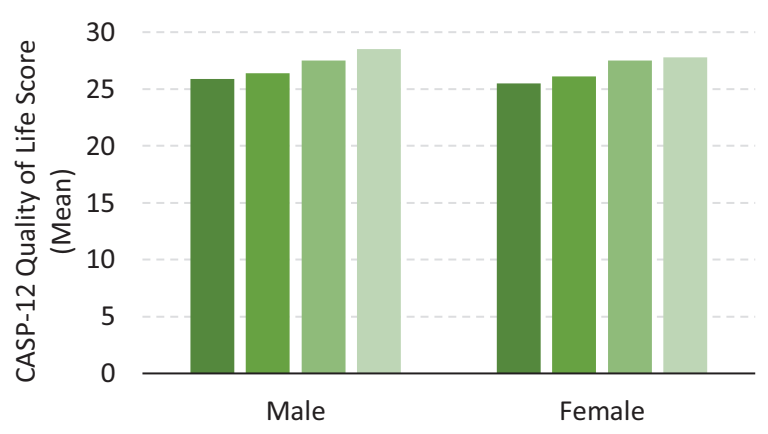

$\square$ Not at all $\square$ Less often $\square$ About the same $\square$ More often

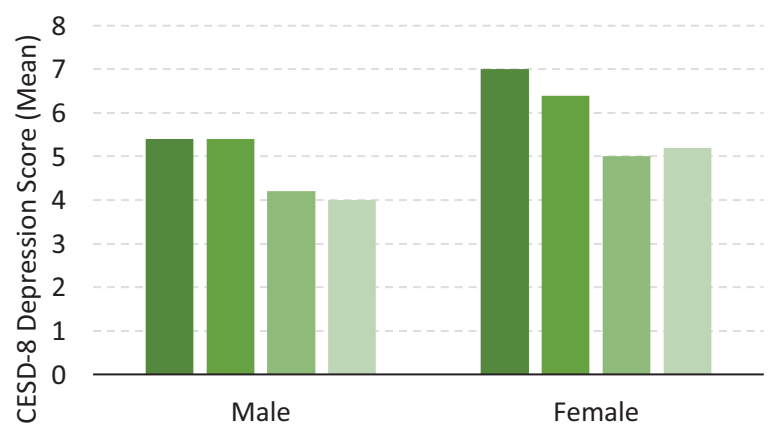

$\square$ Not at all $\square$ Less often $\square$ About the same $\square$ More often

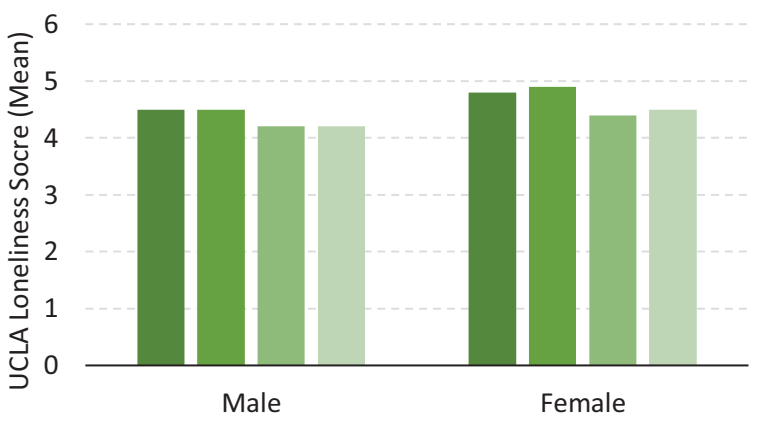

Not at all $\square$ Less often $\square$ About the same $\square$ More often

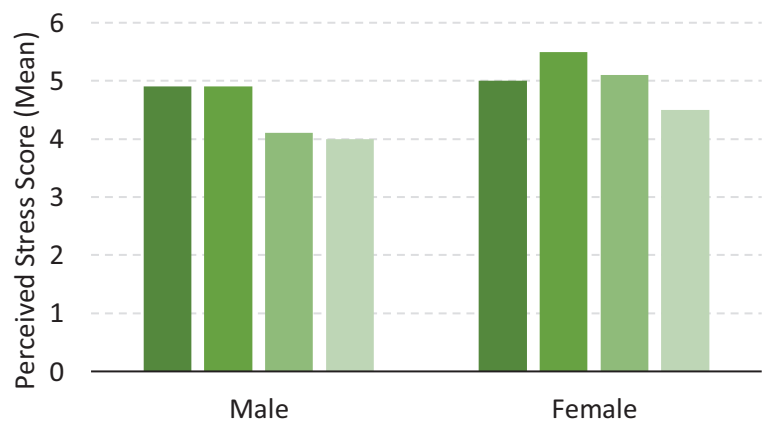

Table 8.10 shows associations between time spent doing hobbies, crafts or puzzles during COVID-19 restrictions and quality of life, loneliness, depression, and perceived stress scores. Relative to spending about the same time as before the COVID19 era, spending time less often, or not at all, on hobbies, crafts or puzzles were both associated with significantly lower quality of life and with higher loneliness, depression, and perceived stress scores.

Table 8.10. Linear regression models predicting quality of life, loneliness and depression and perceived stress by time spent doing hobbies, crafts or puzzles during COVID-19 restrictions

\begin{tabular}{|c|c|c|c|c|}
\hline & $\begin{array}{l}\text { Quality of life } \\
\qquad \text { B (SE) }\end{array}$ & $\begin{array}{l}\text { Loneliness } \\
\qquad \text { B (SE) }{ }^{1}\end{array}$ & $\begin{array}{l}\text { Depression } \\
\text { B (SE) }\end{array}$ & $\begin{array}{c}\text { Perceived Stress } \\
\text { B (SE) }{ }^{1}\end{array}$ \\
\hline \multicolumn{5}{|c|}{ Doing hobbies, crafts or puzzles } \\
\hline Not at all & $-1.56(0.26)^{* * *}$ & $0.30(0.07)^{* * *}$ & $1.52(0.20)^{* * *}$ & $0.79(0.13)^{* * *}$ \\
\hline Less often & $-1.20(0.33)^{* * *}$ & $0.40(0.09)^{* * *}$ & $1.31(0.26)^{* * *}$ & $0.74(0.17)^{* * *}$ \\
\hline About the same & Ref & Ref & Ref & Ref \\
\hline More often & $0.41(0.24)$ & $0.01(0.06)$ & $0.09(0.18)$ & $0.02(0.12)$ \\
\hline \multicolumn{5}{|c|}{ Model adjusted for age, sex, educational attainment, location of residence and financial situation } \\
\hline \multicolumn{5}{|c|}{$B=$ Unstandardised Beta Coefficient } \\
\hline \multicolumn{5}{|l|}{$\mathrm{SE}=$ Standard Error } \\
\hline$\dagger<0.10$; ${ }^{*}<0.05$; * & $01 ; * * *<0.001$ & & & \\
\hline
\end{tabular}

1 The unstandardised beta coefficient represents the relationship the doing hobbies, crafts or puzzles with quality of life, loneliness, depression, worry or perceived stress. Positive numbers reflect a positive relationship, negative numbers a negative relationship. For each time spent group, the coefficient shows the relationship relative to the reference group: About the same. A positive number suggests this group had higher scores for each measure compared to those who reported the time spent was about the same. 


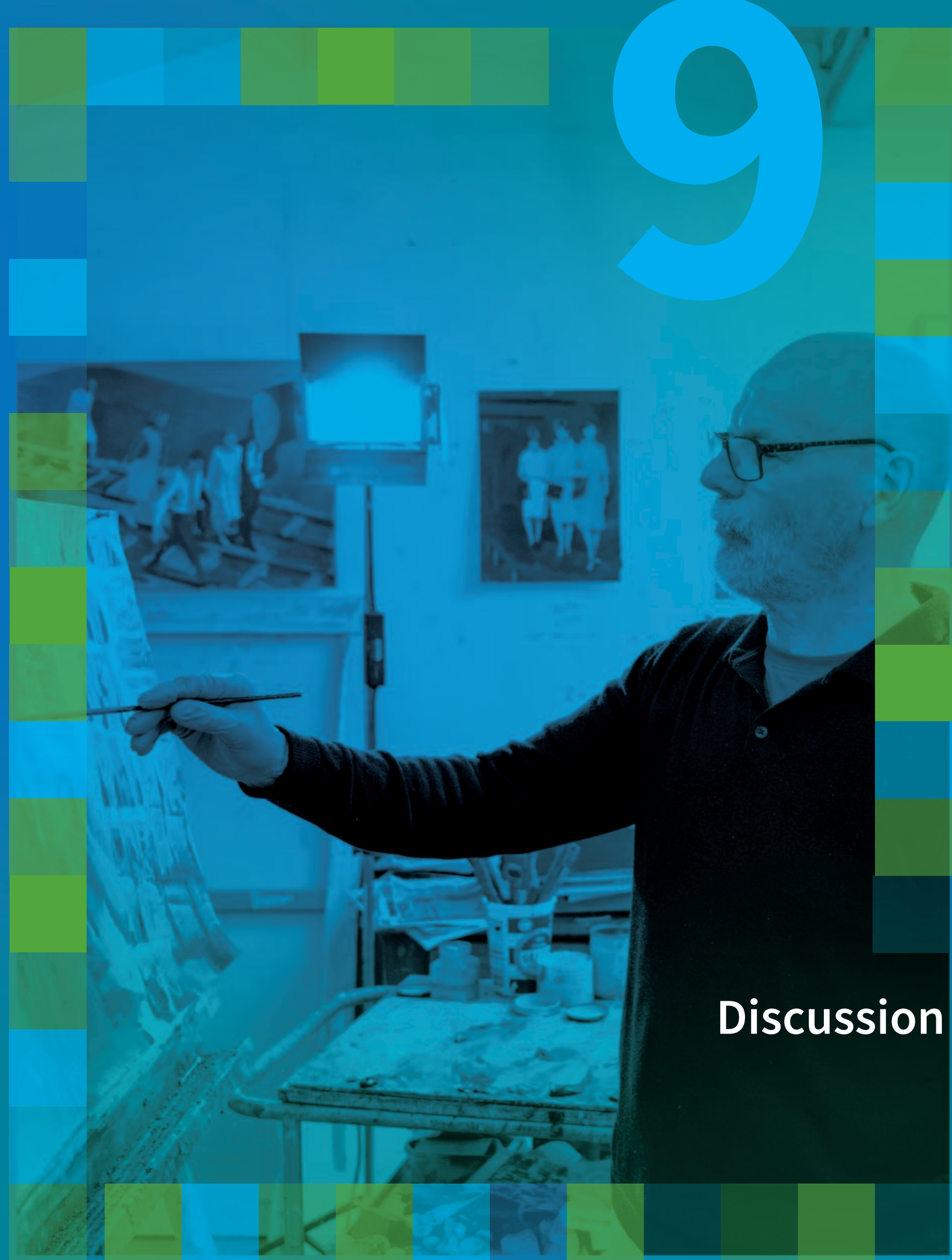

tilda.tcd.ie 


\section{Chapter 9 Discussion}

\subsection{Introduction}

This report used data from The Irish Longitudinal Study on Ageing to explore involvement in creative activities among the over-50s population in Ireland as part of the Creativity in Older Age programme. This report is a first look at creative involvement in a representative population study of older adults in Ireland, covering participation from 2009 to 2018 , and during the recent difficult period of restrictions and isolation for the older population during the COVID-19 pandemic. The nature of TILDA allowed us to explore a broad selection of creative activities in the context of social demographics, physical and behavioural health, and the impact of creative activity on quality of life, loneliness, depression, perceived stress and worry. This chapter discusses the main outcomes and policy implications of this report, and future directions for this area of research.

\subsection{Creative activity during 2009-2018}

Creative activity participation was high among older adults, particularly in passive participation such as listening to music or the radio, and reading books or magazines. While the frequency of participation in active activities was lower, we still found that over half of older adults are spending time on creative activities or hobbies at least weekly. At baseline, we saw higher participation in those with higher educational attainment and the highest income quintiles in all activities with the exception of going out to plays, films or concerts. Older age was associated with less frequent time spent listening to music or radio, or spending time on hobbies or creative activities, but was positively associated with weekly involvement in reading books or magazines for pleasure.

The level of involvement in creative activity was assessed by taking into account both the number of activities and frequency of participation thus enabling a 'a creative activity score' for each participant. Looking at trends of involvement over time, the inflection point for declines in activity began around age 75 years and onwards. We found significantly lower scores with increasing age and for those living in a rural area, while women in higher educational attainment and those in the highest income quintiles had the highest creative activity scores.

The longitudinal design of TILDA allowed us to assess changes in participation at different waves. We assessed participation at both the first wave of TILDA, taking place in 2009 (average age: 61.9 years), and the fifth wave of TILDA, taking place in 2018 (average age 70.4 years). By 2018, 52.2\% of adults who had completed both waves spent time on hobbies or creative activities weekly. We saw some increases in participation with age, particularly in going out to films, plays and concerts, while women remained more likely than men to read for pleasure weekly. Sociodemographic discrepancies remained, with higher participation among those with third level/higher educational attainment and those in higher income quintiles. We used tertiles of creative activity to assess shifts in levels of participation between these two timepoints. We found that almost $10 \%$ of the sample increased from low/moderate activity to high activity, and $14.5 \%$ maintained high activity between timepoints. Increased creative activity was highest among women with third level or higher educational attainment.

Better reported health was linked with greater levels of involvement in creative activity. We found higher mean creative activity scores among adults with excellent/very good/good physical health and vision, although differences in scores were wider among women than men. Similarly, among women we found lower creative activity scores in those reporting a disability, but similar scores among men at all ages. Independent of demographics, we also found that adults with one or more chronic conditions actually had a positive relationship with creative activity; prevalence of chronic conditions was however high in the sample. Future work should consider assessing these on an individual basis, as this may identify particular conditions which are risk factors for lower participation. While we saw an overall decrease in adults reporting fair/poor physical health between Wave 1 and Wave 5, the largest decreases were among adults with consistently high activity and those increasing from low/moderate to high activity. Furthermore, while overall reported disability increased between timepoints, we saw the largest increases in proportion among women in consistently low participation and those decreasing from high to low/moderate participation.

Exploring creative activity with quality of life, loneliness and mental health revealed a number of positive associations. At baseline, adults with either moderate or high creative activity scores had significantly higher quality of life, lower loneliness, depression, worry and perceived stress than adults with low creative activity. Comparing scores across waves with creative activity further revealed that the largest declines in quality of life were among women who decreased from high to low/moderate activity, while this same group had the largest increase in depression, worry and perceived stress. 
The final area explored in this section of the report was that of behavioural health, namely physical activity and smoking status. Higher creative activity was associated with significantly increased odds of participating in moderate or high levels of physical activity. Although overall levels of physical activity declined between timepoints, those in the low/moderate to high, and those maintaining consistently high creative activity reported the highest levels of physical activity in Wave 5. Smoking behaviours were also positively associated with high levels of creative activity. These findings showed the lowest proportions of current smokers were those reporting high levels of creative activity, and the largest declines in proportions of current smokers were among those with low/moderate to high creative activity and consistently high creative activity between timepoints.

\subsection{Creative activity during the COVID-19 pandemic}

The TILDA COVID-19 questionnaire allowed for a unique insight into participation in creative activity during the recent COVID19 pandemic. During a difficult period in which activities were restricted and older adults were asked to isolate, just over a quarter of TILDA participants reported doing hobbies, crafts or puzzles more often, while $37.8 \%$ reported reading more often. Demographic differences were maintained during this period. We found that women, those with higher educational attainment and those in better financial situations were most likely to maintain or increase their participation. Location additionally played a role. Adults in rural locations were less likely to report increased participation than adults living in urban locations, potentially highlighting accessibility as a barrier to participation that became more emphasised during lockdown and travel restriction periods.

Analyses of participation during this time-period also further highlighted the role creative activities can have on the wellbeing of the older population. Where it was reported that the time spent reading or doing hobbies, crafts or puzzles during the COVID-19 era was less often or not at all compared with before, quality of life was significantly lower while loneliness, depression and perceived stress were significantly higher compared with adults who maintained the time spent to be about the same as before. While these analyses do not confirm the direction of this association, consistent patterns suggesting a relationship between creative activity and mental health have been shown, which underpins the importance of better understanding the link between engagement and outcomes in the older population.

Contrary to the findings regarding time spent reading or doing hobbies, crafts or puzzles, increased time spent watching TV, streaming movies, or shows was more prevalent in those reporting worse financial situations. Our findings also showed that, independent of demographic factors, more time spent on these activities was linked with worse quality of life and with higher loneliness, depression and perceived stress. Engagement with digital culture remains an import aspect of creative activity. Increased time here however may identify a significantly increased amount of sedentary behaviour and mentally passive participation in everyday life during COVID-19 restrictions $(2,24,25)$.

Sedentary behaviour has previously been linked with depressive symptoms, as have rapid increases in screen time during COVID-19 in US adults, although the link with stress is still unclear (25-27).

\subsection{Implications for policy and future directions}

The Creativity in Older Age programme commenced in July 2020 with the important focus of counteracting the social side effects of the COVID-19 pandemic (3). The project will deliver on a number of initiatives including: creative residencies, curation of a poetry collection articulating feelings around dying, death and loss, multi-arts programmes, access to artists and facilitators in nursing homes and an artist in residence programme as part of the Mercer's Institute for Successful Ageing in St. James's hospital (3). The programme targets a population which was unfavourably impacted by the COVID-19 era, focusing on areas which may have had limited access to creative programmes in the past. This research is one of the largest studies of creative activity and associations with health and wellbeing in an population representative study of older, community dwelling adults. 
Our research has highlighted the high levels of participation in creative activities among community-dwelling adults aged 50 and over prior to the COVID-19 pandemic and the positive associations this participation has with health, improved quality of life, reduced loneliness and better mental health both before and during the pandemic. Patterns suggesting positive associations with behavioural health were also identified, showing higher levels of physical activity and lower rates of smoking in those more involved in creative activities, findings suggested in other research to result from increased engagement with creativity $(5,6,10,28)$. We saw a decrease in the levels of creative activity in the older ages, but many older adults maintained a high level of involvement and a proportion had increased from low to high levels within the time-period analysed.

Identifying motivating factors for this uptake in creative activity, and highlighting the positive associations as evidenced here may be important factors for encouraging greater involvement in this population. Importantly however, potential drivers of low participation were identified. A focus on these areas for policy interventions may be an effective means of encouraging increased participation, or removing barriers to participation. Many of the demographic differences we found in participation have been highlighted in adolescents in Ireland in recent work (13), which suggests these discrepancies may be maintained through the life course. Smyth (2020) notes the importance of schools for access and exposure and the Creative Schools initiative to support creative activities (13). Among community-dwelling adults, involvement was lowest among those with primary/no formal education, and those in the lowest income quintiles. Additionally, during the COVID-19 era, we saw time spent less often on creative activities particularly among adults in rural areas. Interventions to increase accessibility and exposure in those from lower and more disadvantaged socioeconomic groups, and those outside of urban areas within the community will be key to balancing levels of participation among demographics. The risk of worse physical health increases with older age. We found physical health gradients, with adults reporting worse physical health, vision and presence of a disability having lower levels of participation at baseline and reduced levels at 10-year follow up. Poor health need not act as a barrier to engagement with the creative arts, and positive integration of health and art in healthcare settings has been demonstrated recently (29). Interventions are needed to reduce the impact of declines in health on the ability of the community to participate in creative activities. Further analyses are required to better understand specific barriers to participation so these may be targeted effectively.

This report has developed the foundations for further research into creative activity among the older population in Ireland. Through the data already collected, we have presented an overview of participation, although our data are limited to general activities, without specific focus or expansion on more exact creative or cultural activities, reasons for participation or potential barriers. The analyses presented here have not identified the direction of these associations, but future, more complex analyses may establish this.

With regard to the importance of creative activity in older ages, TILDA has incorporated a more detailed creative activity module into the Wave 6 self-completion questionnaire, with data collection due for completion near the end of 2021. In addition to the measures collected at each previous wave on creative activity, participants are asked about previous participation in arts, creative or cultural activities, barriers to participation or reasons for stopping, current participation in a more extensive list of active and passive forms of participation, frequency, locations of participation, online activities, motivations for participation and the periods in their life they have been involved. This extension of information captured will help to create a more complete picture of creative and cultural activity among the older population and inform policymakers of barriers to participation, activities with low and high levels of participation, and key motivators for participation in this group.

\subsection{Conclusion}

Participation in creative activity is high among the older community-dwelling population and shows positive associations with health, quality of life, loneliness and mental health. Discrepancies in levels of participation were visible among those in lower educational and income groups and those with worse health, while participation appeared to decrease among adults living in rural areas during the COVID-19 pandemic. Policies addressing lower participation levels in these at-risk groups and increasing access to creative activities in the community could be developed as a potential means of improving health and wellbeing. Future work will expand on the level of participation in arts, cultural and creative activities, barriers to access and motivations for involvement among the older population. 


\section{Chapter 10 References}

1. Ward M, O'Mahoney, P, Kenny, RA. Altered lives in a time of crisis: the impact of the COVID-19 pandemic on the lives of older adults in Ireland. Dublin: The Irish Longitudinal Study on Ageing; 2021.

2. De Looze C, McDowell, CP. Physical activity, sedentary behaviour and mental health. In: Ward M, O'Mahoney, P, Kenny, RA, ed. Altered lives in a time of crisis: the impact of the COVID-19 pandemic on the lives of older adults in Ireland Dublin: The Irish Longitudinal Study on Ageing; 2021.

3. Creativity in Older Age - Creative Ireland Programme. Department of Tourism, Culture, Arts, Gaeltacht, Sport and Media. https://www.creativeireland.gov.ie/en/blog/creativity-in-older-age/. Date Accessed: 2nd June 2021

4. Kenny R, Whelan, BJ, Cronin, H, Kamiya, Y, Kearney, P, O'Regan, C, Ziegel, M. The Design of The Irish Longitudinal Study on Ageing. Dublin: The Irish Longitudinal Study on Ageing; 2010.

5. Flood M, Phillips KD. CREATIVITY IN OLDER ADULTS: A PLETHORA OF POSSIBILITIES. Issues in Mental Health Nursing. 2007;28:389-411.

6. Greaves CJ, Farbus L. Effects of creative and social activity on the health and well-being of socially isolated older people: outcomes from a multi-method observational study. J R Soc Promot Health. 2006;126:134-142.

7. Dunphy K, Baker FA, Dumaresq E, Carroll-Haskins K, Eickholt J, Ercole M, et al. Creative Arts Interventions to Address Depression in Older Adults: A Systematic Review of Outcomes, Processes, and Mechanisms. Frontiers in Psychology. 2019;9.

8. Osgood NJ, Meyers BS, Orchowsky S. The Impact of Creative Dance and Movement Training on the Life Satisfaction of Older Adults: An Exploratory Study. Journal of Applied Gerontology. 1990;9:255-265.

9. Leckey J. The therapeutic effectiveness of creative activities on mental well-being: a systematic review of the literature. J Psychiatr Ment Health Nurs. 2011;18:501-509.

10. Cohen GD, Perlstein S, Chapline J, Kelly J, Firth KM, Simmens S. The impact of professionally conducted cultural programs on the physical health, mental health, and social functioning of older adults. Gerontologist. 2006;46:726-734.

11. Everitt A, Hamilton R. Arts, health and community. A study of five arts in community health projects Durham: CAHHM. 2003.

12. Bygren LO, Konlaan BB, Johansson S-E. Attendance at cultural events, reading books or periodicals, and making music or singing in a choir as determinants for survival: Swedish interview survey of living conditions. BMJ. 1996;313:15771580.

13. Smyth E. Arts and Cultural Participation Among 17-Year-Olds. Dublin: Economic and Social Research Institute; 2020.

14. Barrett A, Savva, G, Timonen, V, Kenny, RA. Fifty Plus in Ireland 2011: First Results from The Irish Longitudinal Study on Ageing. Dublin: The Irish Longitudinal Study on Ageing; 2011.

15. Donoghue OA, McGarrigle CA, Foley M, Fagan A, Meaney J, Kenny RA. Cohort Profile Update: The Irish Longitudinal Study on Ageing (TILDA). International journal of epidemiology. 2018;47:1398-1398l

16. Ward M, Clarke N, Wang M, McGarrigle C, De Looze C, O?Halloran A, et al. Study protocol for TILDA COVID-19 survey. Altered lives in a time of crisis: preparing for recovery from the impact of the COVID-19 pandemic on the lives of older adults [version 1; peer review: 1 approved]. HRB Open Research. 2021;4.

17. Sexton E, King-Kallimanis BL, Conroy RM, Hickey A. Psychometric evaluation of the CASP-19 quality of life scale in an older Irish cohort. Qual Life Res. 2013;22:2549-2559.

18. Russell DW. UCLA Loneliness Scale (Version 3): Reliability, Validity, and Factor Structure. Journal of Personality Assessment. 1996;66:20-40. 


\section{Chapter 10 References}

19. Briggs R, Carey D, O'Halloran AM, Kenny RA, Kennelly SP. Validation of the 8-item Centre for Epidemiological Studies Depression Scale in a cohort of community-dwelling older people: data from The Irish Longitudinal Study on Ageing (TILDA). European Geriatric Medicine. 2018;9:121-126.

20. Cohen S, Kamarck T, Mermelstein R. A global measure of perceived stress. Journal of Health and Social Behavior. 1983;24:385-396.

21. Hopko DR, Stanley MA, Reas DL, Wetherell JL, Beck JG, Novy DM, et al. Assessing worry in older adults: confirmatory factor analysis of the Penn State Worry Questionnaire and psychometric properties of an abbreviated model. Psychol Assess. 2003;15:173-183.

22. Fan M, Lyu J, He P. Guidelines for data processing and analysis of the International Physical Activity Questionnaire (IPAQ).2005. URL: http://www.IPAQ.ki.se. 2014.

23. Craig CL, Marshall AL, Sjostrom M, Bauman AE, Booth ML, Ainsworth BE, et al. International physical activity questionnaire: 12-country reliability and validity. Medicine and science in sports and exercise. 2003;35:1381-1395.

24. Schrempft S, Jackowska M, Hamer M, Steptoe A. Associations between social isolation, loneliness, and objective physical activity in older men and women. BMC Public Health. 2019;19:74.

25. Meyer J, McDowell C, Lansing J, Brower C, Smith L, Tully M, et al. Changes in Physical Activity and Sedentary Behavior in Response to COVID-19 and Their Associations with Mental Health in 3052 US Adults. International Journal of Environmental Research and Public Health. 2020;17:6469.

26. del Pozo Cruz B, Alfonso-Rosa RM, McGregor D, Chastin SF, Palarea-Albaladejo J, del Pozo Cruz J. Sedentary behaviour is associated with depression symptoms: Compositional data analysis from a representative sample of 3233 US adults and older adults assessed with accelerometers. Journal of Affective Disorders. 2020;265:59-62.

27. Teychenne M, Stephens LD, Costigan SA, Olstad DL, Stubbs B, Turner Al. The association between sedentary behaviour and indicators of stress: a systematic review. BMC Public Health. 2019;19:1357.

28. Cruz-Ferreira A, Marmeleira J, Formigo A, Gomes D, Fernandes J. Creative Dance Improves Physical Fitness and Life Satisfaction in Older Women. Research on Aging. 2015;37:837-855.

29. Kenny R, Nevin, R, Farina, F. A Hospital's Creative Response in Ireland. A successful collaboration of Arts and Health making a difference as a COVID-19 response. Dublin: Mercer's Institute for Successful Ageing; 2020. 


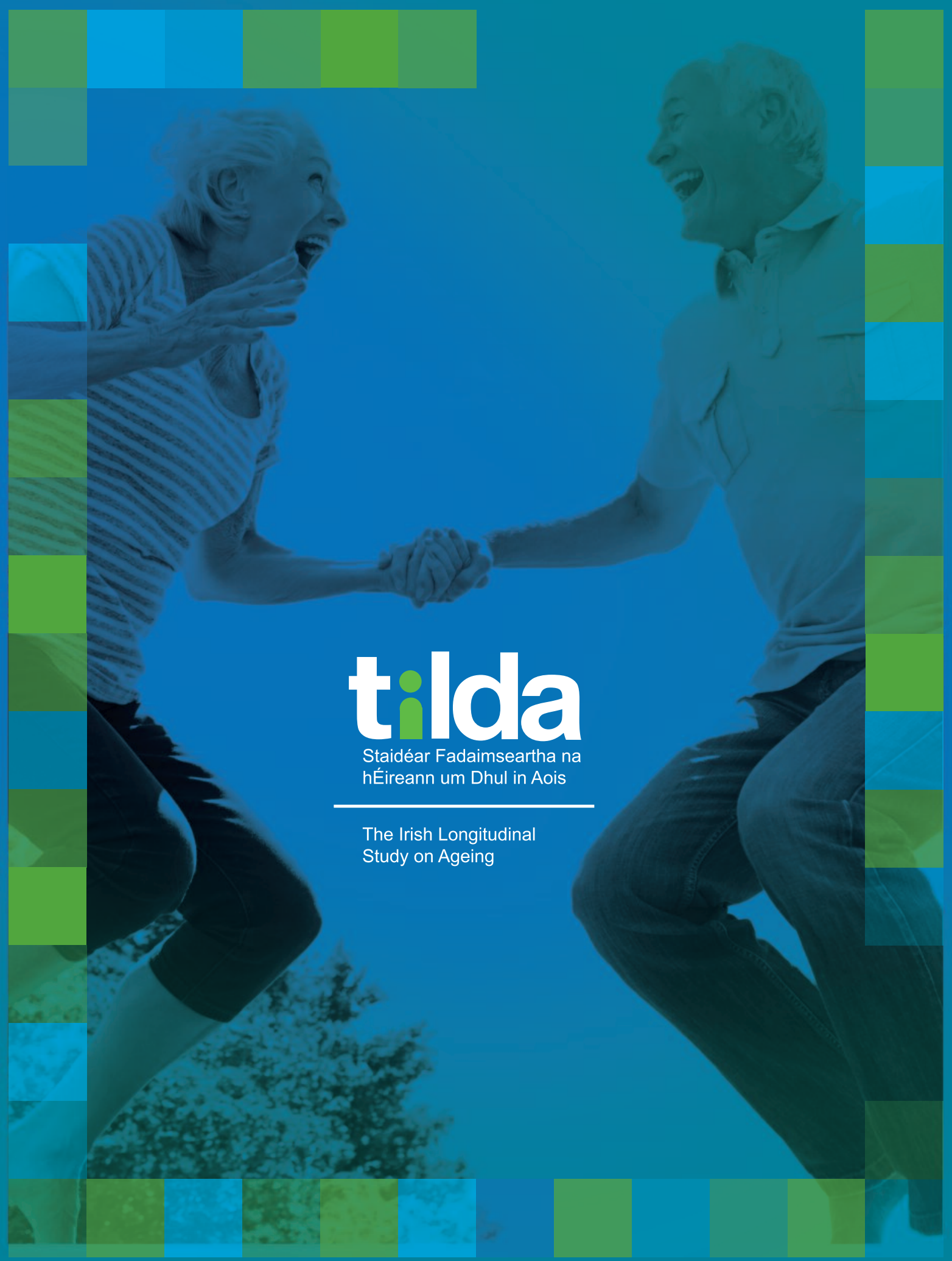

tilda.tcd.ie 